NBER WORKING PAPER SERIES

\title{
CONFIDENCE AND THE PROPAGATION OF DEMAND SHOCKS
}

\author{
George-Marios Angeletos \\ Chen Lian \\ Working Paper 27702 \\ http://www.nber.org/papers/w27702 \\ NATIONAL BUREAU OF ECONOMIC RESEARCH \\ 1050 Massachusetts Avenue \\ Cambridge, MA 02138 \\ August 2020, Revised August 2021
}

This paper subsumes earlier versions, entitled "A (Real) Theory of the Keynesian Multiplier" and "On the Propagation of Demand Shocks," that contained somewhat different frameworks. We are grateful to the editor, Veronica Guerrieri, and three anonymous referees for extensive feedback that helped improve and reshape the paper. For useful comments, we also thank Susanto Basu, Jesse Benhabib, Marty Eichenbaum, Pierre-Olivier Gourinchas, Cosmin Ilut, JianjunMiao, Emi Nakamura, Jón Steinsson, and seminar participants at BU, Berkeley, CREI, Cornell, Goethe University, NYU, MIT, FSU, SF Fed, the 2018 AEA meeting, the 2018 SED meeting, the 2020 NBER Summer Institute, and the 2020 NBER Monetary Economics Fall Meeting. Angeletos acknowledges the financial support of the National Science Foundation, Award \#1757198. Lian acknowledges the financial support of the Alfred P. Sloan Foundation Pre-doctoral Fellowship in Behavioral Macroeconomics, awarded through the NBER. The views expressed herein are those of the authors and do not necessarily reflect the views of the National Bureau of Economic Research.

NBER working papers are circulated for discussion and comment purposes. They have not been peer-reviewed or been subject to the review by the NBER Board of Directors that accompanies official NBER publications.

(C) 2020 by George-Marios Angeletos and Chen Lian. All rights reserved. Short sections of text, not to exceed two paragraphs, may be quoted without explicit permission provided that full credit, including $(\subset$ notice, is given to the source. 
Confidence and the Propagation of Demand Shocks

George-Marios Angeletos and Chen Lian

NBER Working Paper No. 27702

August 2020, Revised August 2021

JEL No. E03,E10,E13,E32

\begin{abstract}
$\underline{\text { ABSTRACT }}$
We revisit the question of why shifts in aggregate demand drive business cycles. Our theory combines intertemporal substitution in production with rational confusion, or bounded rationality, in consumption and investment. The first element allows aggregate supply to respond to shifts in aggregate demand without nominal rigidity. The second introduces a "confidence multiplier," that is, a positive feedback loop between real economic activity, consumer expectations of permanent income, and investor expectations of returns. This mechanism amplifies the business-cycle fluctuations triggered by demand shocks (but not necessarily those triggered by supply shocks); it helps investment to comove with consumption; and it allows front-loaded fiscal stimuli to crowd in private spending.
\end{abstract}

George-Marios Angeletos

Department of Economics, E52-530

MIT

77 Massachusetts Avenue

Cambridge, MA 02139

and NBER

angelet@mit.edu

Chen Lian

Department of Economics

University of California, Berkeley

Evans Hall

Berkeley, CA 94720

and NBER

chen_lian@berkeley.edu 


\section{Introduction}

Fluctuations in consumer spending, such as those triggered by financial shocks, appear to cause business cycles in the data (Mian and Sufi, 2014). Yet, the mechanism through which such a drop in aggregate demand can precipitate a recession is debatable.

To fix ideas, take the textbook New Keynesian model and consider a negative discount rate shock (a standard proxy for shocks in consumer spending). Insofar as monetary policy stabilizes inflation (equivalently, replicates flexible-price outcomes), the drop in Aggregate Demand (AD) does not generate a recession. It only triggers an offsetting movement in the natural rate of interest. ${ }^{1}$ How does the model then make room for demand-driven business cycles? By equating AD shocks to monetary contractions (relative to flexible-price outcomes), and to movements along a Phillips curve.

This seems unsatisfactory, not only for intellectual reasons but also on empirical grounds. Phillips curves are elusive in the data (Mavroeidis, Plagborg-Møller, and Stock, 2014). And the principal component of the business cycle fits better the template of a non-inflationary, non-monetary demand shock (Angeletos, Collard, and Dellas, 2020). In our view, this calls for theories that let AD shocks be the main business-cycle driver without a strict reliance on nominal rigidity.

The theory articulated in this paper combines two key elements. The first element, intertemporal substitution in production via variable utilization, opens the door to demand-driven fluctuations in the natural rate of output. The second element, rational confusion or bounded rationality in the demand side of the economy, introduces a "confidence multiplier." This is a feedback loop between outcomes and expectations that amplifies demand shocks (but not necessarily supply shocks), helps investment comove with consumption, and lets government spending crowd in private spending.

A non-vertical AS curve (with flexible prices). In the textbook New Keynesian model, there is no room for demand-driven business cycles when monetary policy replicates flexible price allocations. This is because Aggregate Supply (AS) is vertical in the sense that the aggregate production of today's goods is irresponsive to their relative price, i.e., the real interest rate. ${ }^{2}$ Our contribution starts with the elementary observation that the AS curve becomes non-vertical once we accommodate intertemporal substitution in production via the combination of two "neoclassical" features: variable capacity utilization; and adjustment costs to capital or investment.

More specifically, our baseline model allows for variable utilization but sets the aforementioned adjustment cost to be infinite. This accommodates the needed supply-side margin while abstractingbut only tentatively - from the question of whether investment comoves with consumption.

Our supply-side margin, which does not require either nominal rigidity or any departure from full information, seems empirically relevant on its own right: utilization is strongly pro-cyclical in the data.

\footnotetext{
${ }^{1}$ This relates to the problem first highlighted in Barro and King (1984).

${ }^{2}$ Note that here we have in mind an AS curve in the space of real output today vs its relative price. This differs from the Keynesian tradition that casts the AS curve as a Phillips curve, namely as a positive relation between real output and the nominal price level, or the nominal inflation rate.
} 
But a literal interpretation of this element of our theory is not strictly needed: as long as there is some neoclassical margin of intertemporal substitution in production, the second part of our contribution, which regards the Aggregate Demand (AD) side of the economy, is likely to go through.

AD and the confidence multiplier. With fully informed and fully rational consumers, the AD side of our model is standard: it boils down to the Euler condition of a representative consumer. We depart from this benchmark by letting consumers confuse aggregate and idiosyncratic income fluctuations when deciding how much to spend. In our main analysis, such confusion is rational, resulting from lack of information about, or inattention to, aggregate economic conditions. ${ }^{3}$ But it could also be the product of bounded rationality. Our key insight is that this friction introduces a Keynesian feedback loop in our neoclassical economy.

Following a negative AD shock, firms cut down on utilization and, along with it, labor demand and production. Consumers experience a drop in their current employment and income but can't tell whether this was because of a negative AD shock or an adverse idiosyncratic shock. For the reason explained next, this causes them to perceive a reduction in their permanent income even though no such reduction actually takes place.

In our environment, $\mathrm{AD}$ shocks have no effect on actual permanent income; they only shift the intertemporal decomposition of aggregate permanent income, not its total value. This property may seem counterintuitive under the prism of the New Keynesian model. But in a neoclassical economy such as ours, it follows naturally from a dynamic translation of Hulten's (1978) theorem: just as in his context sector-specific taste shocks have no first-order effect on GDP, in our context intertemporal taste shocks have no first-order effect on aggregate permanent income. This basic property has the following key implication for our purposes: as long as consumers confuse aggregate income fluctuations for idiosyncratic ones, a negative $\mathrm{AD}$ shock necessarily causes them to turn pessimistic about their permanent income, even though permanent income is actually fixed.

Consumers thus lose confidence, in the sense that they become excessively pessimistic relative to the full-information benchmark. As they do so, they also spend less, amplifying the original drop in aggregate demand. This feeds into a further cut in employment and output, a further drop in confidence, and so on. We refer to this mechanism as the "confidence multiplier."

Discounting the GE adjustment in the real interest rate. Our confidence multiplier is active even if the $\mathrm{AD}$ shock lasts only one period. When it is persistent, an additional mechanism emerges: consumers discount the future GE adjustment in real interest rates, because they perceive the concurrent adjustment as "noise" and/or they under-estimate how much others are reducing their spending.

This mechanism is akin to the form of GE attenuation articulated in Angeletos and Lian $(2017,2018)$ with the help of incomplete information, and the close relatives obtained in Farhi and Werning (2019) and Gabaix (2020) with the help of bounded rationality. But whereas in the New Keynesian context, the

\footnotetext{
${ }^{3}$ This follows the traditions of Lucas (1973) and Sims (2003). See also Mackowiak and Wiederholt (2009) for why agents may optimally choose to be relatively uninformed about aggregate shocks.
} 
focus of the latter three papers, GE attenuation translates to under-reaction of the output gap to news about future monetary policy, in our neoclassical context it maps to over-reaction of the natural rate of output to $\mathrm{AD}$ shocks. ${ }^{4}$ This mechanism thus complements our confidence multiplier in amplifying the business cycles triggered by such shocks.

Behavioral reinterpretation. The last paragraph hinted at how bounded rationality could substitute for incomplete information vis-a-vis the form of discounting discussed above. A similar point applies to our confidence multiplier: the same feedback loop may obtain in variants in which agents are fully informed but form simple extrapolative beliefs as in Greenwood and Shleifer (2014) and Gennaioli, Ma, and Shleifer (2016), or hold a sparse representation of the world as in Molavi (2019). This clarifies that the essential friction is the failure of consumers to differentiate their responses to idiosyncratic and aggregate shocks as finely as assumed in standard macro models. And it allows for a behavioral re-interpretation of our confidence multiplier, which we welcome.

Supply shocks. Consider AS shocks, namely aggregate TFP shocks. Such shocks do affect permanent income, so their confusion with idiosyncratic shocks has an ambiguous effect on consumer confidence: consumers under-estimate the aggregate fluctuations in permanent income at the same time that they over-estimate the idiosyncratic ones. In an empirically plausible benchmark, these effects wash out and our confidence multiplier is switched off. Furthermore, because the GE adjustment in the real interest rate triggered by supply shocks is the reverse of that triggered by demand shocks, the effect of the second mechanism is also the reverse: when consumers under-estimate the adjustment in future real interest rates, they respond more to demand shocks but less to supply shocks. All in all, supply shocks are thus dampened at the same time that demand shocks are amplified, helping match the observed disconnect between business cycles and TFP. ${ }^{5}$

Investment-consumption comovement. As previously mentioned, our baseline model assumes, in effect, an infinite adjustment cost for investment. If we let this cost be finite but non-zero, the intertemporal substitution margin remains active and, as a result, the equilibrium levels of utilization, employment, and output continue to increase with an AD shock. In this sense, the supply side of our theory is not affected. But a familiar puzzle emerges on the demand side: whenever consumers spend less, the real interest rate goes down, causing investment to move in the opposite direction. ${ }^{6}$

A version of our confidence multiplier applied to investment decisions helps resolve this puzzle. Insofar as investors are subject to a similar confusion as consumers, a temporary drop in either the household or the business component of aggregate demand can trigger a drop in both consumer

\footnotetext{
${ }^{4}$ This reflects an important difference in the underlying form of strategic interaction, or the way higher-order beliefs matter. See Section 5.4 for more details.

${ }^{5}$ Consistent with our theory, here we have in mind utilization-adjusted TFP in the data, as in Basu, Fernald, and Kimball (2006). See also Blanchard and Quah (1989), Gali (1999), Barsky and Sims (2011), and Angeletos, Collard, and Dellas (2020) for additional facets of the disconnect between technology and business cycles.

${ }^{6}$ This puzzle extends from the basic RBC model (Barro and King, 1984) to state-of-the-art DSGE models, such as Justiniano, Primiceri, and Tambalotti (2010) and Christiano, Motto, and Rostagno (2014). Jaimovich and Rebelo (2009) is a notable exemption, which we discuss in Section 2 below.
} 
confidence (expectations of income) and investor sentiment (expectations of returns). This allows investment and consumption to comove.

Borrowers and savers. For essentially the same reason as that articulated above, our theory helps generate comovement across different consumers. In particular, when only a subset of the population is hit by an exogenous discount-rate shock (think of them as "borrowers" responding to a "credit crunch"), both the misperception of permanent income and the discounting of the future GE adjustment in the real interest rate contribute towards making the remaining agents (the "savers") cut down their spending, too. This illustrates how our theory is distinct from, but also complementary to, theories emphasizing credit constraints.

Fiscal policy. Commentators often claim that fiscal policy can "boost confidence" without clarifying what this means. ${ }^{7}$ Our theory provides a way to think about this idea. On the one hand, it allows fiscal stimuli to boost consumer confidence in the sense defined here. On the other hand, it qualifies that this is possible only when the stimulus is front-loaded. Such a stimulus raises the aggregate demand for today's goods, putting our confidence multiplier in motion. When this multiplier is large enough, the stimulus can crowd in private spending, despite the higher tax burden. By contrast, news of a backloaded stimulus fails to raise consumer confidence and necessarily crowds out private spending.

\section{Related literature}

Our theory fits the "main business cycle shock" identified by Angeletos, Collard, and Dellas (2020): the principal component of the business-cycle fluctuations in unemployment, GDP, hours worked, consumption, and investment in the data is largely disconnected from both technology and inflation. This provides support for a class of theories that aim at accommodating non-inflationary, non-monetary, demand-driven fluctuations. Examples of such theories include the older literature on coordination failures and multiple equilibria (Benhabib and Farmer, 1994; Cooper and John, 1988; Diamond, 1982), as well as a more recent literature that emphasizes other frictions (Angeletos, Collard, and Dellas, 2018; Angeletos and La'O, 2013; Bai, Rios-Rull, and Storesletten, 2019; Basu et al., 2021; Beaudry and Portier, 2013, 2018; Di Tella and Hall, 2021; Huo and Rios-Rull, 2020). Our marginal contribution vis-a-vis these literatures comes from two novel elements: the margin for intertemporal substitution on the supply side; and the confidence multiplier on the demand side. And although some of these works make room for fluctuations in "confidence," they do so by equating such fluctuations to exogenous shifts across

\footnotetext{
${ }^{7}$ For instance, Robert Shiller made such a claim during the Great Recession (a similar claim is echoed in Akerlof and Shiller, 2010), prompting the following response by N. Gregory Mankiw (http://gregmankiw.blogspot.com/2009/01/):

"Yale's Bob Shiller argues that confidence is the key to getting the economy back on track. I think a lot of economists would agree with that. The question is what it would take to make people more confident. ... Until we figure it out, it is best to be suspicious of any policy whose benefits are supposed to work through the amorphous channel of 'confidence."
} 
multiple equilibria or other extrinsic shocks to higher-order beliefs. We instead allow confidence to vary endogenously, and in response to intrinsic shocks.

Closely related in this respect are Chahrour and Gaballo (2021) and Ilut and Saijo (2020). Like our paper, these papers let intrinsic shocks drive certain "wedges" in beliefs. In addition, Chahrour and Gaballo (2021) features a form of rational confusion that reminds ours even though it works over different shocks; ${ }^{8}$ and Ilut and Saijo (2020) shares the idea of letting the aforementioned belief wedges be the source of comovement. Ultimately, though, the main difference is that both of these works focus on different phenomena and mechanisms than we do. The first focuses on how increases in housing prices driven by adverse supply shocks can be confused for good news about wealth, the second on how ambiguity and learning modify the propagation of shocks in the New Keynesian model.

Another distinctive feature of our paper is that it accommodates an informational friction in AD but rules it out in AS. This serves two functions. First, it allows us to preserve production efficiency, which in turn yields our translation of Hulten's (1978) theorem in terms of the invariance of aggregate permanent income to $\mathrm{AD}$ shocks. And second, it separates our paper from previous works that have shown how informational frictions on the production side can also accommodate Keynesian elements without nominal rigidity, in effect by providing an information-based theory of the movements in the labor wedge (e.g., Angeletos and La'O, 2010; Angeletos, Collard, and Dellas, 2018; Ilut and Saijo, 2020). Needless to say, we view that mechanism and ours as strong complements.

Our confidence multiplier originates from an informational friction à la Lucas (1972), Sims (2003), and Mackowiak and Wiederholt (2009). Empirical evidence in support of such a friction abounds. ${ }^{9}$ Most recently, Andrade et al. (2020) document that firms confuse aggregate and idiosyncratic (industryspecific) shocks. We suspect the same is true for consumers. And while we commit to rational confusion for our main analysis, we welcome behavioral reinterpretations; see the discussion in Section 6.5. From this perspective, our theory has a similar flavor as the narrative in Akerlof and Shiller (2010).

Our combination of informational frictions and demand shocks is reminiscent of Lorenzoni (2009). That paper proposes a new micro-foundation of demand shocks, in terms of noise in expectations of future productivity and income. But it maintains the propagation mechanism of the New Keynesian model, translating such shocks to procyclical gaps from flexible-price outcomes. Our paper instead revisits the propagation mechanism itself, dropping nominal rigidity altogether and allowing for demand-driven fluctuations in the natural rate of output itself.

Last but not least, our paper connects to the RBC literature on utilization (Burnside, Eichenbaum, and Rebelo, 1995; Greenwood, Hercowitz, and Huffman, 1988; King and Rebelo, 1999). This literature has emphasized how variable utilization helps flatten the aggregate labor demand curve and amplify the response of aggregate employment and output to productivity and government spending shocks.

\footnotetext{
${ }^{8}$ While in our paper households confuse a positive aggregate demand shock for good news about idiosyncratic permanent income, in that paper households confuse a negative aggregate supply shock that raises house prices for such good news.

${ }^{9}$ See, inter alia, Mankiw, Reis, and Wolfers (2004), Coibion and Gorodnichenko (2012, 2015), Coibion, Gorodnichenko, and Ropele (2019), Cavallo, Cruces, and Perez-Truglia (2017), Kohlhas and Walther (2019), and Angeletos, Huo, and Sastry (2021). See also Gabaix (2019) for a review of the broader empirical and theoretical literatures on inattention.
} 
But, with a notable exception that we discuss next, this literature has worked with models that render the choice of utilization to a static decision and has thus not accommodated our supply-side margin. The same is true for a DSGE literature that follows the lead of (Christiano, Eichenbaum, and Evans, 2005): that work, too, models utilization as a static decision.

The exemption alluded to above is Jaimovich and Rebelo (2009). That paper shares our two "neoclassical" ingredients, variable utilization and adjustment costs; and it shows that the combination of these ingredients with a third one, a certain form of internal habit in preferences, can generate positive co-movement out of news about future TFP. From this perspective, it may appear that we merely replace their assumption about preferences with an assumption about beliefs. But the differences are much subtler. First, the adjustment cost in Jaimovich and Rebelo (2009) takes the form postulated in Christiano, Eichenbaum, and Evans (2005) as opposed to the classic one in $Q$ theory. This amounts to introducing a desire to smooth investment, which in turn is strictly needed for investment to respond positively to news shocks; with the classic formulation, investment would have moved in the opposite direction. And second, as highlighted in Lorenzoni (2011, p.541-2), the form of habit in Jaimovich and Rebelo (2009) amounts to assuming that labor supply increases in the short run with positive wealth shocks (e.g., capital gains). This is key to the model's ability to generate a positive response in employment to news shocks, but seems counterfactual. By contrast, our model obtains the requisite co-movement in all the key macroeconomic variables, and in the price of capital as well, by letting (i) intertemporal substitution in production and (ii) correlated consumer and investor misperceptions.

The same bottom line separates our paper from Basu and Kimball (1997) and Miao, Wang, and Xu (2015). These works emphasize the forward-looking nature of utilization, but do not share either our focus on consumption-driven business cycles or our confidence mechanism.

\section{The Model}

We consider a neoclassical economy, with flexible prices. There is a single aggregate shock, which proxies for fluctuations in aggregate demand, and various idiosyncratic shocks, which play the dual role of introducing idiosyncratic income fluctuations and of allowing for an informational friction. This friction is the core element of the demand block of our model. The core element of the supply block is a margin for intertemporal substitution in production.

Islands. We represent the economy as a continuum of islands, indexed by $i \in[0,1]$. On each island, there is a continuum of firms, each being a monopolistically competitive producer of a differentiated good. We use $(i, j)$ to identify both the $j$-th variety produced on island $i$ and the firm producing it, with $j \in[0,1]$. On each island, there is also a representative household (or consumer), indexed by $h=i$. Time is discrete and horizons are infinite. In each period $t \in\{0,1, \cdots\}$, the household is employed on the particular island it resides in but consumes the goods of all islands. 
Household preferences. The preferences of any household $h$ are represented by

$$
\mathcal{U}\left(c_{0}^{h}, n_{0}^{h}\right)+\beta_{0}^{h} \mathcal{U}\left(c_{1}^{h}, n_{1}^{h}\right)+\beta_{0}^{h} \beta_{1}^{h} \mathcal{U}\left(c_{2}^{h}, n_{2}^{h}\right)+\cdots,
$$

where $c_{t}^{h}$ and $n_{t}^{h}$ are its consumption and labor supply at $t, \beta_{t}^{h}$ is its discount factor between $t$ and $t+1$, and $\mathcal{U}$ is the per-period utility function. The latter is given by

$$
\mathcal{U}(c, n)=\frac{c^{1-\frac{1}{\sigma}}}{1-\frac{1}{\sigma}}-\frac{n^{1+\frac{1}{\nu}}}{1+\frac{1}{\nu}},
$$

where $\sigma>0$ and $\nu>0$ are, respectively, the elasticity of intertemporal substitution in consumption and the Frisch elasticity of labor supply.

Consumption is given by $c_{t}^{h}=F\left(\left\{c_{i, t}^{h}, \xi_{i, t}\right\}_{i \in[0,1]}\right)$ with $c_{i, t}^{h}=H\left(\left\{c_{i, j, t}^{h}\right\}_{j \in[0,1]}\right)$, where $F$ and $H$ are CES aggregators, $c_{i, j, t}^{h}$ is the consumption of variety $j$ from island $i$ in period $t, c_{i, t}^{h}$ is a consumption index for all the varieties consumed from island $i$ in period $t$, and $\xi_{i, t}$ is an island-specific taste shock. The latter follows an $\operatorname{AR}(1)$ process with persistence $\rho_{\xi} \in[0,1)$ :

$$
\log \xi_{i, t}=\rho_{\xi} \log \xi_{i, t-1}+\log \epsilon_{i, t}^{\xi},
$$

where $\xi_{i,-1}=1$ and $\log \epsilon_{i, t}^{\xi} \sim \mathcal{N}\left(0, \sigma_{\xi}^{2}\right)$ is i.i.d. across $(i, t)$ and independent from other shocks.

One can think of the islands as different categories of expenditure. To simplify the exposition, we fix the elasticity of substitution across them to 1 . On the other hand, we let the elasticity of substitution across the different varieties of the same island be $1+\frac{1}{\mu}$, for some $\mu>0$ that ultimately pins down the monopoly markup. ${ }^{10}$ Perfect competition is nested as $\mu \rightarrow 0 .{ }^{11}$

AD shocks. The household's discount factor follows an $\operatorname{AR}(1)$ process with persistence $\rho_{\beta} \in[0,1)$ :

$$
\log \beta_{t}^{h}=\left(1-\rho_{\beta}\right) \log \beta+\rho_{\beta} \log \beta_{t-1}^{h}-\log \eta_{t}+\log \epsilon_{t}^{\beta, h},
$$

where $\beta \in(0,1)$ is the steady-state discount factor, $\beta_{-1}^{h}=\beta, \log \eta_{t} \sim \mathcal{N}\left(0, \sigma_{\mathrm{AD}}^{2}\right)$ is the aggregate innovation, i.i.d. across $t$, and independent of all other shocks, and $\log \epsilon_{t}^{\beta, h} \sim \mathcal{N}\left(0, \sigma_{\beta}^{2}\right)$ is the idiosyncratic innovation, i.i.d. across $(h, t)$, and independent of other shocks. The aggregate innovation introduces fluctuations in aggregate demand. Note in particular that $\eta_{t}$ enters (4) with a minus, so that a positive realization for $\eta_{t}$ corresponds to an urge to consume more, or a positive AD shock. Finally, the sole modeling role of the idiosyncratic shock, $\epsilon_{t}^{\beta, h}$, is to make sure that the household does not know the aggregate shock even though it knows its own discount factor.

Inter-temporal trading. Let $R_{t}$ denote the aggregate, real, gross, interest rate between $t$ and $t+1$. The corresponding rate faced by the household on island $i$ is given $R_{i, t}=R_{t} \epsilon_{i, t}^{R}$, where $\log \epsilon_{i, t}^{R} \sim \mathcal{N}\left(0, \sigma_{R}^{2}\right)$ is an idiosyncratic shock, i.i.d. across $(i, t)$, and independent from other shocks. This idiosyncratic shock can be interpreted as the product of a random intermediation cost and its sole modeling role is

\footnotetext{
${ }^{10}$ That is, $F\left(\left\{c_{i, t}^{h}, \xi_{i, t}\right\}_{i \in[0,1]}\right)=\exp \left(\frac{\int_{i \in[0,1]} \xi_{i, t} \ln \left(c_{i, t}^{h}\right) d i}{\int_{i \in[0,1]} \xi_{i, t} d i}\right)$ and $H\left(\left\{c_{i, j, t}^{h}\right\}_{j \in[0,1]}\right)=\left(\int_{j \in[0,1]}\left(c_{i, j, t}^{h}\right)^{\frac{1}{1+\mu}} d j\right)^{\mu+1}$.

${ }^{11}$ Monopoly power is allowed but not strictly needed. It only facilitates the narrative that firms respond to consumer demand instead of Walrasian prices, and a bridge to the New Keynesian model (Appendix B).
} 
to limit the information extracted from interest rates. ${ }^{12}$ Rational inattention (Sims, 2003; Mackowiak and Wiederholt, 2009) can play a similar modeling role: the results are essentially unchanged if we reinterpret $\epsilon_{i, t}^{R}$ as idiosyncratic noise in the observation of $R_{t}$.

Household budget. The household's total income in period $t$ is $w_{h, t} n_{t}^{h}+e_{h, t}$, where $w_{h, t}$ is the wage on the island $i=h$ the household lives in, and $e_{h, t}$ is the sum of the local profits, which the household receives as dividends. Its budget constraint can therefore be written as follows:

$$
\int_{i \in[0,1]} \int_{j \in[0,1]} p_{i, j, t} c_{i, j, t}^{h} d j d i+R_{h, t}^{-1} b_{t+1}^{h}=w_{h, t} n_{t}^{h}+e_{h, t}+b_{t}^{h}
$$

where $p_{i, j, t}$ is the price of good $(i, j)$ in period $t$ and $b_{t}^{h}$ is the net amount of bonds held at the start of period $t$, with $b_{0}^{h}=0$. All prices and wages are real, quoted in the same-period basket of goods.

Firms and production. Consider firm $j$ on island $i$. Production is given by a Cobb-Douglas form between labor and land services, so the firm's physical output in period $t$ is given by

$$
q_{i, j, t}=\left(l_{i, j, t}\right)^{\alpha}\left(u_{i, j, t} k_{i, j, t}\right)^{1-\alpha},
$$

where $l_{i, j, t}$ is the labor input and $u_{i, j, t} k_{i, j, t}$ are land services. The latter are given by the product of effective land quantity, $k_{i, j, t}$, and utilization rate, $u_{i, j, t}$.

Each firm is a monopolist in the market for the particular commodity it produces and a price taker in the labor market of the island it operates in (and so is the island's representative household). The firm's operating profit in period $t$ is given by $\pi_{i, j, t}=p_{i, j, t} q_{i, j, t}-w_{i, t} l_{i, j, t}$, where $p_{i, j, t}$ is the price of good $(i, j)$ and $w_{i, t}$ is the wage of the local labor market in island $i$. The firm owns its own land, and is itself owned by the local household. It follows that the firm's objective is its expectation of $\sum_{s=0}^{\infty} m_{i, t, t+s} \pi_{i, j, t+s}$, where $m_{i, t, t+s} \equiv E_{t}^{i}\left[\left(\prod_{l=1}^{s} \beta_{l-1}^{h}\right) \mathcal{U}_{c}\left(c_{t+s}^{i}, n_{t+s}^{i}\right)\right]$ is the local pricing kernel, or the marginal utility of consumption for household $h=i$. Finally, since each firm in island $i$ distributes its profits as dividends to the local household, the latter's dividend income is given by $e_{h, t}=\int \pi_{h, j, t} d j$.

Land and utilization. The "effective" quantity of land obeys the following law of motion:

$$
k_{i, j, t+1}=\left(1-\delta\left(u_{i, j, t}\right)\right) k_{i, j, t},
$$

where $k_{i, j, 0}=\bar{k}_{0}>0$ and $\delta(\cdot)$ is an increasing and convex function. This function captures the negative effect of higher utilization today on land productivity tomorrow. This resembles models where the depreciation of capital increases with its utilization, except that here there is no investment margin.

Accordingly, and to guarantee the existence of a steady state, we herein require that $\delta$ is such that $\delta\left(u^{*}\right)=0$, where $u^{*}$ is the steady-state value of utilization. Once we add investment in Section 6.4 , the steady-state value of depreciation is allowed to be any number in $[0,1)$. Whatever that number is, it

\footnotetext{
${ }^{12}$ Although we do not explicitly model this interpretation, here is a sketch of it. Let borrowing and lending take place via a two-tier market. On the bottom, there is a local market for each island, where households trade with financial intermediaries. On the top, there is a centralized market where only intermediaries trade. Idiosyncratic variation in either the resource ("iceberg") cost of such intermediation or the rents extracted by intermediaries could then offer a micro-foundation of $\epsilon_{i, t}^{R}$. An earlier version of our paper (Angeletos and Lian, 2019) contained a complementary micro-foundation, using decentralized trading and random matching to generate idiosyncratic variation in the intertemporal prices faced by households.
} 
is offset in steady-state by gross investment. The present economy can then be recast as a limit with infinite adjustment costs, or with investment pegged at its steady-state value.

Information. We assume away any informational friction among the firms so as to isolate the role of the informational friction in aggregate consumption, or the demand side of the economy. We then specify the information set of household $h$ in each period $t$ as follows:

$$
\mathcal{I}_{t}^{h}=\mathcal{I}_{t-1}^{h} \cup\left\{\beta_{t}^{h}\right\} \cup\left\{w_{h, t}, e_{h, t}, R_{h, t},\left(p_{i, j, t}\right)_{i \in[0,1], j \in[0,1]}\right\} \cup\left\{\eta_{t-1}\right\} .
$$

That is, the household learns its current discount factor, all the objects that enter its current budget (its income, its interest rate, and all commodity prices), and the past aggregate shock.

These properties, the entire structure of the economy, and the fact that agents have rational expectations are common knowledge. It follows that, in equilibrium, households have common knowledge of the past aggregate outcomes. Had we let learning be slow, we would presumably have been able to deliver not only amplification and comovement but also additional persistence. ${ }^{13}$ But we would have also sacrificed the ability to deliver sharp analytical results, because of the familiar difficulty in tracking the dynamics of higher-order beliefs in GE settings with persistent shocks and slow learning.

Equilibrium. The solution concept is (Noisy) Rational Expectations Equilibrium. Because of the CES specification and the symmetry of the firms within each island $i$, the demand faced by each firm $(i, j)$ in period $t$ can always be written as

$$
\int_{h \in[0,1]} c_{i, j, t}^{h} d h=\left(y_{i, t} / p_{i, t}\right)\left(p_{i, j, t} / p_{i, t}\right)^{-1-1 / \mu} \quad \forall i, j, t,
$$

where $p_{i, t}$ is the ideal price index of the goods produced in island $i$ and $y_{i, t}$ is the total spending on these goods. We denote the corresponding economy-wide aggregates as $p_{t}$ and $y_{t}$, and that for consumption by $c_{t} \cdot{ }^{14}$ We can then define an equilibrium as follows:

1. Each household $h$ chooses contingent plans for consumption and labor supply so as to maximize its expected utility subject to the budget constraint given in (5) and the informational constraints embedded in (8).

2. Each firm $(i, j)$ chooses contingent plans for inputs, production, and prices so as to maximize its expectation of its local valuation subject to (7) and (9).

3. The goods and labor markets clear:

$$
\int_{h \in[0,1]} c_{i, j, t}^{h} d h=q_{i, j, t} \quad \forall i, j, t \quad \text { and } \quad n_{t}^{i}=\int_{j \in[0,1]} l_{i, j, t} d j \quad \forall i, t .
$$

We do not explicitly require that the bond market clears, because this follows from Walras' law once goods and labor markets clear. Finally, by our choice of numeraire, $p_{t}=1$ and $y_{t}=c_{t}$. In the monetary

\footnotetext{
${ }^{13}$ The role of informational frictions in generating persistence is the subject of a large literature, albeit in different contexts (e.g., Mankiw and Reis, 2002; Sims, 2003; Woodford, 2003; Nimark, 2008; Angeletos and Huo, 2021).

${ }^{14}$ To be precise, we let $p_{i, t} \equiv\left(\int_{j \in[0,1]} p_{i, j, t}^{-1 / \mu} d j\right)^{-\mu}, y_{i, t} \equiv \int_{h \in[0,1]} \int_{j \in[0,1]} p_{i, j, t} c_{i, j, t}^{h} d j d h, p_{t} \equiv \int_{i \in[0,1]} \frac{q_{i, t}}{y_{t}} p_{i, t} d i, y_{t} \equiv$ $\int_{i \in[0,1]} y_{i, t} d i=\int_{i \in[0,1]} p_{i, t} q_{i, t} d i$, and $c_{t} \equiv \int_{h \in[0,1]} c_{t}^{h} d h$.
} 
extension spelled out in Appendix B, this maps to a monetary policy that stabilizes the nominal price level and replicates flexible-price outcomes.

Steady state, log-linearization, and notation. To keep the analysis tractable, we henceforth work with the log-linearization of the model around its steady state. ${ }^{15}$ With abuse of notation, we henceforth reinterpret all the variables as the log-deviations from their steady-state counterparts. ${ }^{16}$ Finally, because firms are symmetric within islands, we can drop the firm index from all the relevant variables: $l_{i, j, t}=l_{i, t}, u_{i, j, t}=u_{i, t}, q_{i, j, t}=q_{i, t}$ and $p_{i, j, t}=p_{i, t}$ for all firms $j$ within any given island $i$.

\section{Aggregate Supply, Aggregate Demand, and Beliefs}

In this section, we derive the equilibrium conditions of the economy. We organize them in two blocks, one representing aggregate supply (AS) and another representing aggregate demand (AD). We further show how consumer beliefs are determined and how they enter the demand block. ${ }^{17}$ We thus set the stage for the next section, which completes the equilibrium characterization by studying the fixed point between aggregate supply, aggregate demand, and beliefs.

\subsection{Aggregate Supply}

We characterize the supply side in two steps. First, we momentarily take the utilization decisions as given and obtain aggregate employment and aggregate output as functions of the aggregate utilization and the aggregate stock of land. Second, we work out the optimal utilization decisions.

By the Cobb-Douglas specification of the production function, the local output is

$$
q_{i, t}=(1-\alpha)\left(u_{i, t}+k_{i, t}\right)+\alpha l_{i, t} .
$$

By the first-order condition (FOC) of the firm's problem with respect to its labor input, the local demand for labor is

$$
l_{i, t}=p_{i, t}+q_{i, t}-w_{i, t} .
$$

By the corresponding FOC for household $h=i$, the local supply of labor satisfies

$$
w_{i, t}=\frac{1}{\nu} n_{t}^{i}+\frac{1}{\sigma} c_{t}^{i}
$$

By market clearing in the local labor market, $l_{i, t}=n_{t}^{i}$. Finally, by the Cobb-Douglas specification of the preferences across islands, local demand, or local firm revenue, can be expressed as follows:

$$
p_{i, t}+q_{i, t}=y_{i, t}=y_{t}+\xi_{i, t} .
$$

\footnotetext{
${ }^{15}$ For the existence and characterization of the steady state, see Appendix A.

${ }^{16}$ The only exception to this rule is that we let the new $b_{t}^{h}$ be given by $b_{t}^{h} / c^{*}$, where $c^{*}$ is steady-state spending. This is standard in the literature and takes care of the issue that $b^{*}=0$ in steady state.

${ }^{17}$ Keep in mind that, although the supply side of our model is forward-looking, the informational friction enters the equilibrium only via the demand side, because it is consumers, not firms, who are imperfectly informed.
} 
Aggregating all these conditions, and combining them, we can solve for aggregate output as functions of $u_{t}$ and $k_{t}$, the aggregate utilization rate, and the aggregate land stock. In particular,

$$
y_{t}=(1-\tilde{\alpha})\left(u_{t}+k_{t}\right)
$$

where $\tilde{\alpha} \equiv 1-\frac{(1-\alpha)\left(1+\frac{1}{\nu}\right)}{1+\frac{1}{\nu}-\alpha+\frac{\alpha}{\sigma}} \in(0,1)$. This reduced-form aggregate production function embeds labormarket equilibrium. This in turn explains why $\tilde{\alpha}$ depends on $\nu$, the Frisch elasticity of labor supply. Indeed, insofar as labor supply is procyclical, a higher $\nu$ maps to a lower $\tilde{\alpha}$, or less diminishing returns in the reduced-form production function seen above. ${ }^{18}$

Consider now a firm's optimal choice of utilization. Because more utilization increases output today at the expense of degrading the effective stock of land, the optimal utilization choice is naturally forward-looking. Let $\vartheta_{i, t}$ denote the shadow value of land at the end of period $t$; this is the present analogue of the "Q" in the Q-theory of investment. The typical firm's FOC for utilization can then be expressed as follows:

$$
p_{i, t}+q_{i, t}-u_{i, t}-k_{i, t}=\vartheta_{i, t}+\phi u_{i, t}
$$

where $\phi>0$ is a scalar that parameterizes the elasticity of utilization. ${ }^{19}$ The left-hand side measures the benefit of more utilization in terms of higher current production. The right-hand side measures the cost in terms of higher land depreciation and, thereby, lower production in the future. The evolution of the shadow value of land is finally given by the following asset-pricing-like condition:

$$
\vartheta_{i, t}=-R_{i, t}+(1-\beta) \mathbb{E}_{t}\left[p_{i, t+1}+q_{i, t+1}-k_{i, t+1}-u_{i, t+1}\right]+\beta \mathbb{E}_{t}\left[\vartheta_{i, t+1}\right],
$$

where $\mathbb{E}_{t}[\cdot]$ is the full-information rational expectation in period $t$.

Combining and aggregating (16)-(17), replacing aggregate output from (15), using the law of motion for land, and solving for $u_{t}$, we reach the following Euler condition for aggregate utilization:

$$
u_{t}=\frac{\beta}{\tilde{\alpha}+\beta \phi} R_{t}+\beta \mathbb{E}_{t}\left[u_{t+1}\right] .
$$

This epitomizes the supply-side part of our theory. Other things equal, an increase in the relative price of today's goods stimulates utilization, thus also increasing the aggregate supply of today's goods. Naturally, the elasticity of this margin is negatively related to $\phi$, the degree of convexity of the cost of utilization. And it is positively related to $\nu$, the Frisch elasticity of labor supply, because a more elastic labor supply maps, via $\tilde{\alpha}$, to less diminishing returns in production with respect to utilization. ${ }^{20}$

\footnotetext{
${ }^{18}$ In the model as it is, labor supply is procyclical if and only if $\sigma>1$. But this $\sigma$, which derives from condition (12) and parameterizes the wealth effect on labor supply, is conceptually distinct from the $\sigma$ that shows up in Proposition 2 and that governs the elasticity of aggregate demand with respect to the real interest rate. The two concepts can be disentangled by replacing the optimal labor supply (12) with an exogenous "wage schedule" of the form $w_{i, t}=\chi_{n} n_{t}^{i}+\chi_{c} c_{t}^{i}$, for some $\chi_{c} \neq \frac{1}{\sigma}$. A zero wealth effect on labor supply can then be nested with $\chi_{c}=0$ and maps to $\tilde{\alpha}=\frac{\alpha \chi_{n}}{\chi_{n}+(1-\alpha)}$. This also makes clear the following two points: first, that higher real wage rigidity, proxied here by a lower $\chi_{n}$, maps to a lower $\tilde{\alpha}$ and, thereby, a more elastic AS curve; and second, that our model could readily accommodate a countercyclical labor wedge as long as $\chi_{n}<1 / \nu$.

${ }^{19}$ This scalar is defined by $\phi \equiv \frac{\delta^{\prime \prime}\left(u^{*}\right) u^{*}}{\delta^{\prime}\left(u^{*}\right)}$, where $u^{*}$ denotes the steady-state level of utilization. A higher $\phi$ therefore means a more convex cost for utilization, which translates in equilibrium to a more inelastic utilization margin.

${ }^{20}$ If we re-interpret the model along the lines of footnote 18, this translates as follows: AS is more elastic when the real wage rigidity is larger.
} 
The supply block is completed with the law of motion for $k_{t}$, which in log-linearized form writes as $k_{t+1}=k_{t}-\kappa u_{t}$, for some scalar $\kappa .^{21}$ Putting everything together, we reach the following result.

Proposition 1 (Aggregate Supply). The optimal behavior of the firms, the optimal labor supply of the households, and market clearing impose the following equilibrium restrictions for all t:

$$
\begin{aligned}
y_{t} & =(1-\tilde{\alpha})\left(u_{t}+k_{t}\right), \\
u_{t} & =\frac{\beta}{\tilde{\alpha}+\beta \phi} R_{t}+\beta \mathbb{E}_{t}\left[u_{t+1}\right], \\
k_{t+1} & =k_{t}-\kappa u_{t},
\end{aligned}
$$

along with $k_{0}=\bar{k}_{0}$ exogenously fixed.

Because the above result does not use the optimality of consumer spending, it can be interpreted as a description of the "AS curve" of our model. In the limit as $\phi \rightarrow \infty$, this curve becomes vertical: utilization and output are pegged at their steady-state values. This captures the textbook scenario mentioned at the start of our Introduction. Away from this degenerate case, our AS curve is "upward slopping" in the sense that an increase in the real interest rate triggers an increase in aggregate utilization and, thereby, an increase in aggregate employment and output.

As evident in Proposition 1, our form of upward-sloping AS curve rests on utilization being a forwardlooking decision. This depends on the investment margin being absent (as in the present model) or subject to adjustment costs (as in the extension of Section 6.4). Such adjustment costs are empirically relevant (Caballero and Engel, 1999; Bachmann, Caballero, and Engel, 2013). But they are absent in the early RBC literature on variable utilization, such as Burnside, Eichenbaum, and Rebelo (1995), Greenwood, Hercowitz, and Huffman (1988), and King and Rebelo (1999). These works reduced utilization to a static decision, which explains why they did not share our supply-side mechanism. ${ }^{22}$

It is also worth emphasizing that we have expressed aggregate supply as an increasing function of the relative price of goods today vis-a-vis goods tomorrow. This is like "Econ-101" but unlike the Keynesian tradition, which instead expresses aggregate supply as an increasing function of either the nominal price level or the rate of inflation. But this is not just about graphs. In the textbook New Keynesian model, it is possible —although unusual—-to express aggregate supply as a positive function of the real interest rate by appropriately combining the Phillips curve with the Taylor rule for monetary policy and the Fisher equation. ${ }^{23}$ Still, this possibility hinges exclusively on the presence of nominal

\footnotetext{
${ }^{21}$ This scalar is given by $\kappa \equiv \frac{\delta^{\prime}\left(u^{*}\right) u^{*}}{1-\delta\left(u^{*}\right)}$, where $u^{*}$ denotes the steady-state level of utilization. As explained in Appendix A, $\kappa$ ends up coinciding with $\frac{1-\beta}{\beta}$ in the steady state.

${ }^{22}$ The same is true for the DSGE literature that builds on Christiano, Eichenbaum, and Evans (2005) and Smets and Wouters (2007), albeit for a different reason: although these works include adjustment costs to investment, they recast the cost of utilization in terms of today's goods as opposed to future capital, thus shutting down the forward-looking nature of utilization and our margin of intertemporal substitution in production. Finally, Basu and Kimball (1997), Jaimovich and Rebelo (2009), and Miao, Wang, and Xu (2015) allow utilization to be forward-looking in a similar way as in our paper, but do not study the general-equilibrium implications for discount-rate shocks, as we do here. Nor do they contain our (upcoming) confidence multiplier. See also the discussion at the end of Section 2.

${ }^{23}$ Write the Phillips curve as $\pi_{t}=\kappa\left(y_{t}-y_{t}^{n}\right)+\beta E_{t}\left[\pi_{t+1}\right]$, the Taylor rule as $i_{t}=\varphi \pi_{t}$, and Fisher equation as $i_{t}=R_{t}+$ $E_{t}\left[\pi_{t+1}\right]$, where, for the purposes of this footnote, $\pi_{t}$ is the rate of inflation, $y_{t}-y_{t}^{n}$ is the output gap, $i_{t}$ is the nominal interest
} 
rigidity and a monetary policy that fails to replicate flexible prices: in the flexible-price core of that model, AS is invariant to the real interest rate. By contrast, the reason that AS responds to the real interest rate in our model has nothing to do with either nominal rigidity or monetary policy: it is a feature of the "natural" level of output and it reflects the accommodation of intertemporal substitution in production via variable utilization.

\subsection{Aggregate Demand}

We now turn to optimal consumption and aggregate demand. Consider household $h$. As usual, the Euler equation and the relevant transversality condition are necessary and sufficient for optimality. Combining these conditions with the household's budget constraint, we arrive at the following characterization of the household's (log-linearized) consumption function.

Lemma 1. For every h and t, household h's optimal consumption in period t is given by:

$$
c_{t}^{h}=(1-\beta) b_{t}^{h}-\beta \sigma\left\{\sum_{k=0}^{+\infty} \beta^{k} E_{t}^{h}\left[R_{h, t+k}+\beta_{t+k}^{h}\right]\right\}+(1-\beta)\left\{\sum_{k=0}^{+\infty} \beta^{k} E_{t}^{h}\left[y_{h, t+k}\right]\right\},
$$

where $E_{t}^{h}[\cdot]=E_{t}\left[\cdot \mid \mathcal{I}_{t}^{h}\right]$ is the household's expectation at period $t$.

The first term captures initial wealth. The second term combines two intertemporal-substitution effects: that for interest rates and that for intertemporal preference shocks. The last term captures permanent income. In this last part, we have used the fact the household's income at period $t$ coincides with $y_{h, t}=p_{h, t}+q_{h, t}=y_{t}+\xi_{h, t}$, or the total revenue of the firms operating in the island where the household lives, works, and receives profits from.

To obtain a representation for aggregate demand, we aggregate (22) and use the facts that average bond holdings are zero, that each household knows its current interest rate, and that the future idiosyncratic shocks to interest rates are unpredictable. This yields the following expression:

$$
\begin{aligned}
c_{t}=-\sigma \beta\left(R_{t}+\beta_{t}\right) & -\beta \sigma\left\{\int \sum_{k=1}^{+\infty} \beta^{k} E_{t}^{h}\left[R_{t+k}\right] d h+\int \sum_{k=1}^{+\infty} \beta^{k} E_{t}^{h}\left[\beta_{t+k}^{h}\right] d h\right\} \\
+(1-\beta) & \left\{\int \sum_{k=0}^{+\infty} \beta^{k} E_{t}^{h}\left[y_{h, t+k}\right] d h\right\} .
\end{aligned}
$$

We next manipulate this condition as follows. We rewrite the first integral in (23) as

$$
\int \sum_{k=1}^{+\infty} \beta^{k} E_{t}^{h}\left[R_{t+k}\right] d h=\sum_{k=1}^{+\infty} \beta^{k} \mathbb{E}_{t}\left[R_{t+k}\right]-\frac{1}{\sigma} \mathcal{G}_{t}
$$

where

$$
\mathcal{G}_{t} \equiv-\sigma \sum_{k=1}^{+\infty} \beta^{k} \int\left\{E_{t}^{h}\left[R_{t+k}\right]-\mathbb{E}_{t}\left[R_{t+k}\right]\right\} d h
$$

rate, and $R_{t}$ is the real interest rate. Suppose next that $y_{t}^{n}=0$, meaning the natural rate of output is fixed, and to derive the point as fast as possible, let $E_{t}\left[\pi_{t+1}\right]=\rho \pi_{t}$ for some $\rho \in[0,1]$. The Phillips curve can then be rewritten as $\pi_{t}=\frac{\kappa}{1-\beta \rho} y_{t}$, while the Taylor rule plus the Fisher equation give $R_{t}=i_{t}-E_{t}\left[\pi_{t+1}\right]=(\varphi-\rho) \pi_{t}$. Combining, we get $y_{t}=\frac{(1-\beta \rho)}{\kappa(\varphi-\rho)} R_{t}$, which gives the AS curve in the $(R, y)$ space instead of the $(\pi, y)$ space. 
captures the average misperception of the future adjustment in the real interest rate. Similarly, we rewrite the second integral as

$$
\int \sum_{k=1}^{+\infty} \beta^{k} E_{t}^{h}\left[\beta_{t+k}^{h}\right] d h=\frac{\beta \rho_{\beta}}{1-\beta \rho_{\beta}} \int \beta_{t}^{h} d h=\frac{\beta \rho_{\beta}}{1-\beta \rho_{\beta}} \beta_{t}=\sum_{k=1}^{+\infty} \beta^{k} \mathbb{E}_{t}\left[\beta_{t+k}\right],
$$

and the third integral as

$$
\int \sum_{k=0}^{+\infty} \beta^{k} E_{t}^{h}\left[y_{h, t+k}\right] d h=\sum_{k=0}^{+\infty} \beta^{k} \mathbb{E}_{t}\left[y_{t+k}\right]+\frac{\beta}{1-\beta} \mathcal{B}_{t}
$$

where

$$
\mathcal{B}_{t} \equiv \frac{1-\beta}{\beta} \sum_{k=0}^{+\infty} \beta^{k} \int\left\{E_{t}^{h}\left[y_{h, t+k}\right]-\mathbb{E}_{t}\left[y_{t+k}\right]\right\} d h,
$$

captures average misperception of permanent income. Combining the above expressions and replacing $c_{t}$ with $y_{t}$, we obtain the following forward-looking condition for aggregate demand:

$$
y_{t}=-\sigma \beta\left(R_{t}+\beta_{t}\right)-\beta \sigma \sum_{k=1}^{+\infty} \beta^{k} \mathbb{E}_{t}\left[R_{t+k}+\beta_{t+k}\right]+(1-\beta)\left(y_{t}+\sum_{k=1}^{+\infty} \beta^{k} \mathbb{E}_{t}\left[y_{t+k}\right]\right)+\beta \mathcal{B}_{t}+\beta \mathcal{G}_{t} .
$$

Finally, rewriting this condition in a recursive form, we reach the following result.

Proposition 2 (Aggregate Demand). Aggregate spending satisfies the following condition:

$$
y_{t}=-\sigma\left(R_{t}+\beta_{t}\right)+\mathbb{E}_{t}\left[y_{t+1}\right]+\left(\mathcal{B}_{t}+\mathcal{G}_{t}\right)
$$

where $\mathcal{B}_{t}$ and $\mathcal{G}_{t}$ are defined in conditions (28) and (25).

This is the "AD curve" of our model. It looks like the Euler condition of a textbook, representativeagent economy, except for the inclusion of the terms $\mathcal{B}_{t}$ and $\mathcal{G}_{t}$. When households share the same information, $E_{t}^{h}[\cdot]=\mathbb{E}_{t}[\cdot]$ for all $h$ and these terms vanish. Both terms thus originate from the informational friction. But each one captures a different mechanism.

\subsection{The Two Belief Wedges}

Consider first $\mathcal{B}_{t}$. This term captures the average error in households' beliefs of their permanent income. When $\mathcal{B}_{t}>0$, households on average over-estimate their permanent income, and this contributes, other things equal, to higher spending today. (The converse is true when $\mathcal{B}_{t}<0$.)

To understand how $\mathcal{B}_{t}$ behaves, we first characterize the true aggregate permanent income.

Proposition 3 (A Hulten's Theorem for AD shocks). Aggregate permanent income satisfies

$$
\sum_{k=0}^{+\infty} \beta^{k} \mathbb{E}_{t}\left[y_{t+k}\right]=\frac{1-\tilde{\alpha}}{1-\beta} k_{t}
$$

and is invariant to $\eta_{t}$, the current aggregate demand shock.

As anticipated in the Introduction, this is a corollary of an intertemporal version of Hulten's (1978) theorem. The present discounted value of aggregate income in our dynamic economy is the equivalent 
of aggregate GDP in a static economy. In the latter context, Hulten's theorem, which only requires production efficiency, implies that aggregate GDP is invariant to intra-sectoral taste shocks. The translation of this result to our context, where production efficiency is effectively preserved even though the demand side is ridden with an informational friction, ${ }^{24}$ gives Proposition 3 above. In other words, just as in the static context taste shocks affect the cross-sectoral decomposition of GDP without altering its total value, in our dynamic context aggregate demand shocks shift aggregate output from one period to another without altering its present discounted value.

Using this property, which is itself known to households, we can reduce $\mathcal{B}_{t}$ in (28) to

$$
\mathcal{B}_{t}=\frac{1-\beta}{\beta} \sum_{k=0}^{+\infty} \beta^{k} \int E_{t}^{h}\left[\xi_{h, t+k}\right] d h .
$$

That is, misperceptions of total permanent income reduce to misperceptions of idiosyncratic permanent income. Furthermore, because $E_{t}^{h}\left[\xi_{h, t+k}\right]=\rho_{\xi}^{k} E_{t}^{h}\left[\xi_{h, t}\right]$ and $E_{t}^{h}\left[\xi_{h, t}\right]=y_{h, t}-E_{t}^{h}\left[y_{t}\right]$, we have

$$
\mathcal{B}_{t}=\frac{1-\beta}{\beta\left(1-\beta \rho_{\xi}\right)}\left(y_{t}-\bar{E}_{t}\left[y_{t}\right]\right) \text {, }
$$

where $\bar{E}_{t}[\cdot] \equiv \int E_{t}^{h}[\cdot] d h$. That is, whenever households underestimate the current aggregate income, they also overestimate their permanent income, and this misperception is larger the more persistent the idiosyncratic income fluctuations are.

Consider next $\mathcal{G}_{t}$. By construction, this term captures the average error in beliefs of future real interest rates. When $\mathcal{G}_{t}>0$, households on average under-estimate the future real interests, and this, too, contributes towards higher spending today. (The converse is true when $\mathcal{G}_{t}<0$.)

The characterization of $\mathcal{G}_{t}$ is a bit more complicated than that of $\mathcal{B}_{t}$, because the present discounted value of the real interest rate, unlike that of aggregate income, does vary with the AD shock. However, it can be shown that the innovations in the equilibrium expectations of future interest rates are proportional to the innovations in the current discount factor. It follows that

$$
\mathcal{G}_{t}=-\frac{\sigma^{2}}{\sigma+\varsigma} \frac{\beta \rho_{\beta}}{1-\beta \rho_{\beta}}\left(\beta_{t}-\bar{E}_{t}\left[\beta_{t}\right]\right)=\frac{\sigma^{2}}{\sigma+\varsigma} \frac{\beta \rho_{\beta}}{1-\beta \rho_{\beta}}\left(\eta_{t}-\bar{E}_{t}\left[\eta_{t}\right]\right)
$$

with $\varsigma \equiv \frac{1-\tilde{\alpha}}{\tilde{\alpha}+\beta \phi}$. Therefore, whenever agents underestimate the current aggregate shock, they also underestimate the future GE adjustment in the real interest rate, and this underestimation is larger the more persistent the AD shock is.

In the next section, we show how both of these "wedges" contribute towards amplification. For now, we summarize their characterization in the following result.

Lemma 2. With incomplete information,

$$
\mathcal{B}_{t}=\frac{1-\beta}{\beta\left(1-\beta \rho_{\xi}\right)}\left(y_{t}-\bar{E}_{t}\left[y_{t}\right]\right) \quad \text { and } \quad \mathcal{G}_{t}=\frac{\sigma^{2}}{\sigma+\varsigma} \frac{\beta \rho_{\beta}}{1-\beta \rho_{\beta}}\left(\eta_{t}-\bar{E}_{t}\left[\eta_{t}\right]\right)
$$

where $\bar{E}_{t}[\cdot] \equiv \int E_{t}^{h}[\cdot]$ dh is the average expectation across households.

\footnotetext{
${ }^{24}$ To be precise, production efficiency holds in our setting when firms are perfectly competitive, or $\mu=0$. But even when $\mu>0$, Proposition 3 still holds because the monopoly distortion is state- and time-invariant.
} 


\section{Equilibrium Characterization}

We complete the characterization of the equilibrium in five steps. First, we recast AS and AD in a more convenient form. Second, we show how to measure the informational friction by a scalar $\lambda \in(0,1]$. Third, we isolate the role of the confidence multiplier. Fourth, we study the complementary role of discounting GE adjustment in interest rates. Finally, we show that there is a unique fixed point between the aggregate dynamics and the signal extraction problem of the households, which completes the existence and uniqueness of the equilibrium and pins down the value of $\lambda$.

\subsection{Normalized AS and AD}

For given beliefs, the equilibrium dynamics are characterized by equations (19)-(21), which characterize AS, together with equation (30), which characterizes AD. To solve this system, it is useful to drop the backward-looking variable $k_{t}$ and re-express the equilibrium conditions as a purely forward-looking system. ${ }^{25}$ To this goal, we introduce the following transformation:

$$
\tilde{y}_{t} \equiv \frac{1}{\beta}\left(y_{t}-(1-\tilde{\alpha}) k_{t}\right)=\frac{1-\tilde{\alpha}}{\beta} u_{t} .
$$

The first part defines $\tilde{y}_{t}$ as aggregate output appropriately normalized by the stock of land. The second part notes that $\tilde{y}_{t}$ is proportional to utilization, which is purely forward-looking. We can then combine Propositions 1 and 2 to obtain the following representation of the equilibrium in our economy.

Proposition 4 (AS and AD). A path for $\tilde{y}_{t}$ and $R_{t}$ is part of an equilibrium if it satisfies the terminal condition $\lim _{t \rightarrow \infty} \beta^{t} \tilde{y}_{t}=0$ along with the following two dynamic equations:

$$
\begin{aligned}
& \tilde{y}_{t}=\varsigma R_{t}+\beta \mathbb{E}_{t}\left[\tilde{y}_{t+1}\right], \\
& \tilde{y}_{t}=-\sigma R_{t}+\beta \mathbb{E}_{t}\left[\tilde{y}_{t+1}\right]+\mathcal{B}_{t}+\mathcal{G}_{t}-\sigma \beta_{t},
\end{aligned}
$$

with $\mathcal{B}_{t}=\frac{1-\beta}{1-\beta \rho_{\xi}}\left(\tilde{y}_{t}-\bar{E}_{t}\left[\tilde{y}_{t}\right]\right), \mathcal{G}_{t}=\frac{\sigma^{2}}{\sigma+\varsigma} \frac{\beta \rho_{\beta}}{1-\beta \rho_{\beta}}\left(\eta_{t}-\bar{E}_{t}\left[\eta_{t}\right]\right)$, and $\varsigma \equiv \frac{1-\tilde{\alpha}}{\tilde{\alpha}+\beta \phi}$.

Conditions (34) and (35) are the "normalized" versions of, respectively, aggregate supply (AS) and aggregate demand $(\mathrm{AD})$. Both equations are forward-looking. In the case of AS, it is because utilization is forward-looking. In the case of $\mathrm{AD}$, it is because consumption is forward-looking. Their slopes with respect to the real interest rate are, respectively, $\varsigma$ and $-\sigma$. Finally, the terms $\mathcal{B}_{t}$ and $\mathcal{G}_{t}$, which are present in the $\mathrm{AD}$ equation and encapsulate the two mechanisms of interest, have now been restated in terms of the transformed variable $\tilde{y}_{t}$ rather than the original variable $y_{t}$.

The system provided above is easier to work with than the original given earlier in Propositions 1 and 2, because the new system is purely forward looking whereas the original contains a backwardlooking variable. ${ }^{26}$ But one has to keep in mind that any solution for $\tilde{y}_{t}$ must be transformed back to

\footnotetext{
${ }^{25}$ This simplification is possible here thanks to the abstraction from investment. In Section 6.4, which adds investment, we instead have to work with a more complicated dynamic system, which in turn explains the greater complexity of the formal arguments in the proof of Proposition 14 relative to those in our baseline model.

${ }^{26}$ The relevant backward-looking state variable, the effective stock of land, has dropped out of the new system thanks to
} 
a solution for $y_{t}$. In particular, holding $\tilde{y}_{\tau}$ constant for all $\tau>t$, an increase in $\tilde{y}_{t}$ maps to an increase in current aggregate income but also a decrease in future aggregate income. This underscores that an increase in $\tilde{y}_{t}$ represents an intertemporal shift in resources-which, circling back to our version of Hulten's theorem, is exactly what a "shift in aggregate demand" means in a neoclassical context.

\subsection{Beliefs: a Simple Representation}

Recall that, in any given period $t$, the past is common knowledge and the only aggregate innovation is $\eta_{t}$. It follows that the innovations in the average expectations of all current and future aggregate outcomes, as well in the aggregate outcomes themselves, are all proportional to $\eta_{t}$. That is, for any aggregate variable $x$ in the set $\{\beta, y, \tilde{y}, R\}$ and any $s \geq 0$,

$$
\mathbb{E}_{t}\left[x_{t+s}\right]=\mathbb{E}_{t-1}\left[x_{t+s}\right]+\gamma_{s}^{x} \eta_{t},
$$

for some scalar $\gamma_{s}^{x} .{ }^{27}$ Note that this condition uses the full-information expectation operator, not the expectation of the typical household in the economy. But because the information in $\mathbb{E}_{t}$ is a superset of the information in $E_{t}^{h}$, the expectation of the typical household, and because the latter itself contains the information in $\mathbb{E}_{t-1}$, the following is also true:

$$
E_{t}^{h}\left[x_{t+s}\right]=E_{t}^{h}\left[\mathbb{E}_{t}\left[x_{t+s}\right]\right]=\mathbb{E}_{t-1}\left[x_{t+s}\right]+\gamma_{s}^{x} E_{t}^{h}\left[\eta_{t}\right] .
$$

Aggregating across $h$ and letting $\lambda$ denote the coefficient of the projection of $\bar{E}_{t}\left[\eta_{t}\right]$ on $\eta_{t}$, we get

$$
\bar{E}_{t}\left[x_{t+s}\right]=\mathbb{E}_{t-1}\left[x_{t+s}\right]+\gamma_{s}^{x} \bar{E}_{t}\left[\eta_{t}\right]=\mathbb{E}_{t-1}\left[x_{t+s}\right]+\gamma_{s}^{x} \lambda \eta_{t}
$$

Combining (36) and (37), we finally reach the following result.

Proposition 5. In any equilibrium, there exists a scalar $\lambda \in(0,1)$ such that, for any aggregate variable $x$ in the set $\{\beta, y, \tilde{y}, R\}$, the average forecast of it satisfies

$$
\bar{E}_{t}\left[x_{t+s}\right]=(1-\lambda) \mathbb{E}_{t-1}\left[x_{t+s}\right]+\lambda \mathbb{E}_{t}\left[x_{t+s}\right] \quad \forall t, s \geq 0
$$

That is, it is as if the economy is populated by two representative agents: one that only knows the past, and another that also knows the present, with respective population weights $1-\lambda$ and $\lambda$. By the same token, $\lambda$ is an inverse measure of the severity of the informational friction: the smaller $\lambda$ is, the further away the economy is from the complete-information benchmark.

The exact value of $\lambda$ is determined from the fixed point between the aggregate outcomes and the typical household's inference problem. But the endogeneity of $\lambda$ is not essential for understanding our main results. We thus postpone its characterization for the end of this section.

the adopted transformation of variables. This transformation also explains why $\mathbb{E}_{t}\left[\tilde{y}_{t+1}\right]$ is discounted by $\beta$ in the normalized AD curve (35), whereas there is no such discounting in the original AD curve (30).

${ }^{27}$ The vector $\left\{\gamma_{s}^{x}\right\}_{s \geq 0}$, which identifies the Impulse Response Function of variable $x$ with respect to the AD innovation, is of course endogenously determined in equilibrium. For the present argument, however, this endogeneity is not relevant. 


\subsection{Isolating the Confidence Multiplier}

We first consider the case $\rho_{\beta}=0$, meaning an aggregate demand shock lasting only one period. This implies that $\tilde{\mathcal{G}}_{t}=0$, and therefore that the AS and AD equations take the following, simpler forms:

$$
\begin{aligned}
& \tilde{y}_{t}=\varsigma R_{t}, \\
& \tilde{y}_{t}=-\sigma R_{t}+\underbrace{(1-\lambda)\left(\frac{1-\beta}{1-\beta \rho_{\xi}}\right) \tilde{y}_{t}}_{\mathcal{B}_{t}}+\sigma \eta_{t} .
\end{aligned}
$$

This system is essentially static, allowing a straightforward characterization of how the economy responds to the aggregate demand shock.

Consider a negative realization for $\eta_{t}$ and start with the complete-information benchmark (herein nested as $\lambda=1$ ). In this case, $\mathcal{B}_{t}=0$ and the $\mathrm{AD}$ curve shifts down by an amount equal to $\sigma \eta_{t}$. This is represented in Figure 1 by the shift of the $\mathrm{AD}$ curve from $A D^{\text {old }}$ to $A D^{1}$. The intersection of $A D^{1}$ with $A S$ thus identifies the equilibrium pair of $\tilde{y}$ and $R$ that obtain under complete information.

Consider now the role of incomplete information. Had $\mathcal{B}_{t}$ been zero, the shock would have triggered the same shift in $\mathrm{AD}$ as under complete information. But because this "first-round" shift in $\mathrm{AD}$ causes current aggregate income to fall, and because households confuse aggregate and idiosyncratic movements in current income, they incorrectly perceive a decrease in their permanent income-even though, as already explained, there is no actual change in their permanent income, only an intertemporal shift. As this happens, the $\mathrm{AD}$ curve shifts further down, from $A D^{1}$ to $A D^{2}$ in Figure 1, triggering a further reduction in aggregate income. This in turn feeds to additional misperception (a further reduction in $\mathcal{B}$ ), a further downward shift in the AD curve, and so on.

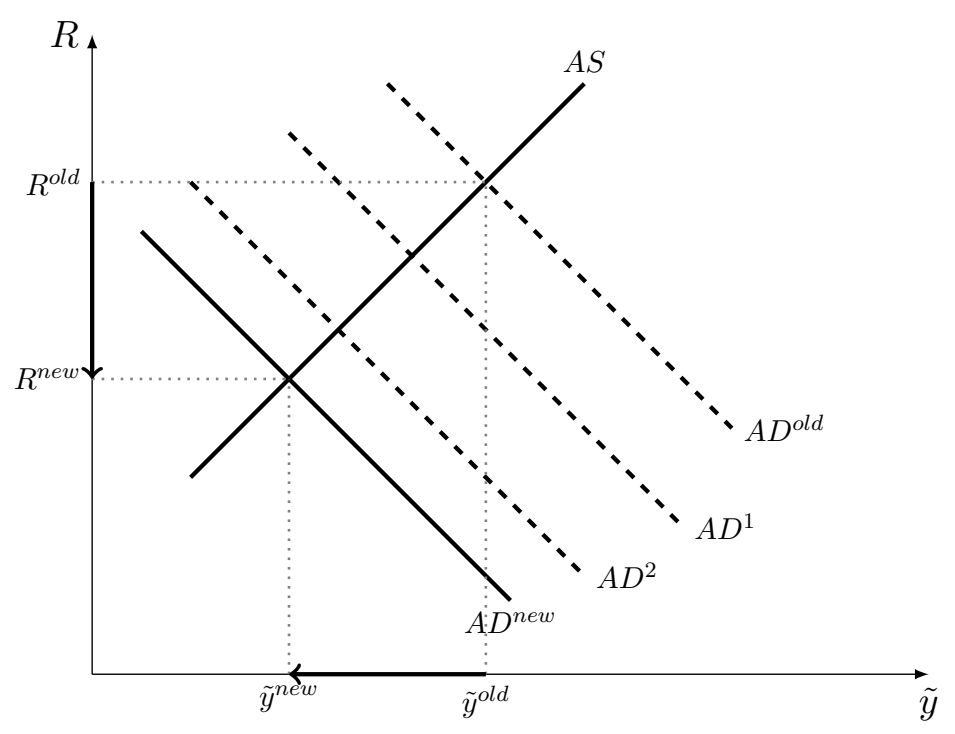

Figure 1. Feedback Mechanism

This series of feedbacks, whose limits correspond to the "final-round" curve $A D^{\text {new }}$ in the figure, explains the economics behind our confidence multiplier. The formal result is offered below. 
Proposition 6 (The confidence multiplier). Suppose the aggregate demand shock is entirely transitory $\left(\rho_{\beta}=0\right)$. The equilibrium response of real aggregate output is given by

$$
\frac{\partial y_{t}}{\partial \eta_{t}}=\gamma_{0} \cdot m^{\text {conf }}\left(\lambda, \rho_{\xi}\right),
$$

where $\gamma_{0} \equiv \frac{\varsigma \sigma \beta}{\varsigma+\sigma}$ is the complete-information counterpart and

$$
m^{\operatorname{conf}}\left(\lambda, \rho_{\xi}\right) \equiv \frac{\varsigma+\sigma}{\varsigma+\sigma-\varsigma \frac{1-\beta}{1-\beta \rho_{\xi}}(1-\lambda)}>1
$$

is the "confidence multiplier," namely a multiplier that captures the mechanism described above.

Note that $m^{\operatorname{conf}}\left(\lambda, \rho_{\xi}\right)$ is decreasing in $\lambda$ and increasing in $\rho_{\xi}$. A lower $\lambda$ means more confusion of the aggregate fluctuations for idiosyncratic income fluctuations, and a higher $\rho_{\xi}$ means more extrapolation of the present to the future and therefore a larger change in perceived permanent income for a given aggregate demand shock. Both forces contribute to a larger shift of the AD curve in each step of the series of feedbacks described in Figure 1, and hence also to a larger confidence multiplier.

\subsection{The General Case: Confidence Plus Discounting of Future Interest Rates}

We now allow the aggregate demand shock to be persistent. This does not affect the logic that the aggregate demand shock has no actual effect on aggregate permanent income: the aggregate demand shock still represents an intertemporal shift between "the long run" and "the short run," although the short run now last multiple periods (in expectation). It also does not affect the size of our confidence multiplier. What changes, though, are the expectations that households form about future real interest rates and their impact on aggregate demand under both complete and incomplete information. This amounts to an additional multiplier, which we formalize below.

Proposition 7 (The General Case). Allow the aggregate demand shock to be persistent $\left(\rho_{\beta} \geq 0\right)$. The equilibrium response of real aggregate output is given by

$$
\frac{\partial y_{t}}{\partial \eta_{t}}=\gamma \cdot m^{\operatorname{conf}}\left(\lambda, \rho_{\xi}\right) \cdot m^{G E}\left(\lambda, \rho_{\beta}\right)
$$

where $\gamma \equiv \frac{\beta \sigma \varsigma}{\sigma+\varsigma} \frac{1}{1-\rho_{\beta} \beta}$ is the complete-information counterpart, $m^{\text {conf }}\left(\lambda, \rho_{\xi}\right)$ is the same confidence multiplier as that defined in Proposition 6 above, and

$$
m^{G E}\left(\lambda, \rho_{\beta}\right) \equiv 1+\frac{\rho_{\beta} \beta \sigma}{\sigma+\varsigma}(1-\lambda) \geq 1
$$

is another multiplier, which captures the mechanism we refer to as "discounting the future GE adjustment in real interest rates."

Note that the confidence multiplier is invariant to $\rho_{\beta}$ and remains exactly the same as in the case of a transitory $\mathrm{AD}$ shock. This is because the size of the misperception in permanent income naturally depends on $\rho_{\xi}$, the persistence of the idiosyncratic income fluctuations, but is invariant to $\rho_{\beta}$, the persistence of the AD shock, thanks to our version of Hulten's theorem. Conversely, $\rho_{\xi}$ is irrelevant to the 
second multiplier, because this has nothing do with expectations of income. Instead, this multiplier has to do with expectations of future interest rates, whose persistence is governed by $\rho_{\beta}$.

Let us explain this new multiplier. When a negative aggregate demand shock hits the economy, it triggers in equilibrium a reduction in the real interest rate, which in turn moderates the original reduction in aggregate demand. This represents a "neoclassical GE adjustment" that partially offsets the direct, PE effect of the shock on aggregate demand. Furthermore, the fall in the real interest rate is as persistent as the demand shock itself.

With complete information, households not only see the current drop in the real interest rate, but also perfectly foresee how much the real interest rate will fall in the future. With incomplete information, households still observe the current drop in real interest rates but under-estimate their future drop. This arrests the forward-looking component of the aforementioned GE adjustment, leaving aggregate demand to move more strongly with the exogenous shock than what it would have done under complete information. ${ }^{28}$

We refer to this mechanism as "discounting the GE adjustment in real interest rates." At a high level, this mechanism is the same as that articulated in Angeletos and Lian (2018), Gabaix (2020) and Farhi and Werning (2019) in the context of forward guidance for monetary policy at the zero lower bound. But there are two key differences, on top of the obvious difference in the topics under consideration.

The first difference regards the identity of the object that adjusts in GE. In the context of the aforementioned works, this object is the output gap. In our context, instead, it is the natural rate of output.

The second difference regards the form of strategic interaction, or the way higher-order beliefs matter. The New Keynesian model studied in the aforementioned works corresponds to a game of strategic complementarity: when I expect others to spend more in the near future, I want to spend more myself today, because I expect monetary policy to fail to track the natural rate of interest and, instead, accommodate a boom. The kind of RBC model studied here instead corresponds to a game of strategic substitutability: when I expect others to spend more in the near future because of a persistent AD shock, I want to spend less myself, because I expect the real interest rate to increase. Under-estimating the responses of others leads to under-reaction (dampening) in the first type of games and to overreaction (amplification) in the latter. ${ }^{29}$ This explains why the same elementary mechanism maps to diametrically opposite effects in our setting relative to the aforementioned works.

Putting aside these clarifications, the key observation for our purposes is that this mechanism works hand-in-hand with our confidence multiplier: they both help sustain larger movements in AD, and thereby in equilibrium output and employment, than under complete information.

We conclude with a note on comparative statics. As evident from (41), $m^{\mathrm{GE}}\left(\lambda, \rho_{\beta}\right)$ is decreasing in $\lambda$ and increasing in $\rho_{\beta}$. Intuitively, the larger the informational friction or the longer the GE adjustment in

\footnotetext{
${ }^{28} \mathrm{Had}$ we allowed households to be inattentive to the current real interest rate, because of rational inattention (Sims, 2003) or sparsity (Gabaix, 2014), we would have arrested the countervailing effect of the concurrent adjustment in the real interest as well, which of course would only increase the related multiplier.

${ }^{29}$ For clear articulations of this point in more abstract settings or other applications, see Angeletos and Lian (2017) and Angeletos and Sastry (2021).
} 
interest rates, the larger the multiplier associated with the discounting of this adjustment. Combining this property with the one obtained earlier for the confidence multiplier, we get the following result.

Corollary. The overall multiplier, $m\left(\lambda, \rho_{\xi}, \rho_{\beta}\right) \equiv m^{\operatorname{conf}}\left(\lambda, \rho_{\xi}\right) m^{G E}\left(\lambda, \rho_{\beta}\right)$, is increasing in the severity of the informational friction and the persistence of both kinds of shocks.

Finally, although our model is too stylized to permit a quantitative evaluation, let us do a simple, back-of-the-envelope calculation. Suppose the slopes of the AS and AD curves are comparable $(\varsigma \approx \sigma)$, the discount factor is close to 1 , idiosyncratic income follows a random walk $\left(\rho_{\xi} \approx 1\right)$, the persistence of the aggregate fluctuations in the model is comparable to that in the data $\left(\rho_{\beta} \approx 0.95\right)$, and $\lambda \approx 1 / 2$ (think of it as half the population being perfectly informed and the rest being completely uninformed). Then, $m \approx 5 / 3$, which suggests that the documented amplification could be substantial.

\subsection{Signal Extraction and the Fixed Point for $\lambda$}

In the preceding analysis, we have treated the value of $\lambda$ as given. However, the severity of the informational friction depends on how much households can extract from the available market signals. This implies that the value of $\lambda$ in our economy is the solution to a fixed point problem that relates the informativeness of these signals to the responsiveness of aggregate output and the real interest rate to the aggregate demand shock: the greater this response, the more precise the information revealed by the aforementioned signals, and the smaller the friction. This fixed point is characterized below.

Proposition 8. There exists a unique $\lambda \in(0,1)$ in equilibrium and is given by the solution of the following fixed point problem:

$$
\lambda=\frac{\sigma_{\beta}^{-2}+\sigma_{R}^{-2}\left\{\varsigma^{-1} \gamma\left[\beta^{-1} m\left(\lambda, \rho_{\xi}, \rho_{\beta}\right)-\rho_{\beta}\right]\right\}^{2}+\sigma_{\xi}^{-2}\left\{\gamma m\left(\lambda, \rho_{\xi}, \rho_{\beta}\right)\right\}^{2}}{\sigma_{A D}^{-2}+\sigma_{\beta}^{-2}+\sigma_{R}^{-2}\left\{\varsigma^{-1} \gamma\left[\beta^{-1} m\left(\lambda, \rho_{\xi}, \rho_{\beta}\right)-\rho_{\beta}\right]\right\}^{2}+\sigma_{\xi}^{-2}\left\{\gamma m\left(\lambda, \rho_{\xi}, \rho_{\beta}\right)\right\}^{2}},
$$

where $m\left(\lambda, \rho_{\xi}, \rho_{\beta}\right) \equiv m^{\operatorname{conf}}\left(\lambda, \rho_{\xi}\right) m^{G E}\left(\lambda, \rho_{\beta}\right)$ is the overall multiplier.

The above condition, which follows from the standard formula for combining multiple Gaussian signals, reflects the fact that the household has three such signals about the underlying AD shock: her own discount rate, $\beta_{t}^{h}$; her local interest rate $R_{h, t}$; and her own income, or the local demand, $y_{h, t}$. And whereas the informativeness of the first signal is exogenous, that of the other two signals is endogenous. In particular, their informativeness increase with the multiplier: the larger the multiplier, the more these market signals moves with the $\mathrm{AD}$ shock, and hence the more precise the information households can extract from them about the underlying shock. This explains why the right-hand side of the above condition decreases with $\lambda$, which in turn guarantees the uniqueness of the equilibrium. ${ }^{30}$

It is also immediate to verify that, for given $\rho_{\xi}$ and $\rho_{\beta}, \lambda$ is a decreasing function of the ratio $\sigma / \sigma_{\mathrm{AD}}$ for any $\sigma \in\left\{\sigma_{\beta}, \sigma_{R}, \sigma_{\xi}\right\}$. By varying these "noise" parameters, we can indeed induce any value for $\lambda$ in

\footnotetext{
${ }^{30}$ In general, signal extraction problems in GE settings can admit multiple equilibria; see Gaballo (2017) and Chahrour and Gaballo (2021). But this is not an issue here because our setting features, in effect, strategic substitutability in signal extraction.
} 
the $(0,1)$ range. This, together with the uniqueness of $\lambda$, justifies our earlier treatment of it as a "free" parameter. Finally, by combining the comparative statics of $m$ with the comparative statics of the fixed point in condition (42) we reach the follow result.

Proposition 9. Let $m^{*}$ denote the overall multiplier evaluated at the equilibrium value of $\lambda$. This is necessarily increasing in the ratio $\sigma / \sigma_{A D}$ for any $\sigma \in\left\{\sigma_{\beta}, \sigma_{R}, \sigma_{\xi}\right\}$, as well as in both $\rho_{\xi}$ and $\rho_{\beta}$.

That is, our statement "a larger friction implies a larger multiplier," which was previously formalized with the monotonicity of $m\left(\lambda, \rho_{\xi}, \rho_{\beta}\right)$ in $\lambda$ treating the latter as exogenous, is now recast as the monotonicity of $m^{*}$ in deeper noise parameters. And the lesson that the overall multiplier increases with the persistence of both shocks, which was previously articulated holding $\lambda$ constant, is robust to taking into account the endogeneity of $\lambda$.

We close this section with the following remark on the interpretation of $\lambda$. In the present version of our model, the value of $\lambda$ hinges on the availability of information about the aggregate shock, or the state of the economy. This in turn suggests that a policymaker could regulate the magnitude of the business cycle by providing more or less information to consumers. But this need not be true in two realistic variants, in which the relevant confusion is present even if information about the aggregate state is abundant. In one variant, consumers rationally choose not to pay enough attention to the aggregate state (or to any related communications by policymakers), for the reasons articulated in Mackowiak and Wiederholt (2009). In another, consumers are boundedly rational, in the sense described in Section 6.5. These variants preserve our predictions about amplification, which were the topic of the previous subsections, but not those about the precise value of $\lambda$, which were the topic of the present subsection. This explains why we "trust" the former predictions more than the latter.

\section{Extensions and Variants}

In this section, we consider four extensions/variants of our baseline model. The first two explore our theory's predictions for the economy's response to aggregate supply shocks and fiscal stimuli. The remaining two show how our theory can rationalize comovement between "borrowers" and "savers," and between consumption and investment. In addition, we discuss how the mechanisms at work can be recast as the product of bounded rationality instead of informational friction.

\subsection{Aggregate Supply Shocks}

The main analysis has focused on $\mathrm{AD}$ shocks, in the sense of aggregate discount-factor shocks. We now turn to AS shocks, in the sense of aggregate productivity shocks. The lesson delivered below is that the documented mechanisms may help dampen AS shocks at the same time they amplify AD shocks.

The model is the same, except that we shut down the shocks to the household's discount factor and, 
instead, introduce aggregate productivity shocks. In particular, a firm's output is given by

$$
y_{i, j, t}=A_{t}\left(l_{i, j, t}\right)^{\alpha}\left(u_{i, j, t} k_{i, j, t}\right)^{1-\alpha},
$$

where $A_{t}$ is an aggregate TFP shock. This follows an $\operatorname{AR}(1)$ process with persistence $\rho_{A} \in[0,1)$ :

$$
\log A_{t}=\rho_{A} \log A_{t-1}+\log \eta_{t}^{A},
$$

where $\log \eta_{t}^{A} \sim \mathcal{N}\left(0, \sigma_{A}^{2}\right)$ and $A_{-1}$ is normalized at 1. Finally, the household's information set in period $t$ is given by $\mathcal{I}_{t}^{h}=\mathcal{I}_{t-1}^{h} \cup\left\{w_{h, t}, e_{h, t}, R_{h, t},\left(p_{i, j, t}\right)_{i \in[0,1], j \in[0,1]}\right\} \cup\left\{\eta_{t-1}^{A}\right\}$. It follows that, although the source of the aggregate shock is different, local income and local interest rates serve again as noisy signals of the underlying aggregate shock.

We once again log-linearize the equilibrium conditions and re-interpret all the variables as logdeviations from their steady-state counterparts. Following similar steps as in Section 4, we reach the following characterization of AS and $\mathrm{AD}$.

Proposition 10. (i) Aggregate supply is given by

$$
\begin{aligned}
y_{t} & =A_{t}+(1-\tilde{\alpha})\left(u_{t}+k_{t}\right), \\
u_{t} & =\frac{\beta}{\tilde{\alpha}+\beta \phi}\left(A_{t}-\mathbb{E}_{t}\left[A_{t+1}\right]\right)+\frac{\beta}{\tilde{\alpha}+\beta \phi} R_{t}+\beta \mathbb{E}_{t}\left[u_{t+1}\right], \\
k_{t+1} & =k_{t}-\kappa u_{t} .
\end{aligned}
$$

(ii) Aggregate demand is given by

$$
y_{t}=-\sigma R_{t}+\mathbb{E}_{t}\left[y_{t+1}\right]+\left(\mathcal{B}_{t}+\mathcal{G}_{t}\right),
$$

where $\mathcal{B}_{t}$ and $\mathcal{G}_{t}$ are defined as (28) and (25).

The characterization of AS is similar to before, except, of course, for the accommodation of the TFP shock. ${ }^{31}$ Turning to $\mathrm{AD}$, this is exactly the same as before, and $\mathcal{B}_{t}$ and $\mathcal{G}_{t}$ have the same mathematical definition. However, both terms behave differently from before.

Consider first $\mathcal{B}_{t}$, which maps to our confidence multiplier. In the case with $\mathrm{AD}$ shocks, the actual aggregate permanent income was fixed, guaranteeing that the confusion of aggregate and idiosyncratic income fluctuations had an unambiguous effect on confidence: following a positive shock, households were necessarily over-estimating their permanent income, so $\mathcal{B}_{t}$ was necessarily positive. This is not the case with AS shocks. Because such shocks do influence actual aggregate permanent income, imperfect knowledge of the shock naturally translates to under-estimation of the corresponding movements in permanent income. In particular, following a positive shock, a consumer over-estimates the idiosyncratic component of her permanent income, which pushes $\mathcal{B}_{t}$ positive, but also underestimates the aggregate component, which pushes $\mathcal{B}_{t}$ negative. This explains why our confidence multiplier is weakened or even turned upside down.

\footnotetext{
${ }^{31}$ This shows up, not only in (44), the production function, but also in (45), the optimality condition for utilization. Intuitively, the optimal intertemporal pattern of production depends, not only on the relative price of today's goods, but also on their relative cost. The former is captured in condition (45) by $R_{t}$, the latter by $A_{t}-\mathbb{E}_{t}\left[A_{t+1}\right]$.
} 
Consider next $\mathcal{G}_{t}$, which corresponds to the discounting of the GE adjustment in real interest rates. In the case of $\mathrm{AD}$ shocks, this mechanism contributed towards amplification. Here, it does the exact opposite. When information is complete, a persistent positive TFP shock triggers a persistent drop in real interest rates, which in turn stimulates aggregate demand. When information is incomplete, consumers under-estimate the drop in future real interest rates and this reduces aggregate demand relative to the complete-information case. This explains why $\mathcal{G}_{t}$ is necessarily negative following a positive TFP shock, or why the corresponding multiplier is necessarily reversed.

These observations explain the following result: ${ }^{32}$

Proposition 11 (Technology Shocks). The equilibrium response of aggregate output to an aggregate technology shock is given by

$$
\frac{\partial y_{t}}{\partial \eta_{t}^{A}}=\gamma^{A} \cdot m_{A}^{c o n f}\left(\lambda, \rho_{\xi}, \rho_{A}\right) \cdot m_{A}^{G E}\left(\lambda, \rho_{A}\right)
$$

where $\gamma^{A}>0$ is the complete-information counterpart, $m_{A}^{G E}\left(\lambda, \rho_{A}\right)$ is a multiplier that captures the effect of $\mathcal{G}_{t}$, or the discounting of the GE adjustment in interest rates, and $m_{A}^{\text {conf }}\left(\lambda, \rho_{\xi}, \rho_{A}\right)$ is a multiplier that captures the effect of $\mathcal{B}_{t}$, or the confusion of idiosyncratic and aggregate income fluctuations. Furthermore,

$$
m_{A}^{\text {conf }}\left(\lambda, \rho_{\xi}, \rho_{A}\right)<1 \text { if and only if } \rho_{\xi}<\bar{\rho}_{\xi},
$$

for some $\bar{\rho}_{\xi}=\bar{\rho}_{\xi}\left(\rho_{A}\right)$ that is itself increasing in $\rho_{A}$, and

$$
m_{A}^{G E}\left(\lambda, \rho_{A}\right)<1 \text { necessarily. }
$$

To sum up, as long as aggregate TFP shocks and idiosyncratic income shocks have comparable persistence, our first mechanism, the confidence multiplier, is basically switched off or even reversed. ${ }^{33}$ And our second mechanism, the discounting of the GE adjustment in the real interest rate, is necessarily reversed.

The following caveat, however, must be raised. In the above analysis, which abstracts from investment, a positive AS shock is necessarily associated with a drop in the real interest rate. But once the investment margin is present, as in the baseline RBC model or the upcoming extension of our model in Section 6.4, the effect of an AS shock on the real interest rate is generally ambiguous. A positive supply shock that is either transitory or does not affect the marginal product of capital tends to lower the real interest rate by increasing today's supply of goods more than consumption; but a positive AS shock that is sufficiently persistent and moves the marginal product of capital enough can cause the real interest rate to rise by increasing the demand for investment. This implies that both of our mechanisms may be ambiguous vis-a-vis AS shocks. But they both seem to work in the "right" direction vis-a-vis AD shocks, which is the core issue for us.

\footnotetext{
${ }^{32}$ Since $m_{A}^{\text {conf }}\left(\lambda, \rho_{\xi}, \rho_{A}\right)$ and $m_{A}^{\mathrm{GE}}\left(\lambda, \rho_{A}\right)$ may increase with $\lambda$ here, we cannot rule out the possibility of multiple equilibrium values for $\lambda$, as we did for $\mathrm{AD}$ shocks in Proposition 8. This, however, does not interfere with the result presented here, because this holds regardless of $\lambda$.

${ }^{33}$ Note that $\bar{\rho}_{\xi}(1)=1$. Hence, when both shocks are highly persistent, the confidence multiplier is muted.
} 


\subsection{Government Spending}

We now study a different kind of AD shocks, namely shocks to government spending. Unsurprisingly, these shocks have similar effects as those featured in our baseline analysis, both with and without common knowledge. But there is an interesting twist, regarding the distinction between front-loaded and back-loaded fiscal stimuli.

The model is the same, except for two modifications. First, we drop the shocks to the household's discount factor and, instead, add shocks to government spending. And second, we abstract from the wealth effect on labor supply. It is well understood both what this effect does in theory and that is probably very weak in reality. By removing it, we isolate what's new. ${ }^{34}$

In each period, the government purchases a basket of all the goods in the economy. The overall expenditure, denoted by $G_{t}$, follows an $\operatorname{AR}(1)$ process with persistence $\rho_{G} \in[0,1)$ :

$$
G_{t}=\rho_{G} G_{t-1}+\eta_{t}^{G},
$$

where $G_{-1}=0$ and $\eta_{t}^{G} \sim \mathcal{N}\left(0, \sigma_{G}^{2}\right)$ is i.i.d. across $t$ and independent from other shocks. The composition of $G_{t}$ mirrors that of private spending. ${ }^{35}$

Turning to taxes, we let government spending be financed by lump-sum taxation and, without further loss of generality, impose budget balance in each period, i.e., $G_{t}=T_{t}$. At the same time, we prevent one's own tax from being a perfect signal of the aggregate level of government spending by introducing idiosyncratic tax shocks. Specifically, we let the lump-sum tax levied to household $h$ in period $t$ be given by $T_{t}^{h}=T_{t}+\Delta_{t}^{h}$, where $T_{t}$ is the average tax and $\Delta_{t}^{h} \sim \mathcal{N}\left(0, \sigma_{\Delta}^{2}\right)$ also follows an $\operatorname{AR}(1)$ process with persistence $\rho_{G}$, and independent from any other shock. ${ }^{36}$

We close the model by letting the information structure be the same as in the baseline model, modulo, of course, that the knowledge of $\eta_{t-1}$ and $\beta_{t}^{h}$ is now replaced with the knowledge of $\eta_{t-1}^{G}$ and $T_{t}^{h}$. That is, $\mathcal{I}_{t}^{h}=\mathcal{I}_{t-1}^{h} \cup\left\{T_{t}^{h}\right\} \cup\left\{w_{h, t}, e_{h, t}, R_{h, t},\left(p_{i, j, t}\right)_{i \in[0,1], j \in[0,1]}\right\} \cup\left\{\eta_{t-1}^{G}\right\}$.

As in the baseline model, we log-linearize the equilibrium conditions and re-interpret all the variables as log-deviations from their steady-state counterparts. ${ }^{37}$ Following similar steps as in Section 5, we reach the following result.

Proposition 12. (i) Aggregate supply remains the same as in Proposition 1.

\footnotetext{
${ }^{34}$ Here, we shut this effect down in the manner described earlier in footnote 18. Similar results obtain if we assume GHH preferences, as we did in an earlier draft.

${ }^{35}$ That is, we impose, for all $i, j$, and $t$,

$$
\frac{p_{i, j, t} g_{i, j, t}}{G_{t}}=\frac{\int_{h \in[0,1]} p_{i, j, t} c_{i, j, t}^{h} d h}{c_{t}},
$$

where $g_{i, j, t}$ is the government's purchase of variety $j$ from island $i$ in period $t$.

${ }^{36}$ By equating the persistence of the idiosyncratic tax shock to that of aggregate government spending, we make sure that households correctly perceive the tax burden of any fiscal stimulus. Relaxing this property may be interesting on its own right-see, for example, Gabaix (2020) for an example that goes in this direction with the help of bounded rationality instead of incomplete information-but it is not the issue we wish to study here.

${ }^{37}$ The following exception applies: $G_{t}, T_{t}, g_{i, j, t}$ and $T_{t}^{h}$ henceforth represent, respectively, $G_{t} / y^{*}, T_{t} / y^{*}, g_{i, j, t} / y^{*}$, and $T_{t}^{h} / y^{*}$, where $y^{*}$ is the steady-state (also, complete-information) value of aggregate output. This is a standard trick in the literature on fiscal multipliers (e.g., Woodford, 2011) and it simply takes care of the issue that the log-deviation of the government spending is not well defined when its steady-state value is 0 .
} 
(ii) Aggregate demand satisfies

$$
y_{t}=-\sigma R_{t}+\left(1-\rho_{G}\right) G_{t}+\mathbb{E}_{t}\left[y_{t+1}\right]+\left(\mathcal{B}_{t}+\mathcal{G}_{t}\right)
$$

where $\mathcal{B}_{t}$ and $\mathcal{G}_{t}$ are the same as in (28) and (25), modulo the replacement of $\rho_{\beta}$ with $\rho_{G}$.

(iii) The equilibrium response of real aggregate output is given by

$$
\frac{\partial y_{t}}{\partial \eta_{t}^{G}}=\gamma^{G} \cdot m^{\operatorname{conf}}\left(\lambda, \rho_{\xi}\right) \cdot m^{G E}\left(\lambda, \rho_{G}\right)
$$

where $\gamma^{G}=\frac{\left(1-\rho_{G}\right) \beta \varsigma}{(\sigma+\varsigma)\left(1-\rho_{G} \beta\right)}$ is the complete-information counterpart and $m^{\operatorname{conf}}(\cdot, \cdot)$ and $m^{G E}(\cdot, \cdot)$ are the same multipliers as those in Propositions 6-7.

In a nutshell, $\left(1-\rho_{G}\right) G_{t}$ replaces $-\sigma \beta_{t}$ as the AD shock in Proposition 2. The rest is the same. And the following is then immediate.

Corollary. With complete information, $\frac{\partial y_{t}}{\partial \eta_{t}^{G}}<1$ necessarily. With incomplete information, instead, $\frac{\partial y_{t}}{\partial \eta_{t}^{G}}>1$ is possible insofar as $\bar{m} \gamma^{G}>1$, where $\bar{m}$ is the maximum of the overall multiplier defined above. ${ }^{38}$ That is, whereas an increase in government spending crowds out private consumption under complete information, it can crowd in under incomplete information.

Our theory therefore helps accommodate the Keynesian narrative of how a fiscal stimulus can help boost consumer spending despite the increase in the tax burden. But unlike the Keynesian framework, our theory does not rely on nominal rigidity and does not require the boom to be inflationary.

The fiscal-policy predictions of our theory are even more distinct from those of the Keynesian paradigm if we shift the focus from "front-loaded" to "back-loaded" fiscal stimuli. By front-loaded stimuli, we mean unanticipated shocks to current government spending, such as those modeled above. By back-loaded stimuli, we instead have news about future government spending.

To see this, let $G_{t}$ be i.i.d. over time and known one period in advance. That is, $G_{t}=\eta_{t-1}^{G}$ where $\eta_{t-1}^{G}$ is a "new shock" observed at $t-1$. Condition (49) then becomes

$$
y_{t}=-\sigma R_{t}+\eta_{t-1}^{G}-\eta_{t}^{G}+\mathbb{E}_{t}\left[y_{t+1}\right]+\left(\mathcal{B}_{t}+\mathcal{G}_{t}\right) .
$$

It is immediate that, other things equal, aggregate demand today decreases with $\eta_{t}^{G}$, the news about tomorrow's government spending. This translates, in equilibrium, to a reduction in $y_{t}$ even when this news shock is perfectly known at $t$, thanks to the optimal intertemporal reallocation in production: when the economy expects an increase in the demand for goods tomorrow, it responds by economizing on its use of resources today. But when information is imperfect, the reduction in current income can be misperceived by the consumers as a reduction in permanent income. Our confidence multiplier thus kicks in, amplifying the contraction triggered by news of future increases in government spending. ${ }^{39}$

\footnotetext{
${ }^{38}$ The maximum overall multiplier is given by $\bar{m} \equiv m(1,1,1)=1+\beta+\frac{\varsigma}{\sigma}$.

${ }^{39}$ There is, however, a countervailing channel. In the frictionless benchmark, the expectation of a higher $G_{t+1}$ triggers an increase in the expected interest rate at $t+1$, which depresses $\mathrm{AD}$ at $t$. Under incomplete information, the consumers discount this GE adjustment, which moderates the contraction in $\mathrm{AD}$.
} 
Finally, the fact that an increase in current government spending crowds in private consumption when the informational friction is large enough hints at our theory's broader ability to generate positive comovement among different components of aggregate demand. We expand on this point in the next two subsections.

\subsection{Borrowers and Savers}

Consider a variant of our model that lets only a fraction $\pi \in(0,1)$ of the households be hit by an exogenous discount-rate shock. Think of them as "borrowers" responding to a credit crunch, and think of the remaining households as "savers." Although we do not explicitly model this situation, we use this interpretation to allude to how our theory differs from, but also complements, the New Keynesian literature on liquidity constraints (e.g., Eggertsson and Krugman, 2012; Guerrieri and Lorenzoni, 2017).

The AS side of the economy remains unaltered. What changes is the AD side. The two groups are identical, except for their different exposure to the exogenous shock. (The borrowers are directly exposed, the savers are not.)

When both groups are fully informed, the group-level demands are given by

$$
\begin{aligned}
c_{t}^{b} & =-\sigma R_{t}+\mathbb{E}_{t}\left[c_{t+1}^{b}\right]-\sigma \beta_{t} \\
c_{t}^{s} & =-\sigma R_{t}+\mathbb{E}_{t}\left[c_{t+1}^{s}\right],
\end{aligned}
$$

where the superscripts $b$ and $s$ stand for, respectively, borrowers and savers. It follows that, in equilibrium, a negative realization of $\eta_{t}$ reduces $c_{t}^{b}$, reduces $R_{t}$, and increases $c_{t}^{s}$. As the borrowers cut down their spending, savers pick up some of the slack. ${ }^{40}$

When information is incomplete, the group-level demands are modified as follows:

$$
\begin{aligned}
c_{t}^{b} & =-\sigma R_{t}+\mathbb{E}_{t}\left[c_{t+1}^{b}\right]+\mathcal{B}_{t}+\mathcal{G}_{t}-\sigma \beta_{t} \\
c_{t}^{s} & =-\sigma R_{t}+\mathbb{E}_{t}\left[c_{t+1}^{s}\right]+\mathcal{B}_{t}+\mathcal{G}_{t} .
\end{aligned}
$$

The terms $\mathcal{B}_{t}$ and $\mathcal{G}_{t}$ are the same as in our baseline model and the informational friction is again measured by $\lambda \in(0,1] .{ }^{41}$

Proposition 13 (Borrowers and Savers). Suppose that the informational friction is sufficiently large ( $\lambda$ small enough) and/or that the AS curve is sufficiently flat ( large enough). Then, $c_{t}^{s}, c_{t}^{b}$, and $y_{t}$ comove.

The logic is straightforward. With complete information, $c_{t}^{s}$ moves in the opposite direction of $c_{t}^{b}$ because of the GE adjustment in the real interest rate. With incomplete information, this effect is attenuated and, on top of this, the reduction in aggregate income causes savers to misperceive a reduction in their permanent income. To the extent that this effect is strong enough (which is the case

\footnotetext{
${ }^{40}$ This is immediate to see when the AS curve is vertical ( $\left.\varsigma \rightarrow 0\right)$. In this case, aggregate output and consumption are invariant to $\eta_{t}$, implying that $c_{t}^{s}=-\frac{\pi}{1-\pi} c_{t}^{b}$. More generally, aggregate output and consumption fall with $\eta_{t}$, but it remains true that $c_{t}^{s}$ moves in the opposite direction than $c_{t}^{b}$.

${ }^{41}$ This imposes, for simplicity, that the two groups have equally precise information about the underlying $\mathrm{AD}$ shock.
} 
when the savers are sufficiently confused) and the adjustment in the real interest rate is small enough (which is the case when the AS curve is sufficiently flat), savers cut down their spending in equilibrium, moving in the same direction as the borrowers.

The New Keynesian framework can obtain a similar comovement between savers and borrowers by assuming a sufficiently irresponsive monetary policy, or by translating the credit crunch to a deflationary spiral, as in the ZLB applications by Eggertsson and Krugman (2012) and Guerrieri and Lorenzoni (2017). But this circles back to our motivation of why we find it useful to obtain realistic demand-driven business cycles outside the nexus of sticky prices and Phillips curves: here, we have offered a reason for why comovement between constrained and unconstrained agents may emerge even if monetary policy tracks the natural rate of interest, the output gap is zero, and inflation is stable.

\subsection{Investment}

As noted earlier, our baseline analysis allows for variable utilization of capital (or "land") but abstracts from investment. If we add investment but let it be decided under complete information, we run into a familiar problem: whenever consumers spend less, the cost of investment (the real interest rate) goes down in equilibrium, causing investment to move in the opposite direction than consumption. We now show how this negative comovement problem is resolved when our confidence multiplier extends from consumption to investment.

To this goal, we re-interpret land as capital and modify its law of motion as follows:

$$
k_{i, t+1}=\left(1-\delta\left(u_{i, t}\right)+\Psi\left(\iota_{t}^{i}\right)+\epsilon_{i, t}^{k}\right) k_{i, t},
$$

where $u_{i, t}$ is the utilization rate, $\iota_{t}^{i}$ is the investment rate per unit of capital, $\epsilon_{i, t}^{k}$ is an idiosyncratic shock, $\delta(\cdot)$ is an increasing and strictly convex function, and $\Psi(\cdot)$ is an increasing and concave function. We let investment choices be made by the households and under the same information as consumption. And we accordingly rewrite the household's budget constraint as

$$
\int_{i \in[0,1]} \int_{j \in[0,1]} p_{i, j, t} c_{i, j, t}^{h} d j d i+R_{h, t}^{-1} b_{t+1}^{h}=w_{h, t} n_{t}^{h}+e_{h, t}-\iota_{t}^{h} k_{t}^{h}+b_{t}^{h},
$$

where $e_{h, t}$, earnings net of labor costs, now represent the returns to capital.

The concavity of $\Psi$ captures adjustment costs to capital, as in standard Q theory. More specifically, we let $\Psi\left(\iota^{*}\right)=\iota^{*}, \Psi^{\prime}\left(\iota^{*}\right)=1$, and $\Psi^{\prime \prime}\left(\iota^{*}\right)=-\psi$, where $\iota^{*}$ denotes the steady-state aggregate investment rate and $\psi>0$ is a scalar that parameterizes how large the adjustment costs are. As anticipated, such adjustment costs make sure that the supply-side logic of our baseline model extends to the present model. In particular, we can show that the AS curve is positively sloped, or that aggregate employment and output respond positively to $\eta_{t}$, for any $\psi>0$ as long as the real wage is sufficiently acyclical. Had we instead set $\psi=0$, as in the classics by Burnside, Eichenbaum, and Rebelo (1995), Greenwood, Hercowitz, and Huffman (1988) and King and Rebelo (1999), it would have been impossible to get 
aggregate employment and output to increase with $\eta_{t} \cdot{ }^{42}$

To make sure that investment also responds positively, we need the increase in the real interest rate to be offset by an increase in "investor sentiment." By the latter we mean the analogue of $\mathcal{B}_{t}$ for investment: in response to an intertemporal shift in aggregate spending, investors confuse an increase in sales and profits today for good news about idiosyncratic firm returns in the future.

The basic logic of how our mechanism gives rise to comovement is therefore similar to that in the previous subsection: just replace borrowers and savers with, respectively, consumption and investment. But the math is considerably more complicated because of the infinite horizon, the transitional dynamics in capital, and the multiple kinds of forward-looking decisions. To contain these complications, we shut down the wealth effect on labor supply, let the aggregate discount-rate shock $\eta_{t}$ be transitory (recall that this isolates the confidence multiplier) and the idiosyncratic demand shock $\xi_{i, t}$ to be a random walk. We then prove the sought-after result under the conditions stated below.

Proposition 14 (Consumption-Investment Comovement). There exist $\bar{\lambda}, \bar{\phi}, \underline{\nu}, \underline{\psi}>0$ such that $\lambda<\bar{\lambda}$ along with $\phi<\bar{\phi}, \nu>\underline{\nu}$, and $\psi>\underline{\psi}$ suffice for both $c_{t}$ and $\iota_{t}$ to increase in response to a positive realization for $\eta_{t}$.

Because of the aforementioned complications, this result only provides sufficiency in the neighborhood of $\lambda, \phi \approx 0$ and $\nu, \psi \approx \infty$. A sharper necessary and sufficient for comovement over the entire parameter space is offered in Appendix A for a more manageable, two-period version of our model. Both results yield the same lesson: comovement is possible as long as the informational friction is sufficiently large (small $\lambda$ ) and the AS curve is sufficiently flat ( $\operatorname{small} \phi$, large $\nu$ and $\psi$ ). The first property maps to large procyclical movements in misperceptions of investment returns, the second to small countervailing movements in the real interest rate.

Needless to say, the result presented above is only a proof of concept; its quantitative potential is an open question. Also, the following qualification is important to make. By abstracting from an informational friction in production, we have made sure that utilization is not directly affected by the kind of misperceptions that affect investment and consumption. Had we allowed for the alternative scenario, the same mistake that causes households to raise their demand for investment could also cause firms to reduce their demand for utilization, simply because the negative of utilization is itself a form of investment. From this perspective, our theory appears to require a separation between investment and production, as in models that emphasize frictions in financial intermediation and asset markets, and a higher degree of over-extrapolation in "Wall Street" than in "Main Street."

That said, once one allows informational frictions to be present in production, such frictions can also affect the demand for labor. Angeletos and La'O $(2010,2013)$ and Angeletos, Collard, and Dellas (2018) have built on this elementary point to generate business cycles with a Keynesian flavor out of extrinsic shocks in producer sentiment; a similar mechanism is also at work in Ilut and Saijo (2020),

\footnotetext{
${ }^{42}$ For the proof of these claims, see the section "Aggregate supply: the role of capital adjustment costs" in Appendix A.
} 
albeit for other shocks. We suspect that a combination of these approaches with ours could provide a more "robust" explanation of how fluctuations in confidence can generate realistic comovement.

\subsection{Bounded Rationality}

Our confidence multiplier originates from an informational friction in the tradition of Lucas (1972) and Sims (2003). Empirical evidence in support of such a friction abounds. ${ }^{43}$ More tellingly for our purposes, a recent paper by Andrade et al. (2020) provides evidence in favor of the confusion between industry-specific and aggregate shocks, which is what our model assumes under the interpretation of an "island" as an industry. But neither this interpretation nor rational confusion is strictly needed for our multiplier to apply. A similar feedback loop obtains in a plausible "behavioral" variant in which agents have a less sophisticated understanding of the world than that assumed in Rational Expectations.

Suppose, in particular, that agents use a simple, random-walk model to extrapolate current income to future income:

$$
E_{t}^{h}\left[y_{h, t+k}\right]=y_{h, t}
$$

This resembles the form of simple, "extrapolative" beliefs found in Barberis et al. (2015) and Gennaioli, $\mathrm{Ma}$, and Shleifer (2016). It also proxies an optimally "sparse" representation of the individual income process, in the spirit of Molavi (2019). ${ }^{44}$ Whenever current aggregate income goes up by one unit, agents believe that their permanent income has gone up by $1 /(1-\beta)$. But if the increase in current aggregate income is triggered by an $\mathrm{AD}$ shock, their permanent income has not actually changed. It follows that the relevant misperception term (28) is given by

$$
\mathcal{B}_{t}=\frac{1}{\beta} \frac{\partial y_{t}}{\partial \eta_{t}} \eta_{t}
$$

In our original model, this term was given by

$$
\mathcal{B}_{t}=\frac{(1-\beta)(1-\lambda)}{\beta\left(1-\beta \rho_{\xi}\right)} \frac{\partial y_{t}}{\partial \eta_{t}} \eta_{t}
$$

Clearly, the two expressions coincide when $\lambda=0$ and $\rho_{\xi}=1$ (maximal informational friction and random-walk idiosyncratic shocks), illustrating how our confidence multiplier can be recast as the product of bounded rationality. This in turn lets us connect to Akerlof and Shiller (2010), who also talk about feedbacks between economic outcomes and confidence, and have a behavioral interpretation in mind, but do not spell out what exactly this means in terms of a fully articulated model.

A similar re-interpretation is possible for our second mechanism, the discounting of the GE adjust-

\footnotetext{
${ }^{43}$ See, inter alia, Coibion and Gorodnichenko (2012, 2015), Coibion, Gorodnichenko, and Ropele (2019), Cavallo, Cruces, and Perez-Truglia (2017), Angeletos and Sastry (2021), and the references there in.

${ }^{44}$ Suppose that individual income is driven by both random-walk idiosyncratic shocks (like $\xi_{h, t}$ in our model) and transitory aggregate shocks (like $\beta_{t}$ in our model). Suppose further that agents can only use a lower-dimension, one-factor, statistical model to track current income and form expectations about future income, but can choose that model optimally, as in Molavi (2019). A reasonable conjecture is that the optimal model converges to the statical process of the idiosyncratic shock as this shock gets larger and larger relative to the aggregate one.
} 
ment in real interest rates. Consider, in particular, the following scenario. While a fraction of $\ell \in(0,1)$ of households are both fully informed and fully rational, the remaining are "level-1 thinkers" a la Farhi and Werning (2019): although they experience an urge to consume less, they do not expect others to spend less in the future. These agents expect future aggregate demand, and hence also the future real interest rate, to remain unchanged. It follows that the relevant term (25) is given by

$$
\mathcal{G}_{t}=(1-\ell) \sigma \sum_{k=1}^{+\infty} \beta^{k} \frac{\partial \mathbb{E}_{t}\left[R_{t+k}\right]}{\partial \eta_{t}} \eta_{t} .
$$

By comparison, in our baseline model, this term satisfies

$$
\mathcal{G}_{t}=(1-\lambda) \sigma \sum_{k=1}^{+\infty} \beta^{k} \frac{\partial \mathbb{E}_{t}\left[R_{t+k}\right]}{\partial \eta_{t}} \eta_{t} .
$$

Clearly, the two terms coincide when $\lambda=\ell$. In this sense, the lack of information can readily be recast as a lack of sophistication (“some people do not understand GE consequences"). ${ }^{45}$

\section{Conclusion}

We revisited the question of why shifts in consumer spending, or other aggregate demand shocks, trigger business cycles. Unlike the dominant paradigm, our theory did not rely on nominal rigidity and the failure to implement the natural rate of output. Instead, it combined a neoclassical margin for intertemporal substitution on the supply side with an informational friction, or bounded rationality, on the demand side. The first element allowed the aggregate production of today's goods to be responsive to intertemporal taste shocks, or other shifts in aggregate demand. The second element gave rise to our confidence multiplier, a positive feedback loop between current economic activity, consumer perceptions of permanent income, and investor expectations of returns.

This mechanism was shown to amplify aggregate demand shocks, without necessarily doing the same for aggregate supply shocks. Furthermore, this mechanism contributed to positive comovement between the different components of aggregate demand, such as private consumption, private investment, and government spending. And last but not least, this mechanism was operating along with flexible-price outcomes, requiring no comovement between inflation and real economic activity.

All in all, our theory is therefore capable of accommodating the Keynesian narrative of the business cycle without a strict reliance on nominal rigidity and on gaps from the natural rate of output. And it helps match—qualitatively—a number of stylized facts about modern business cycles.

Consider, in particular, the empirical template that Angeletos, Collard, and Dellas (2020) provide for the "main business cycle shock" in the data. This is constructed by running a VAR on a few key macroeconomic time series and by identifying the shock (i.e., the linear combination of the VAR residuals) that has the maximal contribution to the fluctuations of unemployment over the business-cycle

\footnotetext{
${ }^{45}$ This example indicates more broadly the similarity of the bounded-rational approaches taken in Gabaix (2020) and Farhi and Werning (2019) to the incomplete-information approach taken in Angeletos and Lian (2018).
} 


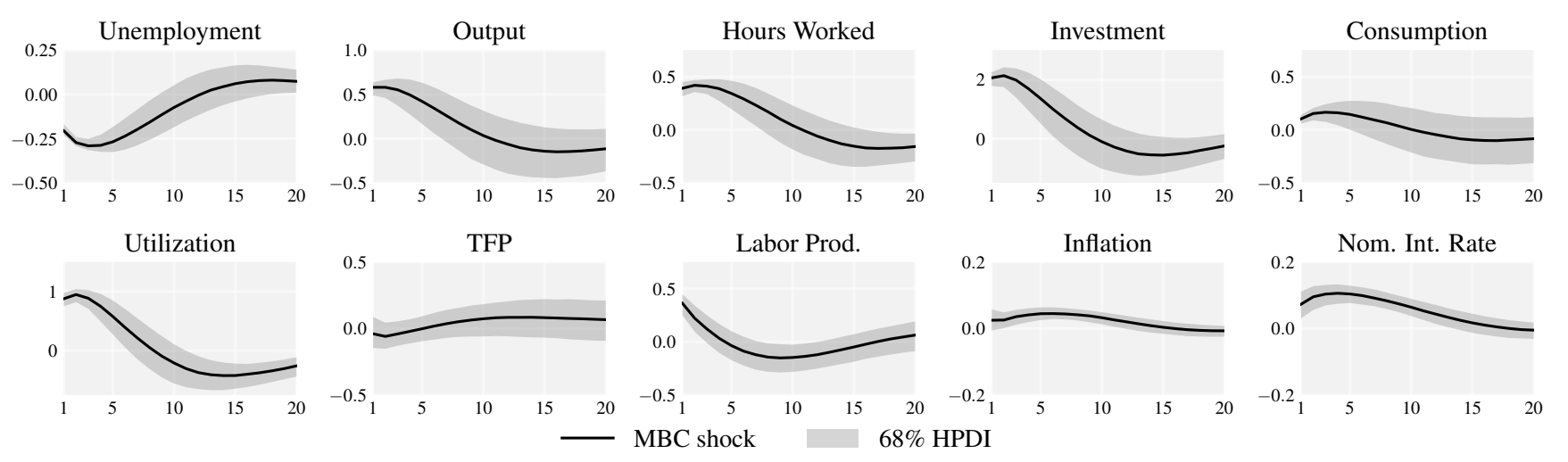

Figure 2. The ”Main Business Cycle Shock“ in the Data, from Angeletos, Collard, and Dellas (2020)

frequencies. Figure 2 reports the IRFs of all the variables under consideration to this shock. ${ }^{46}$

The key observations for our purposes are the following. First, there is significant comovement between unemployment, output, hours worked, investment, and consumption, without commensurate comovement in TFP and inflation. Second, there is significant pro-cyclical movement in utilization, which in turn appears to account for all the pro-cyclical movement in labor productivity. And third, there is significant pro-cyclical movement in the nominal interest rate and, since inflation is relatively stable, there is nearly equal pro-cyclical movement in the real interest rate.

These properties are consistent with our theory. The first property is essentially the definition of the kind of non-inflationary, demand-driven fluctuation in the data that our theory aspired to deliver. The second provides tentative support for our theory's emphasis on utilization. The third supports both the idea that the underlying shock is an aggregate demand shock that pushes up the real interest rate and the idea that the monetary authority is tracking the natural rate.

Another notable feature of the data, seen in the bottom left panel of Figure 2, is that the response of utilization reverses sign after a few quarters. This is in line with the supply side element of our theory, and in particular the idea that demand-driven business cycles represent intertemporal reallocation of utilization and production. And it hints at the broader value of exploring the robustness of this empirical finding and its theoretical implications.

This is all good news for our theory. But none of the above facts directly speak to our confidence multiplier. Ultimately, the sign and size of the kind of misperceptions—rational or irrational—modeled in this paper is an empirical question. And although we must leave this question for future work, we hope to have provided useful guidance for what exactly future empirical work should explore.

Let us expand on the last point by relating our theory to the empirical findings of Rozsypal and Schlafmann (2019), Greenwood and Shleifer (2014), and Gennaioli, Ma, and Shleifer (2016). These

\footnotetext{
${ }^{46}$ Figure 2 here is basically a replica of the solid lines from Figure 17 in the Online Appendix of Angeletos, Collard, and Dellas (2020). Relative to the original, we have dropped three variables (stock prices, the relative price of investment, and the labor share) in order to simplify the figure; but as it can be readily verified by comparing the two figures, the inclusion or exclusion of these variables makes no essential difference for the results. We refer the reader to Angeletos, Collard, and Dellas (2020) for a detailed description of the data and the empirical method, a discussion of structural interpretations, and a barrage of robustness exercises; the replication material can be found at https://www.aeaweb.org/articles?id=10.1257/aer.20181174.
} 
works are supportive of our confidence mechanism in the sense that they point out in the direction of expectations of income and returns being excessively optimistic in good times and excessively pessimistic at bad times. ${ }^{47}$ They do not, however, distinguish whether such good and bad times are driven by the kind of aggregate demand shocks that are the focus of our paper or by other forces, such as TFP shocks. The litmus test of our theory is therefore conditional evidence for how expectations of income and interest rates respond to different kinds of shocks-and it is this specific kind of evidence we invite for future work.

We conclude with the following remark. To isolate our demand-side mechanism, we abstracted from any supply-side friction and any movements in the labor wedge. To the extent that such movements reflect real wage rigidities, they are immediately consistent with the re-interpretation of condition (13) as an arbitrary "real wage schedule," namely a mapping from aggregate employment to real wages that needs not coincide with the household's optimal labor supply condition. ${ }^{48}$ But another possibility, closer in spirit to our paper, is that the labor wedge is itself the product of informational frictions (at least partially). While we abstracted from this possibility in this paper, this is a central ingredient of papers such as Angeletos and La'O (2010), Angeletos, Collard, and Dellas (2018), and Ilut and Saijo (2020). This suggests that a bridge between these papers and ours could be another fruitful direction for future work.

\footnotetext{
${ }^{47}$ Rozsypal and Schlafmann (2019) use micro data on household income expectations, and find that consumers overextrapolate from their current income to expectations of future income, as they overestimate the persistence of their income process. Households with currently high income turn out to be too optimistic about their future income, while households with currently low income turn out to be too pessimistic about their future income. Gennaioli, Ma, and Shleifer (2016) turn the focus to the firm side. They find that firm CFOs over-extrapolate from current earnings to expectations of future earnings. Greenwood and Shleifer (2014) find that investors over-extrapolate from current stock returns to expectations of future stock returns.

${ }^{48}$ See footnote 18 for details. Note that real wage rigidity does not by itself give a non-vertical AS curve. But once our intertemporal-substitution margin is active, it helps make the AS curve flatter (think of real wage rigidity as a larger Frisch elasticity). And, as mentioned in Section 6.2, it also helps mute the wealth effect of government spending.
} 


\section{Appendix A: Proofs}

\section{Preliminary step: the steady state.}

We first provide conditions for the existence of a deterministic steady state and characterize it. By a deterministic steady state we mean a situation in which there are no shocks and all variables $(c, y, l, k, q, w, \vartheta$, $R$, and $u$ ) remain constant. Also, for this step we work with the original variables (not log-deviations).

In a steady state, the optimal labor supply implies

$$
w^{*}\left(c^{*}\right)^{-\frac{1}{\sigma}}=\left(n^{*}\right)^{\frac{1}{\nu}}
$$

while the optimal labor demand implies

$$
w^{*}=\frac{\alpha}{1+\mu} \frac{y^{*}}{l^{*}} .
$$

Using goods and labor market clearing $y^{*}=c^{*}$ and $l^{*}=n^{*}$, we have

$$
l^{*}=\left(\frac{\alpha}{1+\mu}\right)^{\frac{\nu}{1+\nu}}\left(y^{*}\right)^{\frac{\nu}{1+\nu} \frac{\sigma-1}{\sigma}} .
$$

Using it to replace labor in the production function, we have

which is equivalent to

$$
\left(y^{*}\right)^{1-\frac{\alpha \nu}{1+\nu} \frac{\sigma-1}{\sigma}}=\left(\frac{\alpha}{1+\mu}\right)^{\frac{\alpha \nu}{1+\nu}}\left(u^{*} k^{*}\right)^{1-\alpha},
$$

$$
y^{*}=\left(\frac{\alpha}{1+\mu}\right)^{\frac{\alpha}{1+\frac{1}{\nu}-\alpha\left(1-\frac{1}{\sigma}\right)}}\left(u^{*} k^{*}\right)^{\frac{(1-\alpha)\left(1+\frac{1}{\nu}\right)}{1+\frac{1}{\nu}-\alpha\left(1-\frac{1}{\sigma}\right)}} .
$$

Optimal utilization implies

$$
\frac{1-\alpha}{1+\mu} \frac{y^{*}}{u^{*} k^{*}}=\vartheta^{*} \delta^{\prime}\left(u^{*}\right) .
$$

The evolution of the shadow value of the land implies

$$
\vartheta^{*}=\left(R^{*}\right)^{-1}\left(\frac{(1-\alpha)}{1+\mu} \frac{y^{*}}{k^{*}}+\left(1-\delta\left(u^{*}\right)\right) \vartheta^{*}\right),
$$

Optimal consumption implies

$$
1=\left(\beta R^{*}\right)^{-\sigma}
$$

Together, this means that the steady state value $u^{*}$ must satisfy

$$
1=\beta\left(\delta^{\prime}\left(u^{*}\right) u^{*}+\left(1-\delta\left(u^{*}\right)\right)\right) .
$$

Further notice that the evolution of capital in a steady state implies

$$
\delta\left(u^{*}\right)=0 .
$$

As discussed in the main text, for a steady state to exist, one needs the solution to (52) also satisfies (53), which implies

$$
\kappa \equiv \frac{\delta^{\prime}\left(u^{*}\right) u^{*}}{1-\delta\left(u^{*}\right)}=\frac{1-\beta}{\beta} .
$$

Note that the existence of such a steady state imposes a restriction on the economy's parameters. 
When this restriction is violated, the economy exhibits a balance-growth path in which $c, y, l, k, q, w$, and $\vartheta$ grow at constant (although not necessarily equal) rates, while $R$ and $u$ remain constant. We have verified that this possibility does not upset any of our results. But we ignore it here because it is an artifact of the exclusion of an investment margin: once we add this margin (Section 6.4), a no-growth steady state is guaranteed for any non-infinite adjustment cost to capital. The logic is the same as in the textbook RBC model: diminishing returns to capital guarantee that gross investment exceeds (respectively, falls short of) depreciation when $k$ is below (respectively, above) its steady-state value.

\section{Proof of Proposition 1.}

(19) and (21) directly follow from the main text. To derive (20), we first aggregate (16) and (17):

$$
\begin{aligned}
& \vartheta_{t}=y_{t}-(1+\phi) u_{t}-k_{t}, \\
& \vartheta_{t}=-R_{t}+(1-\beta) \mathbb{E}_{t}\left[y_{t+1}-k_{t+1}-u_{t+1}\right]+\beta \mathbb{E}_{t}\left[\vartheta_{t+1}\right] .
\end{aligned}
$$

Combining we get

$$
y_{t}-(1+\phi) u_{t}-k_{t}=-R_{t}+(1-\beta) \mathbb{E}_{t}\left[y_{t+1}-k_{t+1}-u_{t+1}\right]+\beta \mathbb{E}_{t}\left[y_{t+1}-(1+\phi) u_{t+1}-k_{t+1}\right] .
$$

Using the aggregate production in (19), the evolution of aggregate capital in (21), and the fact $\kappa \equiv$ $\frac{\delta^{\prime}\left(u^{*}\right) u^{*}}{1-\delta\left(u^{*}\right)}=\frac{1-\beta}{\beta}$ from (54), we arrive at (20).

\section{Proof of Lemma 1.}

Lemma 1 follows directly from household $h$ 's Euler equation,

$$
c_{t}^{h}=-\sigma\left(\beta_{t}^{h}+R_{h, t}\right)+E_{t}^{h}\left[c_{t+1}^{h}\right],
$$

and its log-linearized budget constraint,

$$
\sum_{k=0}^{+\infty} \beta^{k} c_{t+k}^{h}=b_{t}^{h}+\sum_{k=0}^{+\infty} \beta^{k} y_{h, t+k} .
$$

Note that the Euler condition holds despite the informational friction, because we are using the household's own expectation operator.

\section{Proof of Proposition 2.}

Proposition 2 follows directly from the derivation in the main text.

\section{Proof of Proposition 3.}

From the aggregate production in (19), we have

$$
\mathbb{E}_{t}\left[\sum_{k=0}^{+\infty} \beta^{k} y_{t+k}\right]=(1-\tilde{\alpha}) \mathbb{E}_{t}\left[\sum_{k=0}^{+\infty} \beta^{k}\left(u_{t+k}+k_{t+k}\right)\right]
$$


Then use the evolution of aggregate capital in (21), we have

$$
\mathbb{E}_{t}\left[\sum_{k=0}^{+\infty} \beta^{k}\left(u_{t+k}+k_{t+k}\right)\right]=\mathbb{E}_{t}\left[\sum_{k=0}^{+\infty} \beta^{k} u_{t+k}+\frac{1}{1-\beta} k_{t}-\kappa \sum_{k=0}^{+\infty} \frac{\beta^{k+1}}{1-\beta} u_{t+k}\right] .
$$

Finally, use the fact $\kappa \equiv \frac{\delta^{\prime}\left(u^{*}\right) u^{*}}{1-\delta\left(u^{*}\right)}=\frac{1-\beta}{\beta}$ from (54), we arrive at (31).

\section{Proof of Lemma 2.}

The expression for $\mathcal{B}_{t}$ follows directly from the derivation in the main text. Now we turn to the expression for $\mathcal{G}_{t}$.

First notice that, as all past aggregate shocks and all past aggregate outcomes are common knowledge, future $\mathcal{B}_{t+k}$ and $\mathcal{G}_{t+k}$ are only functions of the future aggregate shock $\eta_{t+k}$. They are henceforth unpredictable in period $t$. That is, $E_{t}^{h}\left[\mathcal{B}_{t+k}\right]=E_{t}^{h}\left[\mathcal{G}_{t+k}\right]=0$ for all $h, t$, and all $k \geq 1$. From Proposition 4 , we then have, for all $h, t$, and all $k \geq 1$,

$$
\begin{aligned}
& E_{t}^{h}\left[\tilde{y}_{t+k}\right]=\varsigma E_{t}^{h}\left[R_{t+k}\right]+\beta E_{t}^{h}\left[\tilde{y}_{t+k+1}\right] \\
& E_{t}^{h}\left[\tilde{y}_{t+k}\right]=-\sigma E_{t}^{h}\left[R_{t+k}+\beta_{t+k}\right]+\beta E_{t}^{h}\left[\tilde{y}_{t+k+1}\right],
\end{aligned}
$$

As a result, we have for all $h, t$, and all $k \geq 1$,

$$
E_{t}^{h}\left[R_{t+k}\right]=-\frac{\sigma}{\sigma+\varsigma} E_{t}^{h}\left[\beta_{t+k}\right]
$$

From the definition of $\mathcal{G}_{t}$ in (25), we then have

$$
\begin{aligned}
\mathcal{G}_{t} & =\frac{\sigma^{2}}{\sigma+\varsigma} \sum_{k=1}^{+\infty} \beta^{k}\left(\bar{E}_{t}\left[\beta_{t+k}\right]-\mathbb{E}_{t}\left[\beta_{t+k}\right]\right) \\
& =-\frac{\sigma^{2}}{\sigma+\varsigma} \frac{\beta \rho_{\beta}}{1-\beta \rho_{\beta}}\left(\beta_{t}-\bar{E}_{t}\left[\beta_{t}\right]\right)=\frac{\sigma^{2}}{\sigma+\varsigma} \frac{\beta \rho_{\beta}}{1-\beta \rho_{\beta}}\left(\eta_{t}-\bar{E}_{t}\left[\eta_{t}\right]\right) .
\end{aligned}
$$

\section{Proof of Proposition 4.}

Proposition 4 follows directly from Proposition 1, Proposition 2, and the definition of $\tilde{y}_{t}$ in (33). Finally, the terminal condition follows from the transversality condition of the firm.

\section{Proof of Proposition 5.}

Proposition 5 follows directly from the derivation in the main text.

\section{Proof of Proposition 6.}

Proposition 6 follows directly from (33), (38), and (39). 


\section{Proof of Proposition 7.}

First notice that, as all past aggregate shocks and all past aggregate outcomes are common knowledge, future $\mathcal{B}_{t+k}$ and $\mathcal{G}_{t+k}$ are only functions of the future aggregate shock $\eta_{t+k}$. They are henceforth unpredictable in period $t$. From Proposition 4, we then have, for all $t$ and all $k \geq 1$,

$$
\begin{aligned}
& \mathbb{E}_{t}\left[\tilde{y}_{t+k}\right]=\varsigma \mathbb{E}_{t}\left[R_{t+k}\right]+\beta \mathbb{E}_{t}\left[\tilde{y}_{t+k+1}\right] \\
& \mathbb{E}_{t}\left[\tilde{y}_{t+k}\right]=-\sigma \mathbb{E}_{t}\left[R_{t+k}+\beta_{t+k}\right]+\beta \mathbb{E}_{t}\left[\tilde{y}_{t+k+1}\right] .
\end{aligned}
$$

As a result, we have for all $t$ and all $k \geq 1$,

$$
\mathbb{E}_{t}\left[R_{t+k}\right]=-\frac{\sigma}{\sigma+\varsigma} \rho_{\beta}^{k} \beta_{t} \text { and } \mathbb{E}_{t}\left[\tilde{y}_{t+k}\right]=-\frac{\sigma \varsigma}{\sigma+\varsigma} \frac{\rho_{\beta}^{k}}{1-\rho_{\beta} \beta} \beta_{t} .
$$

Together with Lemma 2 and Proposition 4, we have that AS and AD can be re-expressed as follows:

$$
\begin{aligned}
& \tilde{y}_{t}=\varsigma R_{t}-\frac{\sigma \varsigma}{\sigma+\varsigma} \frac{\beta \rho_{\beta}}{1-\rho_{\beta} \beta} \beta_{t}, \\
& \tilde{y}_{t}=-\sigma R_{t}-\frac{\sigma \varsigma}{\sigma+\varsigma} \frac{\beta \rho_{\beta}}{1-\rho_{\beta} \beta} \beta_{t}+\frac{1-\beta}{1-\beta \rho_{\xi}}\left(\tilde{y}_{t}-\bar{E}_{t}\left[\tilde{y}_{t}\right]\right)+\frac{\sigma^{2}}{\sigma+\varsigma} \frac{\beta \rho_{\beta}}{1-\beta \rho_{\beta}}\left(\eta_{t}-\bar{E}_{t}\left[\eta_{t}\right]\right)-\sigma \beta_{t} .
\end{aligned}
$$

Together with Proposition 5, we have

$$
\left(1+\sigma \varsigma^{-1}-\frac{1-\beta}{1-\beta \rho_{\xi}}(1-\lambda)\right) \frac{\partial \tilde{y}_{t}}{\partial \eta_{t}}=\frac{\sigma}{1-\rho_{\beta} \beta}\left(1+\frac{\sigma \beta \rho_{\beta}}{\sigma+\varsigma}(1-\lambda)\right) .
$$

It follows that

$$
\frac{\partial y_{t}}{\partial \eta_{t}}=\frac{\sigma \beta \varsigma}{1-\rho_{\beta} \beta} \frac{1+\frac{\sigma \beta \rho_{\beta}}{\sigma+\varsigma}(1-\lambda)}{\varsigma+\sigma-\varsigma \frac{1-\beta}{1-\beta \rho_{\xi}}(1-\lambda)},
$$

which proves Proposition 7. Moreover, from (57), we have

$$
\frac{\partial R_{t}}{\partial \eta_{t}}=\varsigma^{-1}\left(\frac{1}{\beta} \frac{\partial y_{t}}{\partial \eta_{t}}-\rho_{\beta} \gamma\right)>0
$$

with $\gamma$ is defined in Proposition 7.

\section{Proof of Proposition 8.}

Consider household $h$. From (12) - (14), we know

$$
w_{h, t}=\frac{1}{\nu+1} y_{h, t}+\frac{\nu}{\sigma(\nu+1)} c_{t}^{h}
$$

Together with the fact the household's total income is $y_{h, t}$, we know that her knowledge of $\left(w_{h, t}, e_{h, t}\right)$ is informationally equivalent to her knowledge of $y_{h, t}$. In other words, (8) is equivalent to

$$
\mathcal{I}_{t}^{h}=\mathcal{I}_{t-1}^{h} \cup\left\{\beta_{t}^{h}\right\} \cup\left\{y_{h, t}, R_{h, t},\left(p_{i, j, t}\right)_{i \in[0,1], j \in[0,1]}\right\} \cup\left\{\varepsilon_{t-1}^{\beta}\right\} .
$$

We then know that the household $h$ has three sources of knowledge about the AD shock $\eta_{t},\left(R_{h, t}, y_{h, t}, \beta_{t}^{h}\right)$. Since past aggregate shocks and outcomes are common knowledge, the household $h$ 's information about $\eta_{t}$ are given by following three independent signals about $\eta_{t}$ :

$$
\frac{\partial R_{t}}{\partial \eta_{t}} \eta_{t}+\epsilon_{h, t}^{R}, \frac{\partial y_{t}}{\partial \eta_{t}} \eta_{t}+\xi_{h, t}, \text { and }-\eta_{t}+\epsilon_{t}^{\beta, h}
$$


From Proposition 7 and (58), we know $\frac{\partial y_{t}}{\partial \eta_{t}}=\gamma m\left(\lambda, \rho_{\xi}, \rho_{\beta}\right)$ and $\frac{\partial R_{t}}{\partial \eta_{t}}=\varsigma^{-1} \gamma\left[\beta^{-1} m\left(\lambda, \rho_{\xi}, \rho_{\beta}\right)-\rho_{\beta}\right]>0$. Based on the standard formula for combining multiple Gaussian signals, we have

$$
\bar{E}_{t}\left[\eta_{t}\right]=\lambda \eta_{t}=\frac{\sigma_{\beta}^{-2}+\sigma_{R}^{-2}\left\{\varsigma^{-1} \gamma\left[\beta^{-1} m\left(\lambda, \rho_{\xi}, \rho_{\beta}\right)-\rho_{\beta}\right]\right\}^{2}+\sigma_{\xi}^{-2}\left\{\gamma m\left(\lambda, \rho_{\xi}, \rho_{\beta}\right)\right\}^{2}}{\sigma_{\mathrm{AD}}^{-2}+\sigma_{\beta}^{-2}+\sigma_{R}^{-2}\left\{\varsigma^{-1} \gamma\left[\beta^{-1} m\left(\lambda, \rho_{\xi}, \rho_{\beta}\right)-\rho_{\beta}\right]\right\}^{2}+\sigma_{\xi}^{-2}\left\{\gamma m\left(\lambda, \rho_{\xi}, \rho_{\beta}\right)\right\}^{2}} \eta_{t},
$$

which leads to (42).

Then note the following three properties of (42). First, the LHS of (42) increases with $\lambda$ while the RHS of (42) decreases with $\lambda$. Second, at $\lambda=0$, the LHS of (42) is smaller than the RHS of (42). Third, at $\lambda=1$, the LHS of (42) is larger than the RHS of (42). As a result, there is a unique solution of (42) in $(0,1)$. This proves Proposition 8.

\section{Proof of Proposition 9.}

First, from (42), we can directly verify that $\lambda$ is a decreasing function of the ratio $\sigma / \sigma_{\mathrm{AD}}$ for any $\sigma \in$ $\left\{\sigma_{\beta}, \sigma_{R}, \sigma_{\xi}\right\}$. Because $m\left(\lambda, \rho_{\xi}, \rho_{\beta}\right)$ decreases in $\lambda$, we know $m^{*}$ necessarily increases in the ratio $\sigma / \sigma_{\mathrm{AD}}$ for any $\sigma \in\left\{\sigma_{\beta}, \sigma_{R}, \sigma_{\xi}\right\}$.

Second, suppose that there exists $\rho_{\xi}<\tilde{\rho}_{\xi}$ such that $m^{*}$ at $\rho_{\xi}$ is larger than $m^{*}$ at $\tilde{\rho}_{\xi}$. First, we know that the RHS (42) is larger at $\rho_{\xi}$ that at $\tilde{\rho}_{\xi}$. Second, because $m\left(\lambda, \rho_{\xi}, \rho_{\beta}\right)$ increases with $\rho_{\xi}$ and decreases in $\lambda$, a larger $m^{*}$ means that the equilibrium value of $\lambda$ is smaller at $\rho_{\xi}$ that at $\tilde{\rho}_{\xi}$. This means the LHS of (42) is smaller at $\rho_{\xi}$ that at $\tilde{\rho}_{\xi}$. This leads to a contradiction.

Third, suppose that there exists $\rho_{\beta}<\tilde{\rho}_{\beta}$ such that $m^{*}$ at $\rho_{\beta}$ is larger than $m^{*}$ at $\tilde{\rho}_{\beta}$. First, we know that the RHS (42) is larger at $\rho_{\beta}$ than at $\tilde{\rho}_{\beta}$. Second, because $m\left(\lambda, \rho_{\xi}, \rho_{\beta}\right)$ increases with $\rho_{\beta}$ and decreases in $\lambda$, a larger $m^{*}$ means that the equilibrium value of $\lambda$ is smaller at $\rho_{\beta}$ that at $\tilde{\rho}_{\beta}$. This means the LHS of (42) is smaller at $\rho_{\beta}$ that at $\tilde{\rho}_{\beta}$. This leads to a contradiction.

\section{Proof of Proposition 10.}

Optimal local labor demand and supply in (12) - (13) remain to be true, but the local production is given by

$$
q_{i, t}=A_{t}+(1-\alpha)\left(u_{i, t}+k_{i, t}\right)+\alpha l_{i, t}
$$

Imposing labor market clearing and aggregating, we arrive at (44).

Now, note that the optimal utilization in (16) and the asset pricing equation in (17) remain to be true. Aggregating and combine terms, we have

$$
y_{t}-(1+\phi) u_{t}-k_{t}=-R_{t}+(1-\beta) \mathbb{E}_{t}\left[y_{t+1}-k_{t+1}-u_{t+1}\right]+\beta \mathbb{E}_{t}\left[y_{t+1}-(1+\phi) u_{t+1}-k_{t+1}\right] .
$$

Similar to (20) but using the aggregate production in (44), we arrive at (45). The evolution of capital in (46) is the same as (21).

The derivation of the $\mathrm{AD}$ in (47) is exactly the same as the main analysis. 


\section{Proof of Proposition 11.}

First, let us provide the formula for $\mathcal{B}_{t}$ and $\mathcal{G}_{t}$ with aggregate technology shocks. We first notice that, with aggregate technology shocks, the intertemporal version of Hulten's theorem in (31) becomes

$$
\sum_{t=0}^{+\infty} \beta^{t+k} \mathbb{E}_{t}\left[y_{t+k}\right]=\frac{1-\tilde{\alpha}}{1-\beta} k_{t}+\sum_{t=0}^{+\infty} \beta^{t+k} \mathbb{E}_{t}\left[A_{t+k}\right] .
$$

As a result, $\mathcal{B}_{t}$ defined in (28) is now given by

$$
\begin{aligned}
\mathcal{B}_{t} & =\frac{(1-\beta)}{\beta} \sum_{k=0}^{+\infty} \beta^{k} \int\left(E_{t}^{h}\left[A_{t+k}+\xi_{h, t+k}\right]-\mathbb{E}_{t}\left[A_{t+k}\right]\right) d h \\
& =\frac{1-\beta}{\beta\left(1-\beta \rho_{\xi}\right)}\left(y_{t}-\bar{E}_{t}\left[y_{t}\right]\right)+\frac{1-\beta}{\beta\left(1-\beta \rho_{A}\right)}\left(\bar{E}_{t}\left[A_{t}\right]-\mathbb{E}_{t}\left[A_{t}\right]\right) .
\end{aligned}
$$

For $\mathcal{G}_{t}$, from (25), we have

$$
\mathcal{G}_{t} \equiv-\sigma \sum_{k=1}^{+\infty} \beta^{k}\left(\bar{E}_{t}\left[R_{t+k}\right]-\mathbb{E}_{t}\left[R_{t+k}\right]\right) .
$$

We now again define $\tilde{y}_{t} \equiv \frac{1}{\beta}\left(y_{t}-(1-\tilde{\alpha}) k_{t}\right)$, similar to (33). Similar to Proposition 4 , the AS and AD in Proposition 10 can be re-written as

$$
\begin{aligned}
& \tilde{y}_{t}=\left[\varsigma\left(1-\rho_{A}\right)+\frac{1-\beta \rho_{A}}{\beta}\right] A_{t}+\varsigma R_{t}+\beta \mathbb{E}_{t}\left[\tilde{y}_{t+1}\right], \\
& \tilde{y}_{t}=-\sigma R_{t}+\frac{1-\beta}{\beta} A_{t}+\beta \mathbb{E}_{t}\left[\tilde{y}_{t+1}\right]+\left(\mathcal{B}_{t}+\mathcal{G}_{t}\right) .
\end{aligned}
$$

From the above two equations, and similar to (55) and (56) in the proof of Lemma 2, we have, for all $h, t$, and all $k \geq 1$,

$$
\begin{aligned}
& E_{t}^{h}\left[\tilde{y}_{t+k}\right]=\left[\varsigma\left(1-\rho_{A}\right)+\frac{1-\beta \rho_{A}}{\beta}\right] E_{t}^{h}\left[A_{t+k}\right]+\varsigma E_{t}^{h}\left[R_{t+k}\right]+\beta E_{t}^{h}\left[\tilde{y}_{t+k+1}\right], \\
& E_{t}^{h}\left[\tilde{y}_{t+k}\right]=-\sigma E_{t}^{h}\left[R_{t+k}\right]+\frac{1-\beta}{\beta} E_{t}^{h}\left[A_{t+k}\right]+\beta E_{t}^{h}\left[\tilde{y}_{t+k+1}\right] .
\end{aligned}
$$

As a result, we have for all $h, t$, and all $k \geq 1$,

$$
E_{t}^{h}\left[R_{t+k}\right]=-E_{t}^{h}\left[\frac{\varsigma+1}{\sigma+\varsigma}\left(1-\rho_{A}\right) A_{t+k}\right] .
$$

We can then rewrite $\mathcal{B}_{t}$ and $\mathcal{G}_{t}$ as

$$
\begin{aligned}
\mathcal{B}_{t} & =\frac{1-\beta}{1-\beta \rho_{\xi}}\left(\tilde{y}_{t}-\bar{E}_{t}\left[\tilde{y}_{t}\right]\right)+\frac{1-\beta}{\beta\left(1-\beta \rho_{A}\right)}\left(\bar{E}_{t}\left[A_{t}\right]-A_{t}\right) \\
\mathcal{G}_{t} & =\frac{\sigma(\varsigma+1)}{\sigma+\varsigma} \frac{\left(1-\rho_{A}\right) \beta \rho_{A}}{1-\beta \rho_{A}}\left(\bar{E}_{t}\left[A_{t}\right]-A_{t}\right) .
\end{aligned}
$$

Similar to (61), we have $\mathbb{E}_{t}\left[R_{t+k}\right]=-\mathbb{E}_{t}\left[\frac{\varsigma+1}{\sigma+\varsigma}\left(1-\rho_{A}\right) A_{t+k}\right]$ for all $t$ and $k \geq 1$. From (59), we then have

$$
\begin{aligned}
\mathbb{E}_{t}\left[\tilde{y}_{t+1}\right] & =\left[\frac{\varsigma\left(1-\rho_{A}\right)}{1-\beta \rho_{A}}+\frac{1}{\beta}-\frac{\varsigma(\varsigma+1)}{\sigma+\varsigma} \frac{\left(1-\rho_{A}\right)}{1-\beta \rho_{A}}\right] \rho_{A} A_{t} \\
& =\left[\frac{1}{\beta}+\frac{\varsigma(\sigma-1)}{\sigma+\varsigma} \frac{\left(1-\rho_{A}\right)}{1-\beta \rho_{A}}\right] \rho_{A} A_{t} .
\end{aligned}
$$


We can then rewrite (59) as

$$
\tilde{y}_{t}=\left[\varsigma\left(1-\rho_{A}\right)\left(1+\frac{(\sigma-1)}{\sigma+\varsigma} \frac{\beta \rho_{A}}{1-\beta \rho_{A}}\right)+\frac{1}{\beta}\right] A_{t}+\varsigma R_{t}
$$

or

$$
R_{t}=\varsigma^{-1} \tilde{y}_{t}-\left[\left(1-\rho_{A}\right)\left(1+\frac{(\sigma-1)}{\sigma+\varsigma} \frac{\beta \rho_{A}}{1-\beta \rho_{A}}\right)+\frac{\varsigma^{-1}}{\beta}\right] A_{t} .
$$

Substituting into (60), we have

$$
\left(1+\sigma \varsigma^{-1}\right) \tilde{y}_{t}=\left[\sigma\left(\frac{\varsigma^{-1}}{\beta}+\frac{1-\rho_{A}}{1-\beta \rho_{A}}\right)+\frac{1-\beta}{\beta\left(1-\beta \rho_{A}\right)}\right] A_{t}+\left(\mathcal{B}_{t}+\mathcal{G}_{t}\right),
$$

and henceforth

$$
\gamma^{A}=\frac{\partial y_{t}}{\partial \eta_{t}^{A}}=\beta \frac{\partial \tilde{y}_{t}}{\partial \eta_{t}^{A}}=\frac{\sigma\left(\varsigma^{-1}+\frac{\beta\left(1-\rho_{A}\right)}{1-\beta \rho_{A}}\right)+\frac{1-\beta}{1-\beta \rho_{A}}}{1+\sigma \varsigma^{-1}} .
$$

Now we calculate $m_{A}^{\operatorname{conf}}\left(\lambda, \rho_{\xi}, \rho_{A}\right)$ by using (62) and temporarily letting $\mathcal{G}_{t}=0$. We have $\left(1+\sigma \varsigma^{-1}\right) \tilde{y}_{t}=\left[\sigma\left(\frac{\varsigma^{-1}}{\beta}+\frac{1-\rho_{A}}{1-\beta \rho_{A}}\right)+\frac{1-\beta}{\beta\left(1-\beta \rho_{A}\right)}\right] A_{t}+\frac{1-\beta}{1-\beta \rho_{\xi}}\left(\tilde{y}_{t}-\bar{E}_{t}\left[\tilde{y}_{t}\right]\right)+\frac{1-\beta}{\beta\left(1-\beta \rho_{A}\right)}\left(\bar{E}_{t}\left[A_{t}\right]-A_{t}\right)$.

As a result,

$$
m_{A}^{\operatorname{conf}}\left(\lambda, \rho_{\xi}, \rho_{A}\right)=\left(1+\frac{\frac{(1-\beta)}{1-\beta \rho_{\xi}}(1-\lambda)}{1+\sigma \varsigma^{-1}-\frac{(1-\beta)}{1-\beta \rho_{\xi}}(1-\lambda)}\right)\left(1-\frac{\frac{1-\beta}{1-\beta \rho_{A}}(1-\lambda)}{\sigma\left(\varsigma^{-1}+\frac{\beta\left(1-\rho_{A}\right)}{1-\beta \rho_{A}}\right)+\frac{1-\beta}{\left(1-\beta \rho_{A}\right)}}\right) .
$$

We then know that

$$
m_{A}^{\operatorname{conf}}\left(\lambda, \rho_{\xi}, \rho_{A}\right)<1 \text { if and only if } \rho_{\xi}<\bar{\rho}_{\xi}\left(\rho_{A}\right) \equiv \frac{1}{\beta}-\frac{\sigma\left(\varsigma^{-1}\left(1-\beta \rho_{A}\right)+\beta\left(1-\rho_{A}\right)\right)+(1-\beta)}{\beta\left(1+\sigma \varsigma^{-1}\right)},
$$

where $\bar{\rho}_{\xi}\left(\rho_{A}\right)<\frac{1}{\beta}$ (so $\sum_{k=0}^{+\infty} \beta^{k} \mathbb{E}_{t}\left[\xi_{i, t+k}\right]$ always converges) and increasing in $\rho_{A}$.

Now, we use (63) to replace $\mathcal{G}_{t}$ in (64) and have

$$
m_{A}^{\mathrm{GE}}\left(\lambda, \rho_{A}\right)=1-\frac{\frac{\sigma(\varsigma+1)}{\sigma+\varsigma} \frac{\left(1-\rho_{A}\right) \beta^{2} \rho_{A}}{1-\beta \rho_{A}}(1-\lambda)}{\sigma\left(\varsigma^{-1}+\frac{\beta\left(1-\rho_{A}\right)}{1-\beta \rho_{A}}\right)+\frac{1-\beta}{\left(1-\beta \rho_{A}\right)} \lambda}<1 .
$$

\section{Proof of Proposition 12.}

As mentioned in the main text, here, we shut down the wealth effect on labor supply. As a result, the optimal labor supply in (13) becomes

$$
n_{t}^{i}=\nu w_{i, t},
$$

and $\tilde{\alpha}$ in aggregate production in (15) becomes

$$
\tilde{\alpha}=1-\frac{(1-\alpha)\left(1+\frac{1}{\nu}\right)}{1+\frac{1}{\nu}-\alpha} .
$$

With this new $\tilde{\alpha}$, the aggregate supply equations in Proposition 1 remains to be true.

In terms of aggregate demand, the individual optimal consumption in (22) becomes

$$
c_{t}^{h}=(1-\beta) b_{t}^{h}-\beta \sigma\left\{\sum_{k=0}^{+\infty} \beta^{k} E_{t}^{h}\left[R_{h, t+k}\right]\right\}+(1-\beta)\left\{\sum_{k=0}^{+\infty} \beta^{k} E_{t}^{h}\left[y_{h, t+k}-T_{t+k}^{h}\right]\right\},
$$


taking into consideration of the tax. Aggregating the above condition, using aggregate market clearing $y_{t}=c_{t}+G_{t}$ and the budget balance $G_{t}=T_{t}$, we have

$$
\begin{aligned}
y_{t} & =-\sigma \beta R_{t}-\beta \sigma \sum_{k=1}^{+\infty} \beta^{k} \mathbb{E}_{t}\left[R_{t+k}\right]+(1-\beta)\left(y_{t}+\sum_{k=1}^{+\infty} \beta^{k} \mathbb{E}_{t}\left[y_{t+k}\right]\right) \\
& +G_{t}-(1-\beta)\left(G_{t}+\sum_{k=1}^{+\infty} \beta^{k} \int E_{t}\left[G_{t+k}\right] d h\right)+\beta \mathcal{B}_{t}+\beta \mathcal{G}_{t} .
\end{aligned}
$$

where $\mathcal{B}_{t}$ and $\mathcal{G}_{t}$ are defined as (28) and (25). Rewriting this condition in recursive form and using (48), we reach at (49) in the main text:

$$
y_{t}=-\sigma R_{t}+\left(1-\rho_{G}\right) G_{t}+\mathbb{E}_{t}\left[y_{t+1}\right]+\left(\mathcal{B}_{t}+\mathcal{G}_{t}\right) .
$$

In a nutshell, $\left(1-\rho_{G}\right) G_{t}$ replaces $-\sigma \beta_{t}$ as the AD shock in Proposition 2. The third part of Proposition 12 then follows directly from Proposition 7.

\section{Proof of Proposition 13.}

The aggregate supply block of the economy in Proposition 1 is unchanged and our intertemporal version of the Hulten's theorem in Proposition 3 is maintained. On the demand side, from the consumer optimality in Lemma 1 and similar to (29), we have

$$
\begin{aligned}
& c_{t}^{b}=-\beta \sigma\left(R_{t}+\beta_{t}\right)-\beta \sigma \sum_{k=1}^{+\infty} \beta^{k} \mathbb{E}_{t}\left[R_{t+k}+\beta_{t+k}\right]+(1-\beta)\left(y_{t}+\sum_{k=1}^{+\infty} \beta^{k} \mathbb{E}_{t}\left[y_{t+k}\right]\right)+\beta \mathcal{B}_{t}+\beta \mathcal{G}_{t} . \\
& c_{t}^{s}=-\beta \sigma R_{t}-\beta \sigma \sum_{k=1}^{+\infty} \beta^{k} \mathbb{E}_{t}\left[R_{t+k}\right]+(1-\beta)\left(y_{t}+\sum_{k=1}^{+\infty} \beta^{k} \mathbb{E}_{t}\left[y_{t+k}\right]\right)+\beta \mathcal{B}_{t}+\beta \mathcal{G}_{t} .
\end{aligned}
$$

Together, the aggregate demand $y_{t}=\pi c_{t}^{b}+(1-\pi) c_{t}^{s}$ is given by

$$
y_{t}=-\beta \sigma\left(R_{t}+\pi \beta_{t}\right)-\beta \sigma \sum_{k=1}^{+\infty} \beta^{k} \mathbb{E}_{t}\left[R_{t+k}+\pi \beta_{t+k}\right]+(1-\beta)\left(y_{t}+\sum_{k=1}^{+\infty} \beta^{k} \mathbb{E}_{t}\left[y_{t+k}\right]\right)+\beta \mathcal{B}_{t}+\beta \mathcal{G}_{t},
$$

where, similar to (25) and (32), $\mathcal{B}_{t}=\frac{1-\beta}{\beta\left(1-\beta \rho_{\xi}\right)}\left(y_{t}-\bar{E}_{t}\left[y_{t}\right]\right)$ and $\mathcal{G}_{t}=-\sigma \sum_{k=1}^{+\infty} \beta^{k}\left(\bar{E}_{t}\left[R_{t+k}\right]-\mathbb{E}_{t}\left[R_{t+k}\right]\right)$.

Together, this means that, the response of aggregate output to the AD shock is essentially the same as our benchmark economy, with aggregate discount factor now given by $\pi \beta_{t}$ and $\lambda$ is still given by Proposition 5:

$$
\frac{\partial y_{t}}{\partial \eta_{t}}=\pi \gamma \cdot m^{\operatorname{conf}}\left(\lambda, \rho_{\xi}\right) \cdot m^{\mathrm{GE}}\left(\lambda, \rho_{\beta}\right)
$$

We now turn to saver's consumption. From (33), (66), Proposition 4, and Lemma 2, we have

$$
\frac{\partial c_{t}^{s}}{\partial \eta_{t}}=-\varsigma^{-1} \sigma \frac{\partial y_{t}}{\partial \eta_{t}}+\frac{1-\beta}{1-\beta \rho_{\xi}}(1-\lambda) \frac{\partial y_{t}}{\partial \eta_{t}}+\beta \frac{\sigma^{2}}{\sigma+\varsigma} \frac{\beta \rho_{\beta}}{1-\beta \rho_{\beta}} \pi(1-\lambda) \text {. }
$$

As a result, $\frac{\partial c_{t}^{s}}{\partial \eta_{t}}>0$ if and only if

$$
\left[\frac{1-\beta}{1-\beta \rho_{\xi}}(1-\lambda)-\varsigma^{-1} \sigma\right] \gamma \cdot m^{\mathrm{conf}}\left(\lambda, \rho_{\xi}\right) \cdot m^{\mathrm{GE}}\left(\lambda, \rho_{\beta}\right)+\beta \frac{\sigma^{2}}{\sigma+\varsigma} \frac{\beta \rho_{\beta}}{1-\beta \rho_{\beta}}(1-\lambda)>0 .
$$


A sufficient condition for the above is

$$
\frac{1-\beta}{1-\beta \rho_{\xi}}(1-\lambda)-\varsigma^{-1} \sigma>0 .
$$

That is, when the confusion of the savers is sufficiently large ( $\lambda$ small enough) and/or that the AS curve is sufficiently flat ( $\varsigma$ large enough), the saver's consumption also positively comoves with the AD shock.

Similarly, for borrowers, from (33), (66), Proposition 4, and Lemma 2, we have

$$
\frac{\partial c_{t}^{b}}{\partial \eta_{t}}=\sigma\left(\frac{\beta}{1-\rho_{\beta} \beta}-\varsigma^{-1} \frac{\partial y_{t}}{\partial \eta_{t}}\right)+\frac{1-\beta}{1-\beta \rho_{\xi}}(1-\lambda) \frac{\partial y_{t}}{\partial \eta_{t}}+\beta \frac{\sigma^{2}}{\sigma+\varsigma} \frac{\beta \rho_{\beta}}{1-\beta \rho_{\beta}} \pi(1-\lambda) .
$$

We then know that, if (67) or (68) is true, we also have $\frac{\partial c_{t}^{b}}{\partial \eta_{t}}>0$. In sum, as long as (67) or (68) holds, $c_{t}^{s}$, $c_{t}^{b}$, and $y_{t}$ comove.

\section{Aggregate supply: the role of capital adjustment costs.}

Here we verify the claim that, even with complete information, the combination of variable utilization and capital adjustment costs allows for an "upward-slopping AS curve," or for aggregate employment and output to comove with aggregate consumption in response to discount-rate shocks. In particular, we show that this is true for any $\psi>0$, as long as the real wage is sufficiently acyclical, or equivalently when the wealth effect on labor supply is small enough and the Frisch elasticity is large enough.

Concretely, we consider the complete information version of the investment model in Proposition 14. We still assume away from wealth effect of labor supply, but allow a general AR(1) process for the idiosyncratic demand shock and allow the AD shock to be persistent. The complete information equilibrium can be solved based on a system of equations consisting of the aggregate production (15), the aggregate, complete-information version of (72), (73), (74), and (76), the aggregate Euler equation,

$$
c_{t}=-\sigma\left(R_{t}+\beta_{t}\right)+\mathbb{E}_{t}\left[c_{t+1}\right]
$$

and the aggregate resource constraint,

$$
y_{t}=\frac{c^{*}}{y^{*}} c_{t}+\left(1-\frac{c^{*}}{y^{*}}\right)\left(\iota_{t}+k_{t}\right)
$$

Using Mathematica, we can solve the equilibrium policy rules in closed form for arbitrary parameters. Consider in particular the policy rule for utilization, which is the object of interest. This can be expressed as

$$
u_{t}=\Lambda_{u k} k_{t}-\Lambda_{u \beta} \beta_{t}
$$

for some scalars $\left(\Lambda_{u k}, \Lambda_{u \beta}\right)$ that are complicated functions of the underlying parameters. Taking the limit as labor supply becomes infinitely elastic, or wages become nearly acyclical, we obtain

$$
\lim _{\nu \rightarrow+\infty} \Lambda_{u \beta}=\frac{\beta \frac{c^{*}}{y^{*}} \delta \sigma \psi}{-\beta^{2} \frac{c^{*}}{y^{*}} \delta \rho_{\beta} \sigma \psi \phi+\beta\left(\phi\left(\frac{c^{*}}{y^{*}}\left(\delta \sigma \psi+\delta+\rho_{\beta}-1\right)-\rho_{\beta}+1\right)+\delta \psi\left(\frac{c^{*}}{y^{*}}(1-\delta)-\rho_{\beta}+1\right)\right)+\frac{c^{*}}{y^{*}} \delta \psi},
$$

which is strictly positive for any $\psi>0$ (and 0 for $\psi=0$ ). We conclude that, as long as $\psi>0$, a 
large enough $\nu$, or a sufficiently acyclical real wage, suffices for aggregate employment and output to increase with $\eta_{t}$.

On the other hand, had we instead set $\psi=0$ (no adjustment cost), as in the classics by Burnside, Eichenbaum, and Rebelo (1995), Greenwood, Hercowitz, and Huffman (1988) and King and Rebelo (1999), $\Lambda_{u \beta}=0$ for any $\nu$ because utilization ceases to be forward-looking. It then follows from the intratemporal condition for labor, as in Barro and King (1984), that aggregate employment and output necessarily move in the opposite direction than aggregate consumption.

\section{Proof of Proposition 14.}

We first characterize the deterministic steady state. In this steady state, we have

$$
\iota^{*}=\delta\left(u^{*}\right) \equiv \delta .
$$

Optimal utilization implies

$$
\frac{1-\alpha}{1+\mu} \frac{y^{*}}{u^{*}}=\vartheta^{*} \delta^{\prime}\left(u^{*}\right) k^{*} .
$$

The evolution of the shadow value of capital implies

$$
\vartheta^{*}=\beta\left[\frac{(1-\alpha)}{1+\mu} \frac{y^{*}}{k^{*}}+(1-\delta) \vartheta^{*}\right] .
$$

Together, this means

$$
1=\beta\left[\delta^{\prime}\left(u^{*}\right) u^{*}+(1-\delta)\right] .
$$

Now, we turn to the analysis away from the steady state, in response to the aggregate demand shock. As mentioned in the main text, we let investment choices be made by the households and under the same information as consumption. The household $h$ 's information set in period $t$ is given by $\mathcal{I}_{t}^{h}=$ $\mathcal{I}_{t-1}^{h} \cup\left\{\beta_{t}^{h}\right\} \cup\left\{w_{h, t}, e_{h, t}, R_{h, t},\left(p_{i, j, t}\right)_{i \in[0,1], j \in[0,1]}, k_{h, t+1}\right\} \cup\left\{\eta_{t-1}\right\}$.

As in the baseline model, we log-linearize the equilibrium conditions, re-interpret all the variables as log-deviations from their steady-state counterparts. ${ }^{49}$ As mentioned in the main text, we shut down the wealth effect on labor supply. We thus write labor supply (or the "wage equation") of the representative household on island $i$ as

$$
n_{t}^{i}=\nu w_{i, t}
$$

As in our analysis of government spending, the aggregate production in (15) continues to hold, with $\tilde{\alpha}$ redefined as follows:

$$
\tilde{\alpha}=1-\frac{(1-\alpha)\left(1+\frac{1}{\nu}\right)}{1+\frac{1}{\nu}-\alpha} .
$$

Similarly, the local firm's FOC for utilization is still given by (16), which is rewritten here:

$$
y_{i, t}-u_{i, t}-k_{i, t}=\vartheta_{i, t}+\phi u_{i, t} .
$$

\footnotetext{
${ }^{49}$ The only exception to this rule is that we let the new $\epsilon_{i, t}^{k}$ be the original $\epsilon_{i, t}^{k}$. This takes care of the issue that the steadystate value of $\epsilon_{i, t}^{k}$ is zero.
} 
The evolution of the shadow value of capital on island $i$ is now given by ${ }^{50}$

$$
\vartheta_{i, t}=-R_{i, t}+(1-\beta(1-\delta)) \mathbb{E}_{t}\left[y_{i, t+1}-k_{i, t+1}-u_{i, t+1}\right]+\beta \mathbb{E}_{t}\left[\vartheta_{i, t+1}\right] .
$$

Optimal investment by the representative household on island $i$ is given by

$$
0=E_{t}^{i}\left[\vartheta_{i, t}\right]-\psi \delta \iota_{t}^{i}
$$

Optimal consumption by the representative household on island $i$ is given by

$$
c_{i, t}=-\sigma\left(\beta_{t}^{i}+R_{i, t}\right)+E_{t}^{i}\left[c_{i, t+1}\right] .
$$

The evolution of local capital is given by

$$
k_{i, t+1}=-\left(\delta+\frac{1-\beta}{\beta}\right) u_{i, t}+\delta \iota_{t}^{i}+\epsilon_{i, t}^{k}+k_{i, t},
$$

where we use (70).

To prove Proposition 14, we first take a detour and solve the complete-information policy rules of two different cases of our economy. They will be useful in the characterization of the incomplete information equilibrium later.

First, we solve the local equilibrium when the interest rate is fixed at the steady state value and the local demand is independent from the aggregate condition and is only given by the idiosyncratic shock

$$
y_{i, t}=\xi_{i, t},
$$

where $\xi_{i, t}$ follows a random walk $\left(\rho_{\xi}=1\right)$. Using (72), (73), (74), and (76) with $E_{t}^{i}[\cdot]=\mathbb{E}_{t}[\cdot]$, we can solve the local shadow value of capital as a function of the local capital stock and the local demand:

$$
\vartheta_{i, t}=l_{k} k_{i, t}+l_{\xi} \xi_{i, t}
$$

Unfortunately, there are no simple closed-form formulas for $l_{k}$ and $l_{\xi}$. However, using Mathematica, we are able first to obtain a complicated closed-form solution for arbitrary parameters and then to obtain the following simpler formulas for the case of a vanishing curvature in the utilization costs:

$$
\lim _{\phi \rightarrow 0} l_{k}=-\frac{\psi\left(\beta^{2} \delta^{2}+\beta(2 \delta-1)+1\right)}{(\beta \delta+1)(\beta(\delta-1) \psi+\beta+\psi)} \text { and } \lim _{\phi \rightarrow 0} l_{\xi}=\frac{\psi(\beta(\delta-1)+1)\left(\beta^{2} \delta^{2}+\beta(2 \delta-1)+1\right)}{(\beta \delta+1)\left(\beta\left(\delta-\rho_{\xi}\right)+1\right)(\beta(\delta-1) \psi+\beta+\psi)} .
$$

Now, we solve the complete-information policy rule of the aggregate economy without the aggregate demand shock. In particular, we consider a system of equations consists of the aggregate production (15), the aggregate, complete information, version of (72), (73), (74), and (76), the aggregate Euler equation without the aggregate demand shock

$$
c_{t}=-\sigma R_{t}+\mathbb{E}_{t}\left[c_{t+1}\right]
$$

and the aggregate market clearing $y_{t}=\frac{c^{*}}{y^{*}} c_{t}+\left(1-\frac{c^{*}}{y^{*}}\right)\left(\iota_{t}+k_{t}\right)$. We arrive at the following aggregate

${ }^{50}(73)$ comes from the log-linearization of the following condition:

$$
\vartheta_{i, t}=R_{i, t}^{-1} \mathbb{E}_{t}\left[\frac{(1-\alpha)}{1+\mu} \frac{y_{i, t+1}}{u_{i, t+1} k_{i, t+1}} u_{i, t+1}-\iota_{t+1}^{i}+\left(1-\delta\left(u_{i, t+1}\right)+\psi\left(\iota_{t+1}^{i}\right)\right) \vartheta_{i, t+1}\right] .
$$


policy rule:

$$
u_{t}=\Lambda_{u k} k_{t} \text { and } q_{t}=\Lambda_{q k} k_{t} .
$$

Again, we use Mathematica to obtain $\Lambda_{u k}$ and $\Lambda_{q k}$ for arbitrary parameters and then take the limit as $\phi \rightarrow 0$ to get a somewhat more tractable solution. ${ }^{51}$

Now, we turn to the incomplete information economy. To prove Proposition 14, we impose three additional simplification restrictions: aggregate demand shock is i.i.d $\left(\rho_{\beta}=0\right)$; the idiosyncratic demand shock is random walk ( $\left.\rho_{\xi}=1\right)$; and the information friction is large $(\lambda=0)$. That is, the typical household has no knowledge about the aggregate demand shock $\eta_{t}$ and $\lambda$ in Proposition 5 is zero. To prove Proposition 14, we only need to prove that, with those restrictions, there exists $\bar{\phi}, \underline{\nu}, \underline{\psi}>0$ such that whenever $\nu>\underline{\nu}, \phi<\bar{\phi}$, and $\psi>\underline{\psi}$, the equilibrium levels of employment, output, investment, and consumption positively comove in response to the aggregate demand shock.

We want to characterize the equilibrium responses of the period- $t$ outcomes to the concurrent $\mathrm{AD}$ shock, $\eta_{t}$. But since in the log-linearized economy the equilibrium response is independent from $t$, it suffices to characterize the equilibrium responses of the period- 0 outcomes to $\eta_{0}$ (recall that the initial capital is fixed $\left.k_{0}=0\right)$.

From (72), (73), and (74), the household's optimal investment decision is given by:

$$
\iota_{i, 0}=\frac{1}{\psi \delta}\left(-R_{i, 0}+(1-\beta(1-\delta)) \frac{\phi}{\phi+1} E_{i, 0}\left[y_{i, 1}-k_{i, 1}\right]+\left(\frac{(1-\beta(1-\delta))}{\phi+1}+\beta\right) E_{i, 0}\left[\vartheta_{i, 1}\right]\right) .
$$

Now, because the typical household has no knowledge about the aggregate demand shock. In her expectation, future local demand is as if given only by the idiosyncratic shock, e.g., $E_{i, 0}\left[y_{i, 1}\right]=E_{i, 0}\left[\xi_{i, 1}\right]$. Then because the current period shocks become common knowledge next period, in the typical household's expectation, future shadow value of land can be characterized by the complete information policy rule in (77):

$$
E_{i, 0}\left[\vartheta_{i, 1}\right]=E_{i, 0}\left[l_{k} k_{i, 1}+l_{\xi} \xi_{i, 1}\right]
$$

We then have:

$$
\begin{aligned}
& \iota_{i, 0}=\frac{1}{\psi \delta}\left(-R_{i, 0}+(1-\beta(1-\delta)) \frac{\phi}{\phi+1}\left(E_{i, 0}\left[\xi_{i, 1}-k_{i, 1}\right]\right)+\left(\frac{(1-\beta(1-\delta))}{\phi+1}+\beta\right)\left(E_{i, 0}\left[l_{k} k_{i, 1}+l_{\xi} \xi_{i, 1}\right]\right)\right) .
\end{aligned}
$$

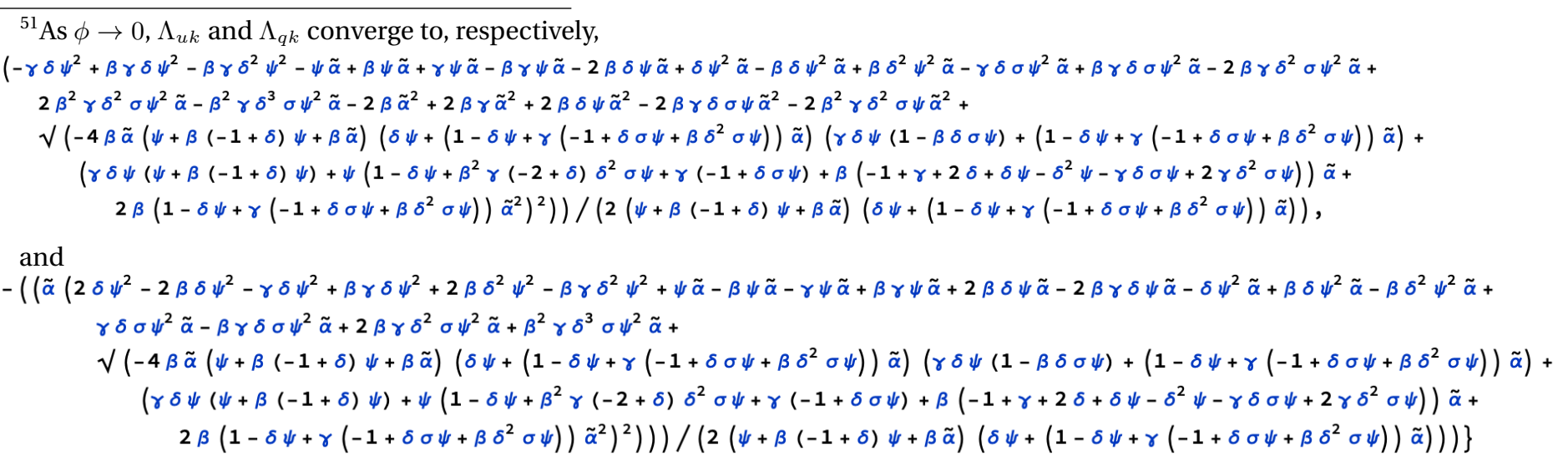$$
\text { where } \gamma \text { in the formulas corresponds to } \frac{c^{*}}{y^{*}} \text { in the paper. }
$$ 
Now, we aggregate the above and use the fact that $\xi_{i, 0}$ is a random walk and the fact that the household knows the local capital stock $k_{i, 1}$ at period 0 . We have:

$$
\begin{aligned}
\iota_{0} & =\frac{1}{\psi \delta}\left\{-R_{0}+\left[(1-\beta(1-\delta)) \frac{\phi}{\phi+1}+\left(\frac{(1-\beta(1-\delta))}{\phi+1}+\beta\right) l_{\xi}\right] y_{0}\right. \\
& \left.+\left[\left(\frac{(1-\beta(1-\delta))}{\phi+1}+\beta\right) l_{k}-(1-\beta(1-\delta)) \frac{\phi}{\phi+1}\right] k_{1}\right\}
\end{aligned}
$$

We now turn to optimal utilization. First, note that, as the aggregate shock is i.i.d., the rational expectation of future utilization and future shadow value of capital are given by (78):

$$
\mathbb{E}_{0}\left[u_{1}\right]=\Lambda_{u k} k_{1} \text { and } \mathbb{E}_{0}\left[\vartheta_{1}\right]=\Lambda_{q k} k_{1} .
$$

From the aggregate production (15), the optimal utilization (72), and the evolution of shadow value in (73), we have:

$$
\vartheta_{0}=-R_{0}+\left(\beta \Lambda_{q k}-\tilde{\alpha}(1-\beta(1-\delta))\left(\Lambda_{u k}+1\right)\right) k_{1}
$$

Using (79), (80), the evolution of capital in (76), and the production (19), we can solve $\left(u_{0}, \iota_{0}, R_{0}, \vartheta_{0}\right)$ as a function of $y_{0}$ and $k_{0}$. In particular, we have

$$
\iota_{0}=\Gamma_{\iota y} y_{0}+\Gamma_{\iota k} k_{0},
$$

where, again with the help of Mathematica, we can show that

$$
\lim _{\nu \rightarrow+\infty, \phi \rightarrow 0} \Gamma_{\iota y}=\frac{\beta^{3} \delta^{3}+\beta^{2}(3 \delta-1) \delta+\beta(3 \delta-1)+1}{\beta \delta\left(\beta^{2} \delta^{2}+\beta \delta(\psi+2)-\beta \psi+\psi+1\right)}>0 .
$$

It follows that there exist $\bar{\phi}, \underline{\nu}>0$ such that: whenever $\nu>\underline{\nu}$ and $\phi<\bar{\phi}$, investment and output comove when the informational friction is large enough.

To complete the argument, we must verify that consumption also comoves. Take the aggregate resource constraint (or goods market clearing):

$$
y_{0}=\frac{c^{*}}{y^{*}} c_{0}+\left(1-\frac{c^{*}}{y^{*}}\right)\left(\iota_{0}+k_{0}\right)
$$

Solving this for $c_{0}$ and replacing our solution for investment, we have

$$
c_{0}=\frac{y^{*}}{c^{*}} y_{0}-\frac{y^{*}-c^{*}}{c^{*}}\left(\iota_{0}+k_{0}\right)=\left(\frac{y^{*}}{c^{*}}-\frac{y^{*}-c^{*}}{c^{*}} \Gamma_{\iota y}\right) y_{0}-\frac{y^{*}-c^{*}}{c^{*}}\left(\Gamma_{\iota k}+1\right) k_{0} .
$$

From the above condition together with (81), we then conclude that, when $\phi, \lambda$ are small enough and $\nu$ and $\psi$ are large enough (so $\Gamma_{\iota y}>0$ and $\frac{y^{*}}{c^{*}}-\frac{y^{*}-c^{*}}{c^{*}} \Gamma_{\iota y}>0$ ), output, investment, and consumption all positively comove in response to the aggregate demand shock. Finally, the comovement of employment is immediate, since

$$
n_{0}=\frac{\nu}{\nu+1} y_{0}
$$

\section{Two-period investment model.}

Now, we provide a two-period version of the investment model in Section 6.4. This model can be solved analytically (without the help of Mathematica) and allows us to obtain a sharp necessary and sufficient 
condition for positive comovement between all key macroeconomic quantities (employment, output, consumption, and investment) in response to the aggregate discount rate shock.

In this two-period version of our model, at $t=1$, households make investment, consumption, labor supply decisions, ${ }^{52}$ and the firm makes utilization and labor demand decisions, as in Section 6.4. The capital still evolves according to (50). At $t=2$, there are only consumption and labor decisions, but no investment and utilization. All capital depreciate completely after $t=2$.

We log-linearize the equilibrium conditions and re-interpret all the variables as log-deviations from their counterparts in the deterministic equilibrium without aggregate and idiosyncratic shocks. ${ }^{53}$

The labor supply, labor demand, and the aggregate production in both periods (with $u_{2}=0$ ) are still given respectively by (71), (12), and (15). The optimal utilization at $t=1$ is still given by (16). The shadow value of capital at the end of $t=1$ is given by

$$
\vartheta_{i, 1}=-R_{i, 1}+\mathbb{E}_{t}\left[y_{i, 2}-k_{i, 2}\right]
$$

The optimal investment at $t=1$ is still given by (74). The evolution of local capital is given by

$$
k_{i, 2}=-\frac{\delta^{\prime}\left(u_{1}^{*}\right) u_{1}^{*}}{1-\delta\left(u_{1}^{*}\right)+\iota_{1}^{*}} u_{i, 1}+\frac{\iota_{1}^{*}}{1-\delta\left(u_{1}^{*}\right)+\iota_{1}^{*}} \iota_{1}^{i}+k_{i, 1} .
$$

Aggregating the above conditions and using Proposition 5, the fact that $E_{1}^{i}\left[\xi_{i, 2}\right]=\rho_{\xi} E_{1}^{i}\left[\xi_{i, 1}\right]=\rho_{\xi}\left[y_{i, 1}-E_{1}^{i}\left[y_{1}\right]\right]$, and that $k_{1}=0$, we have

$$
\begin{aligned}
u_{1} & =\frac{1}{\tilde{\alpha}+\phi} R_{1}+\frac{\tilde{\alpha}}{\tilde{\alpha}+\phi} k_{2} \\
\iota_{1} & =\frac{1}{\psi \iota_{1}^{*}}\left((1-\lambda) \rho_{\xi} y_{1}-[1-\lambda(1-\tilde{\alpha})] k_{2}-R_{1}\right) \\
k_{2} & =-\frac{\delta^{\prime}\left(u_{1}^{*}\right) u_{1}^{*}}{1-\delta\left(u_{1}^{*}\right)+\iota_{1}^{*}} u_{1}+\frac{\iota_{1}^{*}}{1-\delta\left(u_{1}^{*}\right)+\iota_{1}^{*}} \iota_{1} .
\end{aligned}
$$

Together, we have

$$
\iota_{1}=\frac{\left((1-\lambda)\left(\rho_{\xi}+\frac{\delta^{\prime}\left(u_{1}^{*}\right) u_{1}^{*}}{1-\delta\left(u_{1}^{*}\right)+\iota_{1}^{*}}\right)-\frac{\tilde{\alpha}+\phi}{1-\tilde{\alpha}}\right)}{\psi \iota_{1}^{*}\left(1+\frac{(1-\lambda)(1-\tilde{\alpha})}{\psi\left(1-\delta\left(u_{1}^{*}\right)+\iota_{1}^{*}\right)}\right)} y_{1} .
$$

As a result, investment and output (and employment, similar to (82)) comove if and only if

$$
(1-\lambda)\left(\rho_{\xi}+\frac{\delta^{\prime}\left(u_{1}^{*}\right) u_{1}^{*}}{1-\delta\left(u_{1}^{*}\right)+\iota_{1}^{*}}\right)>\frac{\tilde{\alpha}+\phi}{1-\tilde{\alpha}}
$$

Using the aggregate goods market clearing, $y_{1}=\frac{c_{1}^{*}}{y_{1}^{*}} c_{1}+\frac{\iota_{1}^{*} k_{1}^{*}}{y_{1}^{*}} \iota_{1}$, we have that consumption and output comove if and only if

$$
(1-\lambda)\left(\rho_{\xi}+\frac{\delta^{\prime}\left(u_{1}^{*}\right) u_{1}^{*}}{1-\delta\left(u_{1}^{*}\right)+\iota_{1}^{*}}\right)-\frac{y_{1}^{*}}{k_{1}^{*}} \psi\left(1+\frac{(1-\lambda)(1-\tilde{\alpha})}{\psi\left(1-\delta\left(u_{1}^{*}\right)+\iota_{1}^{*}\right)}\right)<\frac{\tilde{\alpha}+\phi}{1-\tilde{\alpha}} .
$$

(83) and (84) together are necessary and sufficient for comovement among employment, output, in-

\footnotetext{
${ }^{52}$ The household's information at $t=1$ is given by $\mathcal{I}_{1}^{h}=\left\{\beta_{1}^{h}\right\} \cup\left\{w_{h, 1}, e_{h, 1}, R_{h, 1},\left(p_{i, j, 1}\right)_{i \in[0,1], j \in[0,1]}, k_{h, 2}\right\}$.

${ }^{53}$ Here, in this deterministic equilibrium, we do not need to assume $k_{1}^{*}=k_{2}^{*}$. That is, we do not need to impose that $\delta\left(u_{1}^{*}\right)=\iota_{1}^{*}$. We only impose that, in this deterministic equilibrium, there is no adjustment cost. That is, $\Psi\left(\iota_{1}^{*}\right)=\iota_{1}^{*}, \Psi^{\prime}\left(\iota_{1}^{*}\right)=$ 1 , and $\Psi^{\prime \prime}\left(\iota_{1}^{*}\right)=-\psi$.
} 
vestment, and consumption.

Finally, note that (83) is more easily satisfied when $\lambda$ is small, underscoring the role of misperceptions in helping investment increase in response to $\eta_{t}$ despite the increase in the real interest rate. On the other hand, (84) is more easily satisfied when $\psi$ is large, underscoring how capital adjustment costs together with variable utilization allow aggregate employment and output to comove with aggregate consumption.

\section{Appendix B: Monetary Extension}

The starting point of our paper was the desire to accommodate the Keynesian narrative of demanddriven fluctuations outside the nexus of sticky prices and Phillips curves. But the mechanisms we have identified do not hinge on the absence of nominal rigidity: in its presence, they influence the properties of both the underlying natural rate of output and the output gap. We sketch the logic below.

Consider our baseline model and add sticky prices. Because our supply block abstracts from informational frictions, the standard derivation of the Phillips curve remains valid: inflation can still be expressed as a function of the output gap. What has changed, however, is the process for the natural rate of output, relative to which this gap must be calculated.

Turning to the demand side, Proposition 2 remains valid. But now the belief wedges $\mathcal{B}_{t}$ and $\mathcal{G}_{t}$ combine misperceptions about natural outcomes with misperceptions about output gaps, and they therefore depend on the conduct of monetary policy. To illustrate this point more, we next bypass any specific description of how monetary policy is conducted (e.g., a specific Taylor rule) and instead represent monetary policy in terms of "wedges." 54

As well known (e.g., Correia, Nicolini, and Teles, 2008), introducing sticky prices is equivalent to maintaining flexible prices but allowing for a time-varying tax on labor and utilization, which is effectively under the control of monetary policy. Denoting this tax by $\tau_{t}$, we have the following modification of Proposition 1 and 2.

Proposition 15 (AS and AD with sticky prices). Let $\tau_{t}$ denote a tax, or wedge, on labor and utilization. Aggregate supply is given by

$$
\begin{aligned}
y_{t} & =(1-\tilde{\alpha})\left(u_{t}+k_{t}\right)-\tau_{t}, \\
u_{t} & =\frac{\beta}{\tilde{\alpha}+\beta \phi} R_{t}-\frac{\beta}{\tilde{\alpha}+\beta \phi}\left(\left(1+\frac{\nu+\sigma}{\tilde{\alpha} \sigma \nu}\right) \tau_{t}-\left(1+\beta \frac{\nu+\sigma}{\tilde{\alpha} \sigma \nu}\right) \mathbb{E}_{t}\left[\tau_{t+1}\right]\right)+\beta \mathbb{E}_{t}\left[u_{t+1}\right], \\
k_{t+1} & =k_{t}-\kappa u_{t} .
\end{aligned}
$$

\footnotetext{
${ }^{54}$ There is one subtlety here. To the extent that monetary policy does not stabilize the aggregate price level, its fluctuations may reveal the aggregate shock. To avoid perfect revelation, we can either assume that consumers are inattentive or introduce random consumption baskets along the lines of Lorenzoni (2009) and an earlier version of our paper. Namely, we could let each household be randomly matched to, consume the goods of, and observe the prices of, a non-representative sample of the islands in each period. This guarantees that the household would not learn the aggregate shock from observing the prices of the islands it visits even when these prices comove with that shock. With the exception of the very last paragraph, in the remainder of this Appendix we ignore this subtlety and focus on how our mechanisms interact with monetary policy holding $\lambda$ constant.
} 
Aggregate demand is given by

$$
y_{t}=-\sigma\left(R_{t}+\beta_{t}\right)+\mathbb{E}_{t}\left[y_{t+1}\right]+\left(\mathcal{B}_{t}+\mathcal{G}_{t}\right),
$$

where $\mathcal{B}_{t}$ and $\mathcal{G}_{t}$ are defined as (28) and (25).

Under this representation, a "hawkish" monetary policy that stabilizes inflation maps to $\tau_{t}=0$, whereas an "accommodative" monetary policy that lets positive demand shocks trigger inflation and positive output gaps maps to a counter-cyclical $\tau_{t}$ : it is as if there is a subsidy on production whenever monetary policy is expansionary relative to the benchmark of replicating prices.

The textbook New Keynesian model, which abstracts from variable utilization, corresponds to either $\tilde{\alpha}=1$ (utilization is unproductive) or $\phi \rightarrow \infty$ (variation in utilization is prohibitively costly). Aggregate supply then reduces to $y_{t}=0-\tau_{t}$, where 0 stands for the natural rate of output and $\tau_{t}$ for the wedge, or equivalently the output gap, induced by any monetary policy that does not replicate flexible prices. Relative to this familiar case, the key supply-side novelty of our analysis is to let the natural rate of output be sensitive to the real interest rate, in the manner explained in Section 4.

Let us now turn to aggregate demand, or equation (88) above. In the textbook version of the New Keynesian, this equation holds with $\mathcal{B}_{t}=\mathcal{G}_{t}=0$. Relative to this case, we see that the informational friction continues to give rise to our two mechanisms, captured by the same terms $\mathcal{B}_{t}$ and $\mathcal{G}_{t}$ as in our baseline analysis. However, because the GE adjustment in the real interest rate is now modulated by monetary policy, the magnitude of $\mathcal{G}_{t}$ now depends on monetary policy.

Similarly, and more crucially for our narrative about confidence, $\mathcal{B}_{t}$ here contains not only misperceptions of the "natural" level of permanent income but also misperception of the output gaps induced by monetary policy. In particular, $\mathcal{B}_{t}$ can be decomposed as follows:

$$
\mathcal{B}_{t}=\mathcal{B}_{t}^{\text {natural }}+\mathcal{B}_{t}^{\text {gap }},
$$

where

$$
\begin{aligned}
\mathcal{B}_{t}^{\text {natural }} & \equiv \frac{1-\beta}{\beta} \sum_{k=0}^{+\infty} \beta^{k} \int E_{t}^{h}\left[\xi_{h, t+k}\right] d h \\
\mathcal{B}_{t}^{\text {gap }} & \equiv \overline{\mathbb{E}}_{t}\left[\mathcal{M}_{t}\right]-\mathcal{M}_{t} \\
\mathcal{M}_{t} & \equiv-\frac{1-\beta}{\beta} \sum_{k=0}^{+\infty} \beta^{k} \mathbb{E}_{t}\left[\tau_{t+k}\right]
\end{aligned}
$$

$\mathcal{B}_{t}^{\text {natural }}$ is the value of $\mathcal{B}_{t}$ that obtains when monetary policy replicates flexible prices (equivalently, the value of $\mathcal{B}_{t}$ in our baseline analysis); $\mathcal{M}_{t}$ is a measure of how much monetary policy deviates from that benchmark; and $\mathcal{B}_{t}^{\text {natural }}$ is the corresponding average misperception, or equivalently the misperception of output gaps.

To put more structure on the new term, let us assume that monetary policy is such that

$$
\tau_{t}=-\varphi \eta_{t}+\rho_{\tau} \tau_{t-1}
$$

where $\varphi \geq 0$ parameterizes the degree of policy accommodation, or the elasticity of the output gap 
with respect to the demand shock, and $\rho_{\tau} \in[0,1)$ indexes its persistence. We then have that the gap between the actual present discounted value of the output gap and the average expectation of it is given by

$$
\mathcal{B}_{t}^{\text {gap }} \equiv \overline{\mathbb{E}}_{t}\left[\mathcal{M}_{t}\right]-\mathcal{M}_{t}=-\frac{\varphi(1-\beta)}{\beta\left(1-\beta \rho_{\tau}\right)}(1-\lambda) \eta_{t} .
$$

As long as $\lambda<1$ and $\varphi>0$, a positive aggregate demand shock therefore generates a negative value for $\mathcal{B}_{t}^{\text {gap }}$ at the same time that it generates a positive value for $\mathcal{B}_{t}^{\text {natural }}$.

What does this mean? As long as $\varphi>0$, monetary policy lets output expand beyond its natural rate in response to a positive demand shock. This translates to an increase in true aggregate permanent income, via $\mathcal{M}_{t}$, which is perfectly forecasted under complete information $(\lambda=1)$ but imperfectly so under incomplete information $(\lambda<1)$. It follows that, as long as information is incomplete, consumers underestimate the increase in aggregate permanent income sustained by an accommodative monetary policy. And because the true increase in aggregate permanent income is larger when the output gaps induced by monetary policy are themselves larger (higher $\varphi$ ) or more persistent (higher $\left.\rho_{\tau}\right)$, the size of belief mistake is larger under the same circumstances.

In this sense, an accommodative monetary policy goes against our confidence multiplier. But such a policy also complements our confidence multiplier by helping aggregate supply be more responsive to aggregate demand under sticky prices than under flexible prices. To see what we mean by this, let us shut down variable utilization. In this case, the flexible-price AS curve is vertical and the natural rate of output is invariant to aggregated demand shocks. It follows that, as long as monetary policy replicates flexible prices $(\varphi=0)$, our confidence multiplier is switched off regardless of how large the informational friction is. But as soon as monetary policy is accommodative $(\varphi>0)$, our confidence multiplier is active under sticky prices, even though it is inactive under flexible prices.

Perhaps more interestingly, our confidence multiplier helps amplify the power of monetary policy itself. To see this, abstract from the exogenous shock to consumer spending and, instead, modify (89) as follows:

$$
\tau_{t}=-\eta_{t}^{M P}+\rho_{\tau} \tau_{t-1}
$$

where $\eta_{t}^{M P}$ represents a pure policy shock, independent of any other shock in the economy. Then, while the informational friction dampens the effect of this shock via (90), it amplifies it via $\mathcal{B}_{t}^{\text {natural }}$.

We conclude with a comment on optimal monetary policy. In the textbook New Keynesian model, a monetary policy that stabilizes the price level is optimal becomes it minimizes relative price distortions (or other costs of inflation). But in our setting, a monetary policy that does the opposite could be desirable because it could let the variation in commodity prices reveal more information about the underlying state of the economy (and, thereby, increase $\lambda$ and arrest our amplification). This suggests a novel policy trade-off, whose investigation we leave for future work. ${ }^{55}$

\footnotetext{
${ }^{55}$ Note, though, that the presence of such a trade-off is likely to hinge on the informational-based interpretation of our setting. In the behavioral variants discussed in Section 6.5, there may or may not exist a relation between monetary policy and $\lambda$.
} 


\section{Proof of Proposition 15.}

Since here we work directly with time-varying wedge $\left(\tau_{t}\right)$, we can still work with real prices and wages as in the main analysis, in the sense of denominated by the basket of all goods produced in the current period.

We define the production wedge as the as-if time varying tax on revenue reflected in the local firm's labor demand and utilization decisions:

$$
\begin{aligned}
l_{i, t} & =y_{i, t}-w_{i, t}-\tilde{\tau}_{i, t}, \\
p_{i, t}+q_{i, t}-u_{i, t}-k_{i, t}-\tilde{\tau}_{i, t} & =\vartheta_{i, t}+\phi u_{i, t} .
\end{aligned}
$$

The local labor supply in (13) is still given by:

$$
n_{t}^{i}=\nu w_{i, t}-\frac{\nu}{\sigma} c_{t}^{i}
$$

Imposing labor market clearing, using the production function in (11), and aggregating, we have

$$
y_{t}=(1-\tilde{\alpha})\left(u_{t}+k_{t}\right)-\frac{\sigma \nu}{\sigma+\nu} \tilde{\alpha} \tilde{\tau}_{t} .
$$

Defining $\tau_{t}=\frac{\sigma \nu}{\sigma+\nu} \tilde{\alpha} \tilde{\tau}_{t}$. We arrive at (85).

The shadow value of land is given by ${ }^{56}$

$$
\vartheta_{i, t}=-R_{i, t}+(1-\beta) \mathbb{E}_{t}\left[p_{i, t+1}+q_{i, t+1}-k_{i, t+1}-u_{i, t+1}\right]+\beta \mathbb{E}_{t}\left[\vartheta_{i, t+1}\right]
$$

Aggregating (92) and (93) and combining terms, we have

$y_{t}-(1+\phi) u_{t}-k_{t}-\tilde{\tau}_{t}=-R_{t}+(1-\beta) \mathbb{E}_{t}\left[y_{t+1}-k_{t+1}-u_{t+1}\right]+\beta \mathbb{E}_{t}\left[y_{t+1}-(1+\phi) u_{t+1}-k_{t+1}-\tilde{\tau}_{t+1}\right]$.

Similar to (20) but using the aggregate production in (85), we arrive at (86).

The evolution of capital in (87) is the same as (21).

The derivation of the $\mathrm{AD}$ in (88) is exactly the same as the main analysis.

\footnotetext{
${ }^{56}$ Note that what matters for the shadow value of land is the actual marginal productivity of capital, which does not depend on the wedge $\tau_{i, t}$ directly.
} 


\section{References}

Akerlof, George A and Robert J Shiller. 2010. Animal Spirits: How Human Psychology Drives the Economy, and Why it Matters for Global Capitalism. Princeton University Press.

Andrade, Philippe, Olivier Coibion, Erwan Gautier, and Yuriy Gorodnichenko. 2020. “No Firm is an Island? How Industry Conditions Shape Firms' Aggregate Expectations.” NBER Working Paper No. 27317 .

Angeletos, George-Marios, Fabrice Collard, and Harris Dellas. 2018. "Quantifying Confidence." Econometrica 86 (5):1689-1726.

—. 2020. “Business-cycle Anatomy.” American Economic Review 110 (10):3030-70.

Angeletos, George-Marios and Zhen Huo. 2021. "Myopia and Anchoring.” American Economic Review $111(4): 1166-1200$.

Angeletos, George-Marios, Zhen Huo, and Karthik Sastry. 2021. "Imperfect macroeconomic expectations: Evidence and theory.” NBER Macroeconomics Annual 35 (1):1-86.

Angeletos, George-Marios and Jennifer La'O. 2010. “Noisy Business Cycles.” NBER Macroeconomics Annual :319-378.

—. 2013. "Sentiments.” Econometrica 81 (2):739-779.

Angeletos, George-Marios and Chen Lian. 2017. "Dampening General Equilibrium: from Micro to Macro.” NBER Working Paper No. 23379.

— 2018. "Forward Guidance without Common Knowledge." American Economic Review 108 (9):2477-2512.

—. 2019. “Confidence and the Propagation of Demand Shocks.” MIT mimeo .

Angeletos, George-Marios and Karthik Sastry. 2021. "Managing Expectations: Instruments vs. Targets.” Quarterly Journal of Economics .

Bachmann, Rüdiger, Ricardo J. Caballero, and Eduardo M. R. A. Engel. 2013. "Aggregate Implications of Lumpy Investment: New Evidence and a DSGE Model." American Economic Journal: Macroeconomics 5 (4):29-67.

Bai, Yan, José-Vıctor Rıos-Rull, and Kjetil Storesletten. 2019. “Demand Shocks as Productivity Shocks.” University of Pennsylvania mimeo .

Barberis, Nicholas, Robin Greenwood, Lawrence Jin, and Andrei Shleifer. 2015. "X-CAPM: An Extrapolative Capital Asset Pricing Model.” Journal of Financial Economics 115 (1):1-24. 
Barro, Robert J and Robert King. 1984. “Time-separable Preferences and Intertemporal-substitution Models of Business Cycles.” The Quarterly Journal of Economics 99 (4):817-839.

Barsky, Robert B and Eric R Sims. 2011. “News Shocks and Business Cycles.” Journal of Monetary Economics 58 (3):273-289.

Basu, Susanto, Giacomo Candian, Ryan Chahrour, and Rosen Valchev. 2021. "Risky Business Cycles." NBER Working Paper No. 28693.

Basu, Susanto, John Fernald, and Miles Kimball. 2006. "Are Technology Improvements Contractionary?” American Economic Review 96 (5):1418-1448.

Basu, Susanto and Miles Kimball. 1997. “Cyclical Productivity with Unobserved Input Variation.” NBER working paper No. 5915 .

Beaudry, Paul and Franck Portier. 2013. "Understanding Noninflationary Demand-Driven Business Cycles.” In NBER Macroeconomics Annual 2013, Volume 28. 69-130.

— . 2018. "Real Keynesian Models and Sticky Prices.” NBER Working Paper No. 24223 .

Benhabib, Jess and Roger Farmer. 1994. “Indeterminacy and Increasing Returns.” Journal of Economic Theory 63 (1):19-41.

Blanchard, Olivier and Danny Quah. 1989. "The Dynamic Effects Of Aggregate Demand And Supply Disturbances." American Economic Review 79 (4):655-673.

Burnside, Craig, Martin Eichenbaum, and Sergio Rebelo. 1995. "Capital Utilization and Returns to Scale.” NBER Macroeconomics Annual 10:67-110.

Caballero, Ricardo J. and Eduardo M. R. A. Engel. 1999. "Explaining Investment Dynamics in U.S. Manufacturing: A Generalized (S, s) Approach.” Econometrica 67 (4):783-826.

Cavallo, Alberto, Guillermo Cruces, and Ricardo Perez-Truglia. 2017. "Inflation Expectations, Learning, and Supermarket Prices: Evidence from Survey Experiments.” American Economic Journal: Macroeconomics 9 (3):1-35.

Chahrour, Ryan and Gaetano Gaballo. 2021. "Learning from House Prices: Amplification and Business Fluctuations.” The Review of Economic Studies .

Christiano, Lawrence, Martin Eichenbaum, and Charles Evans. 2005. “Nominal Rigidities and the Dynamic Effects of a Shock to Monetary Policy.” Journal of Political Economy 113 (1):1-45.

Christiano, Lawrence, Roberto Motto, and Massimo Rostagno. 2014. "Risk Shocks.” American Economic Review 104 (1):27-65. 
Coibion, Olivier and Yuriy Gorodnichenko. 2012. "What Can Survey Forecasts Tell Us about Information Rigidities?” Journal of Political Economy 120 (1):116-159.

- 2015. "Information Rigidity and the Expectations Formation Process: A Simple Framework and New Facts." American Economic Review 105 (8):2644-78.

Coibion, Olivier, Yuriy Gorodnichenko, and Tiziano Ropele. 2019. "Inflation Expectations and Firm Decisions: New Causal Evidence.” The Quarterly Journal of Economics :165-219.

Cooper, Russell and Andrew John. 1988. “Coordinating Coordination Failures in Keynesian Models.” Quarterly Journal of Economics :441-463.

Correia, Isabel, Juan Pablo Nicolini, and Pedro Teles. 2008. “Optimal Fiscal and Monetary Policy: Equivalence Results.” Journal of Political Economy 116 (1):141-170.

Di Tella, Sebastian and Robert Hall. 2021. "Risk Premium Shocks Can Create Inefficient Recessions." The Review of Economic Studies .

Diamond, Peter. 1982. “Aggregate Demand Management in Search Equilibrium.” The Journal of Political Economy :881-894.

Eggertsson, Gauti B and Paul Krugman. 2012. "Debt, Deleveraging, and the Liquidity Trap: A FisherMinsky-Koo Approach.” Quarterly Journal of Economics 127 (3):1469-1513.

Farhi, Emmanuel and Iván Werning. 2019. "Monetary Policy, Bounded Rationality, and Incomplete Markets.” American Economic Review 109 (11):3887-3928.

Gabaix, Xavier. 2014. “A Sparsity-Based Model of Bounded Rationality.” Quarterly Journal of Economics 129 (4):1661-1710.

- 2019. "Behavioral inattention." Handbook of Behavioral Economics: Applications and Foundations 2:261-343.

— 2020. “A behavioral New Keynesian model.” American Economic Review 110 (8):2271-2327.

Gaballo, Gaetano. 2017. “Price Dispersion, Private Uncertainty, and Endogenous Nominal Rigidities.” The Review of Economic Studies 85 (2):1070-1110.

Gali, Jordi. 1999. “Technology, Employment, and the Business Cycle: Do Technology Shocks Explain Aggregate Fluctuations?” American Economic Review 89 (1):249-271.

Gennaioli, Nicola, Yueran Ma, and Andrei Shleifer. 2016. "Expectations and Investment." NBER Macroeconomics Annual 30 (1):379-431.

Greenwood, Jeremy, Zvi Hercowitz, and Gregory Huffman. 1988. "Investment, Capacity Utilization, and the Real Business Cycle.” The American Economic Review :402-417. 
Greenwood, Robin and Andrei Shleifer. 2014. “Expectations of Returns and Expected Returns.” The Review of Financial Studies 27 (3):714-746.

Guerrieri, Veronica and Guido Lorenzoni. 2017. "Credit Crises, Precautionary Savings, and the Liquidity Trap.” Quarterly Journal of Economics .

Hulten, Charles. 1978. "Growth Accounting with Intermediate Inputs.” Review of Economic Studies $45(3): 511-518$.

Huo, Zhen and Jose-Victor Rios-Rull. 2020. “Demand Induced Fluctuations.” Review of Economic Dynamics .

Ilut, Cosmin and Hikaru Saijo. 2020. “Learning, Confidence, and Business Cycles.” Tech. rep.

Jaimovich, Nir and Sergio Rebelo. 2009. "Can News about the Future Drive the Business Cycle?" American Economic Review 99 (4):1097-1118.

Justiniano, Alejandro, Giorgio Primiceri, and Andrea Tambalotti. 2010. "Investment Shocks and Business Cycles.” Journal of Monetary Economics 57 (2):132-145.

King, Robert and Sergio Rebelo. 1999. "Resuscitating Real Business Cycles." Handbook of Macroeconomics 1:927-1007.

Kohlhas, Alexandre and Ansgar Walther. 2019. “Asymmetric Attention.” IIES miméo .

Lorenzoni, Guido. 2009. “A Theory of Demand Shocks.” American Economic Review 99 (5):2050-84.

—. 2011. "News and Aggregate Demand Shocks.” Annual Review of Economics 3 (1):537-557.

Lucas, Robert. 1972. “Expectations and the Neutrality of Money.” Journal of Economic Theory 4 (2):103124.

—. 1973. "Some International Evidence on Output-Inflation Tradeoffs." American Economic Review 63 (3):326-334.

Mackowiak, Bartosz and Mirko Wiederholt. 2009. “Optimal Sticky Prices under Rational Inattention.” American Economic Review 99 (3):769-803.

Mankiw, Gregory and Ricardo Reis. 2002. "Sticky Information versus Sticky Prices: A Proposal to Replace the New Keynesian Phillips Curve.” Quarterly Journal of Economics 117 (4):1295-1328.

Mankiw, Gregory, Ricardo Reis, and Justin Wolfers. 2004. "Disagreement about Inflation Expectations." In NBER Macroeconomics Annual 2003, Volume 18. The MIT Press, 209-270. 
Mavroeidis, Sophocles, Mikkel Plagborg-Møller, and James H. Stock. 2014. "Empirical Evidence on Inflation Expectations in the New Keynesian Phillips Curve." Journal of Economic Literature $52(1): 124-88$.

Mian, Atif and Amir Sufi. 2014. “What Explains the 2007-2009 Drop in Employment?” Econometrica $82(6): 2197-2223$.

Miao, Jianjun, Pengfei Wang, and Zhiwei Xu. 2015. "A Bayesian dynamic stochastic general equilibrium model of stock market bubbles and business cycles.” Quantitative Economics 6 (3):599-635.

Molavi, Pooya. 2019. "Macroeconomics with Learning and Misspecification: A General Theory and Applications.”.

Nimark, Kristoffer. 2008. “Dynamic Pricing and Imperfect Common Knowledge.” Journal of Monetary Economics 55 (2):365-382.

Rozsypal, Filip and Kathrin Schlafmann. 2019. "Overpersistence Bias in Individual Income Expectations and its Aggregate Implications.” IIES mimeo .

Sims, Christopher A. 2003. "Implications of Rational Inattention." Journal of Monetary Economics 50 (3):665-690.

Smets, Frank and Rafael Wouters. 2007. "Shocks and Frictions in US Business Cycles: A Bayesian DSGE Approach.” American Economic Review 97 (3):586-606.

Woodford, Michael. 2003. "Imperfect Common Knowledge and the Effects of Monetary Policy." Knowledge, Information, and Expectations in Modern Macroeconomics: In Honor of Edmund S. Phelps.

— 2011. "Simple Analytics of the Government Expenditure Multiplier." American Economic Journal: Macroeconomics 3 (1):1-35. 